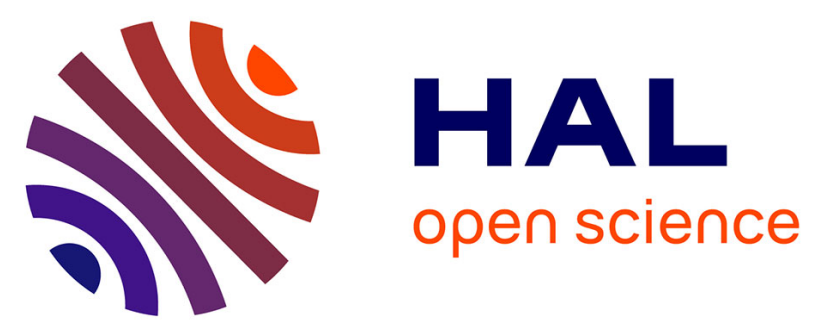

\title{
Aspects et rythmes de l'azilianisation dans le Bassin parisien : caractérisation de l'industrie lithique recueillie au Cornet (locus 33) à Ambenay, Eure
}

Boris Valentin, Gérard Fosse, Cyrille Billard

\section{- To cite this version:}

Boris Valentin, Gérard Fosse, Cyrille Billard. Aspects et rythmes de l'azilianisation dans le Bassin parisien : caractérisation de l'industrie lithique recueillie au Cornet (locus 33) à Ambenay, Eure. Gallia Préhistoire - Archéologie de la France préhistorique, 2004, 46, pp.171-209. 10.3406/galip.2004.2042 . hal-02346162

\author{
HAL Id: hal-02346162 \\ https://hal.science/hal-02346162
}

Submitted on 21 Jan 2020

HAL is a multi-disciplinary open access archive for the deposit and dissemination of scientific research documents, whether they are published or not. The documents may come from teaching and research institutions in France or abroad, or from public or private research centers.
L'archive ouverte pluridisciplinaire HAL, est destinée au dépôt et à la diffusion de documents scientifiques de niveau recherche, publiés ou non, émanant des établissements d'enseignement et de recherche français ou étrangers, des laboratoires publics ou privés.

\section{(ㅇ)(1) $\$$}

Distributed under a Creative Commons Attribution - NonCommercial - NoDerivatives $\mid 4.0$ 


\title{
ASPECTS ET RYTHMES DE L'AZILIANISATION DANS LE BASSIN PARISIEN
}

\author{
Caractérisation de l'industrie lithique \\ recueillie au Cornet (locus 33) à Ambenay, Eure
}

Boris VAlentin $^{*}$, Gérard FossE* ${ }^{* *}$ et Cyrille BILlaRD ${ }^{* * *}$

Mots-clés. Tardiglaciaire, Azilien, Federmesser (groupes à), Bassin parisien, Normandie, industrie lithique.

Résumé. Dans le Bassin parisien, le développement récent des recherches permet d'étudier les mécranismes de l'azilianisation depuis la fin du Bølling jusqu'au début du Dryas récent: ce processus a connu au moins trois phases successives, et éventuellement quatre. Cet article expose en détail les choix techniques observés au Cornet ì Ambenay, une occupation de Normandie, qui a livré un assemblage lithique caractéristique d'une phase avancée de ce processus. C'est ce qui ressort de l'analyse des armatures et des outils ainsi que des concepts très simples qui ont guidé les activités de débitage. Au vu de ces caractères, nous cherchons ici à corréler celte industrie non datée. L'entreprise se heurte à des difficultés qui soulignent l'ampleur des incertitudes sur les rythmes exacts de l'azilianisation et la difficulté des corrélations d'une région à l'autre.

Key-words. Lateglacial, Azilian, Federmesser (groups), Paris Basin, Normandy, lithic industry.

Abstract. Due to the recent development of research in the Bassin Parisien, the mechanisms of azilianisation from the end of Bolling up to the Late Dryas can be analysed. At least three successive phases have been detected in this process, and maybe four. This article gives a full presentation of the technical choices observed at the "Cornet" at Ambenay in Normandy, a site which has yielded a lithic assemblage characteristic of a developped phase of this process. This point is brought out from the analysis of projectile points and tools and also of the simple concepts which guide flaking actizities. From theses features, we try to find correlations to this undated industry. This study contends with difficulties which underline the vast uncertainties concerning the precise rythms of azilianisation and the correlations between different areas.

Schlagwörter. Späteiszeit, Azilien, Federmessergruppen, Pariser Becken, Normandie, Steingeräteindustrie.

Zusammenfassung. Die jüngste Entwicklung der Forschung im Pariser Becken macht es möglich, hier die Mechanismen der Ausbreitung des Azilien vom Ende des Bølling-Interstadials bis zum Beginn der jüngeren Dryas zu untersuchen. Dieser Prozeß verlief in mindestens drei, vielleicht sogar in vier aufeinanderfolgenden Phasen. Der Beitrag legt detailliert die Techniken dar, die sich in Cornet beobachten ließen. Dieser Fundplatz bei Ambenay in der Normandie hat eine Auswahl an Steingeräten geliefert, die charakteristisch für eine fortgeschrittene Phase besagter Entwicklung ist. Das ergibt sich aus der Auswertung der Geschoßeinsätze und Werkzeuge sowvie aus der Analyse der auf sehr einfachen Konzepten beruhenden Schlagtechnik. Wir versuchen hier; die nicht datierte Industrie anhand dieser Merkmale einzuordnen. Das Unternehmen stößt allerdings auf gewisse Schwierigkeiten, die verdeutlichen, in welchem Umfang über den

*Lniversité Paris-I, Institut d’art et archéologie, 3 rue Michelet, F-75006, Paris et L’MR 7041, Archéologies et Sciences de l'Antiquité, MAE, 21 allée de l'Université, F-92023 Nanterre Cédex. Mél : valentin@univ-parisl.fr.

** Service régional de l'archéologie du Nord - Pas-de-Calais, Forme Saint-Sauveur, BP 51, F-5965l Villencuve-d'Ascq Cedex.

**:Service régional de l'archéologie de Basse-Normandie. 13 $3^{\text {tiv }}$ rue Saint-Ouen, F-14052 Caen Cedex 04. Mél : cyrille.billard@culture.gouv.fr. 
zeillichen Ablauf der Ausbreitung des Azilien noch immer Unklatheit besteht und die sich aus der Problematik ergeben, Querrerbindungen von der einen Region zur andern herzustellen.

Übersetzung : Stefan Wirth

Depuis une quarantaine d'années, le Tardiglaciaire weichsélien du Bassin parisien est devenu un excellent terrain d'application pour les études qui visent, à travers l'analyse des cultures matérielles, la reconstitution des choix et des valeurs fondant l'unité des sociétés préhistoriques. Bien entendu, c'est le Magdalénien qui a d'abord bénéficié de cette visée, pour des raisons qui tiennent essentiellement aux hasards de la taphonomie et de la recherche. Plus récemment, à mesure que l'archéologie préventive renouvelait les sources, notre intérêt s'est éveillé pour des traditions plus tardives, celle des groupes à Federmesser - de plus en plus souvent assimilée à l'Azilien -, celle aussi des communautés qui ont fréquenté les véritables ateliers de taille du "Belloisien ", lors de la transition avec l'Holocène (Fagnart, 1993, 1997; Valentin, 1995, 1999; Bodu, 2000b). Les recherches sur la culture matérielle ont donc progressivement adopté une large perspective diachronique, l'identité du Magdalénien étant d'ailleurs revisitée à la lumière des contrastes qu'il affiche avec les traditions plus récentes (voir notamment Pigeot dir., sous presse). En parallèle, datations et reconstitutions paléoenvironnementales se sont multipliées dans notre région et dans les aires avoisinantes. Tous ces résultats donnent aujourd'hui matière à des scénarios paléohistoriques, fondés sur des corrélations encore délicates entre évolutions techniques et transformations du milieu. Un effort tout particulier est consacré au décryptage des mécanismes et rythmes de l'azilianisation, désormais reconnue comme une lente mutation conduisant à la dissolution progressive des identités magdaléniennes. Pour cette enquête sur les sociétés de la fin du Bolling et de l'Allerød, nous bénéficions à la fois de sources abondantes provenant d'une trentaine de sites (fig. 1), et de calages radiométriques plutôt fiables, car apparemment non soumis aux effets des plateaux (Valentin, 1995; Fagnart, 1997; Bodu, 1998, 2000a ; Fagnart, Coudret, 2000).

C'est dans ce contexte que nous avons choisi de présenter ici intégralement les choix techniques observés dans une de ces occupations d'affinité arilienne : le locus 33 du Cornet à Ambenay (Eure). Entre 1982 et 1986, la fouille de ce locus livra un assemblage lithique qui constitue, aujourd'hui encore, un des plus riches découverts en place pour le Tardiglaciaire de Normandie. Deux principales raisons ont motivé notre choix d'exhaustivité pour la présentation de cet assemblage, qui, bien que parfaitement homogène, provient d'un contexte archéologique offrant une documentation asse\% limitée. D'abord, les informations recueillies à travers plusieurs remontages alimentent une étude qui, parmi celles publiées à ce jour, est une des plus détaillées sur un assemblage nettement azilianisé. À ce titre, nous espérons donc qu'elle pourra servir comme référence. On déplorera immédiatement que l'absence de toute donnée chronostratigraphique limite cruellement la contribution de cette étude à l'affinement des sériations qui fut la priorité de ces dernières années de recherche. Mais, de ce fait, l'attribution devant ici se faire sans la sécurité d'un cadre stratigraphique, elle peut devenir, par sa difficulté, le prétexte à tester les modèles récemment construits à propos de l'azilianisation et de ses rythmes.

\section{APERÇU SUR L'AZILIANISATION ET SES RYTHMES DANS LE BASSIN PARISIEN}

Depuis la fouille du Cornet, il y a une vingtaine d'amnées, il s'est donc produit un enrichissement notable de nos connaissances sur les groupes humains qui ont occupé la moitié septentrionale de la France depuis la fin du Bølling jusqu'au début de l'Holocène. L'impulsion décisive est venue du bassin de la Somme. Dès la fin des années 1980, J.-P. Fagnart et son équipe y ont entrepris une reconstitution détaillée de la chronologie des successions culturelles, à partir du décryptage minutieux de plusieurs séquences archéologiques préservées dans des milieux favorables à la restitution d'un contexte biostratigraphique (Fagnart, $1988 ; 1993 i$. Nos premiers travaux sur l'industrie du Comet ont bénéficié avantageusement des acquis de cette première sériation proposée pour la France septentrionale. Il était alors suggéré que la tradition à Federmesser avait pu y connaître une "phase ancienne " juste avant l'Allerod et à son début, puis qu'elle s’était pleinement épanouic au cours d'une "phase récente ", contemporaine du même événement climatique, dans sa seconde moitié. Cé n'est qu'à l'extrême fin du Dryas récent, donc bien après le déve- 


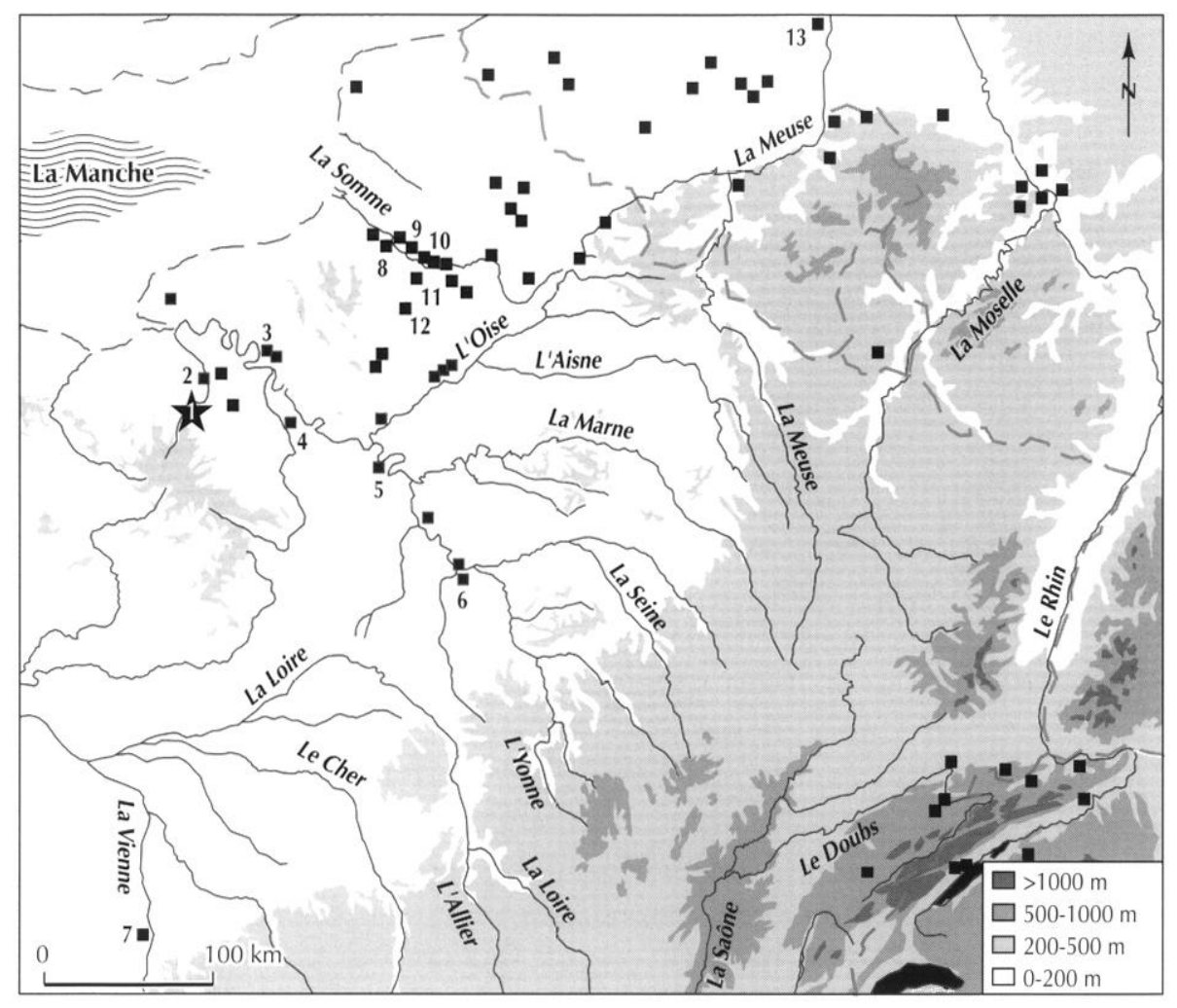

Fig. 1 - Principales occupations des groupes à Federmesser (ou aziliens) dans le Bassin parisien et ses alentours. Les numéros correspondent aux sites énoqués dans le texte: 1, Le Cornet à Ambenay; 2, Le Bois des Rangées à Romilly-la-Puthenaye; 3, La grolte du Cheoal et Foumares à (iouy; 4, La Rochelle à Blaru; .5, Le Closeau à Rueil-Malmaison; 6, Pincevent (niveau III.2) à La Grande-Paroisse; 7, La grotte du Bois-Ragot à Gouex; 8, Le Marais à Hangest-sur-Somme; 9, Les Prés du Mesnil à La Chaussée-Tirancourt; 10, Derrière le Village ì Dreuil-less-Amiens ; 11, La Vierge Catherine à Saleux; 12, Le Maruis à Comty'; 13, Rekem. loppement de ces traditions techniques, qu'était située l'éclosion des faciès " belloisiens " affichant plusieurs nettes rupures avec les industries à Federmesser (Fagnart, 1993). En 1995, nous notions: "Par de nombreux aspects, l'assemblage recueilli au Cornet s'apparente aux séries que J.-P. Fagnart attribue actuellement aux industries de la "phase récente " de la tradition à Fodermesser " (Valentin, 1995, p. 521). La description détaillée de cette industrie nous servit alors comme référence pour interpréter divers assemblages de Normandie et d'île-de-France, provenant pour une grande part de ramassages de surface et restés jusque-là sans attribution ou rapprochés sans plus de précision des industries à Federmesser (Valentin, op. cit., p. 522-566). La plupart furent assimilés à celui du Cornet et donc à des assemblages attribués à la " phase récente " du nord de la France. Seule l'industrie de La Grotte du Cheval à Gouy (Seine-Maritime) en fut nettement distinguée ; nous la rapprochions non seulement du niveau inférieur d'Hangest III.1, seul alors, parmi les gisements de plein air de la Somme, à contenir les indices d'une "phase ancienne ", mais également des niveaux les plus anciens de certaines séquences aziliennes découvertes au sud de la Loire, et notamment du niveau 4 du Bois-Ragot à Gouex (ibid., p. 560 ; Fosse et al., 1997, p. 254). En écho à la sériation proposée par J.-P. Fagnart, nous proposions alors un premier modèle d'évolution des industries consistant à retracer la logique des principales innovations techniques plutôt qu'à en préciser la chronologie, car le sud du Bassin parisien restait encore pauvre en données chronostratigraphiques. Ce modèle $d$ '“ azilianisation " fut ensuite opportunément mis à l'épreuve des faits lors de la découverte du gisement stratifié du Closeau, à Rueil-Malmaison dans les Hauts-de-Seine (Bodu, 1995). On y découvrit un " niveau ancien ". enfoui sous un sol de l'Allerød, et dont l'industrie présente des similitudes avec celle du niveau inférieur d'Hangest III.1 et, plus encore, avec celle de La grotte du Cheval à Gouy ou celle du niveau 4 du Bois-Ragot. Au sommet de ce sol de l'Allersd, le "niveau supérieur" du Closeau livra d'abord une industrie radicalement distincte de celle du "niveau ancien " et, de surcroît, asse $z$ différente des industries attribuées alors à la " phase récente " dans la Somme. Cette industrie du Closeau fut donc considérée comme l'expression possible d'une phase "finale ", attribuée au début du Dryas récent d'après les dates sur charbons de bois alors disponibles (Bodı, Valentin, 1997, p. 345). Depuis, l'extension considérable des fouilles au Closeau a confirmé l'originalité du "niveau ancien ", mais elle a largement compliqué la chronologie du " niveau 
supérieur ", désormais considéré comme un palimpseste d'occupations attribuables non plus à une mais à deux phases récentes de l'azilianisation, dont une peut-être "finalc" (Bodu, 1998; 2000a; Bodu dir., 1998). Dans le même temps, les sériations ont été affinées dans la Somme (Coudret, Fagnart, 1997 ; Fagnart, 1997 ; Fagnart, Coudret, 2000), si bien que l'azilianisation dans le Bassin parisien est maintenant connue à travers au moins trois phases, et éventuellement quatre :

1, la plus ancienne est immédiatement antérieure à l'Allerød ;

2, la suivante est contemporaine du début de cet épisode ;

3 , la troisième de sa fin ;

4, l'éventuelle phase " finale ", uniquement reconnue sur le niveau supérieur du Closeau, serait contemporaine des débuts du Dryas récent.

En parallèle, les recherches se sont beaucoup développées dans certaines régions voisines, depuis l'Angleterre jusqu'à la Suisse (Barton, 1992 ; Floss, 1992, 2000 ; Leesch, 1993 ; Street, Baales, 1997, 1998; Baales, 2000, 2002 ; Barton, Dumont, 2000 ; De Bie, Caspar, 2000 ; Cattin, 2000 ; Street el al., 2001...). Elles ont largement précisé l'environnement et le mode de vie de groupes, dont on ne sait plus trop s'il faut encore les nommer "à Federmesser " ou tout simplement "aziliens" (Bodu, Valentin, 1997, p. 342). Ces autres travaux participent bien sûr aux débats sur la chronologie de l'azilianisation, sans toutefois fournir des sériations aussi détaillées que celle dont on dispose pour le Bassin parisien.

\section{RAPPEL CONCERNANT LES DÉCOUVERTES EFFECTUÉES AU CORNET}

Le cadre général étant dressé, il faut maintenant évoquer brièvement le contexte particulier des découvertes effectuées à Ambenay. À cette fin, nous résumerons les principales informations qui figurent dans la première courte synthèse publiée sur le site (Fosse et al., 1997).

La commune d'Ambenay est située au sud-ouest du département de l'Eure dans le Pays d'Ouche. Le site du Cornet se trouve sur le rebord occidental du plateau de Breteuil, au sommet d'une petite éminence (+ $206 \mathrm{~m} \mathrm{NGF)}$ dominant d'une quarantaine de mètres la vallée empruntée par la Risle, qui coule à $1 \mathrm{~km}$ environ du gisement. Cette butte qui accueille le site correspond à une accumulation de limons de couverture, préservée sur une zone restreinte d'une vingtaine d'hectares. Tout autour affleurent des limons à silex, édifiés sur des argiles et des grès tertiaires surmontant le substrat de la craie cénomanienne. D'après l'étude géomorphologique de P. Lebret, les limons à silex résultent d'un remaniement, sous conditions périglaciaires, des dépôts loessiques anté-weichséliens et des altérites tertiaires sous-jacentes. Précisons que les silex qui sont contenus dans ces formations sont très souvent gélifractés et donc plutôt impropres à la taille.

L'occupation tardiglaciaire a été mise en évidence à partir de 1977 par les prospections de G. Jacquet. En 1982, G. Fosse décida d'implanter une série de sondages pour vérifier l'état de préservation de ce gisement de surface, le plus riche alors de Haute-Normandie pour le Paléolithique supérieur. Quarante petits sondages manuels ont été ouverts sur environ 8 hectares. Un seul, le locus 33 , a livré une concentration d'artefacts en place, dès la première campagne. Ce sondage a ensuite été étendu à $130 \mathrm{~m}^{2}$ au cours de deux opérations successives de fouille, en 1985 et 1986 (fig. 2), tandis que les nouveaux sondages périphériques, ouverts à cette occasion, sont restés stériles.

Dans le locus 33, "la couche archéologique se situe immédiatement sous la partie remaniée par les labours, au sommet du loess de couverture (Pléniglaciaire weichsélien) supportant à son sommet la pédogenèse de surface igley oxydé), soit à 40 cm de profondeur environ sous le sol actuel (étude géomorphologique $\mathrm{P}$. Lebret). Le très faible développement de la stratigraphie ne fournit aucun élément de datation de ce niveau archéologique au sein du Tardiglaciaire. La grande acidité des limons n'a pas permis la conservation des vestiges osseux et des pollens (recherche M.-F. Huault, université de Rouen) " (Fosse et al., 1997, p. 246).

Le locus 33 a été en partie remanié par les travaux agricoles et notamment par le creusement de drains. En conséquence, près de $50 \%$ des artefacts de ce locus ont été découverts dans l'horizon de labour. L’homogénéité de l'assemblage n'en est pas pour autant remise en cause, ce que confirment d'assez nombreux remontages associant parfois des témoins remaniés et des vestiges en provenance de la couche archéologique (fig. 3). Compte tenu de cette homogénéité et du caractère partiel des remaniements, G. Fosse a pu proposer quelques observations préliminaires sur l'organisation spatiale de cette unité d'occupation bien circonscrite (fig. 2 et 3). La structure F2 a été interprétée comme un petit foyer en cuvette non appareillé, de $50 \mathrm{~cm}$ de diamètre environ. Centrée sur cette structure de combus- 


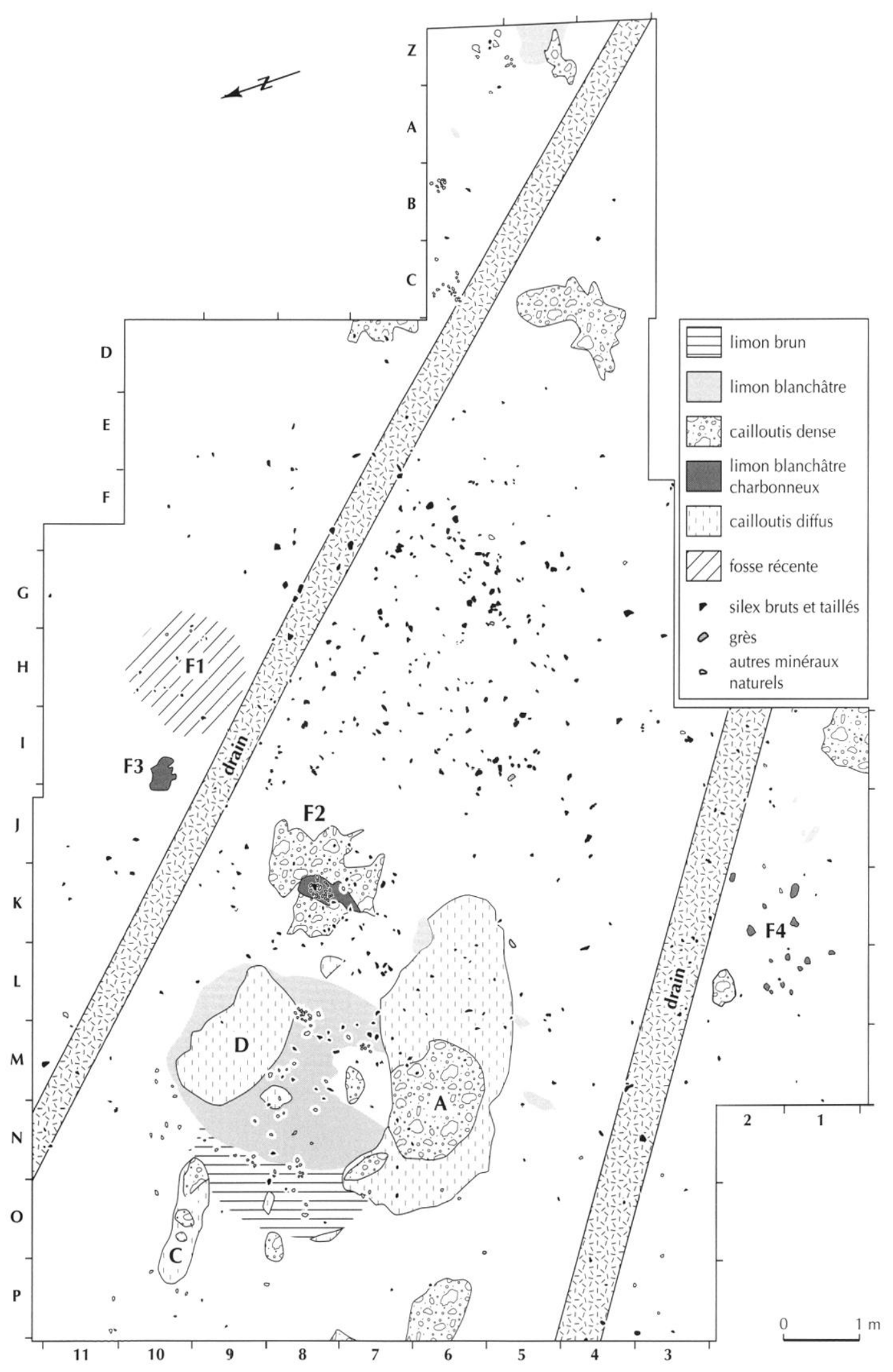

Fig. 2 - Plan d'ensemble du locus 33 (dessin (.: Billard). 


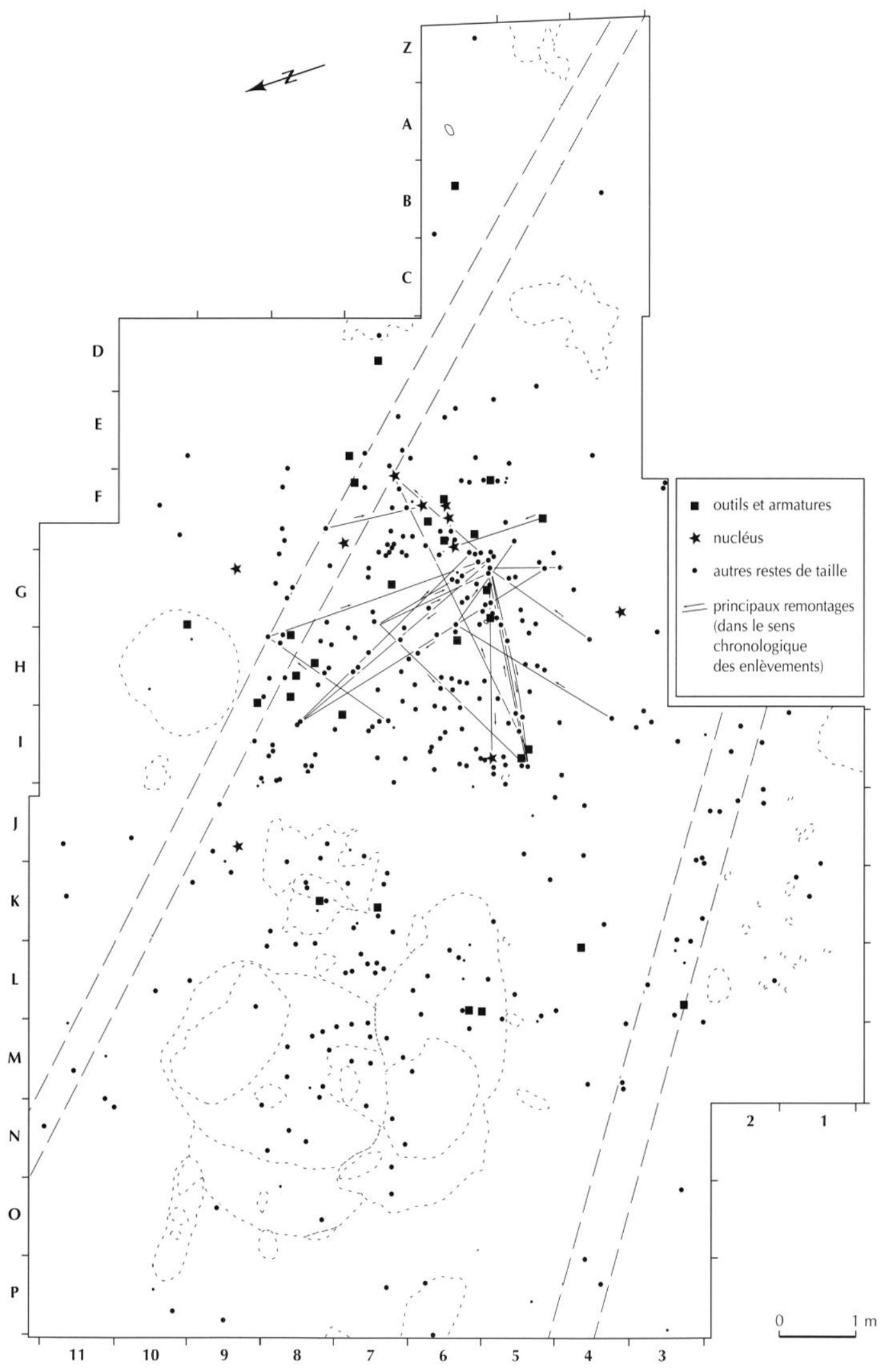

Fig. 3 - Réparlition de l'industrie lithique et principaux remontages (dessin (.. Billard). 
tion, l'aire de dispersion maximale des artefacts lithiques couvre une surface elliptique de $20 \mathrm{~m}^{2}$ à peu près. La plus grande concentration de vestiges est située à l'est et au sudest, un peu en retrait du foyer. C'est dans cette concentration que l'on trouve la plupart des outils ainsi que plusieurs nucléus, plutôt abondants en périphérie. Par contraste, la densité de vestiges est très faible de l'autre côté du foyer, au nord et à l'est de la surface fouillée. Dans le même locus, on a pu inventorier d'autres structures plus énigmatiques: F3 et F4 sont des taches charbonneuses considérées prudemment comme de possibles vidanges du foyer F2 ; F1 (fosse ou foyer ?) pourrait être d'âge médiéval ; A, C et D sont des nappes de cailloutis considérées comme étant d'origine naturelle.

I Iors du locus 33, les découvertes d'artefacts en silex ont été très abondantes en surface : selon G. Fosse, on en compte "quelques milliers [...], dont 256 outils" (Fosse et al., op. cit., p. 246), parmi lesquels on trouve peu de témoins explicites d'autres périodes que le Paléolithique final. En somme, l'industrie remontéc par les labours en plusieurs endroits du Cornet est très cohérente et très similaire à celle qui fut recueillie en place dans le locus 33 . Il est donc clair que ce locus appartenait à un ensemble archéologique plus vaste, mais la contemporanéité absolue des différentes unités qui pouvaient former cet ensemble archéologique est, bien entendu, impossible à établir. En conséquence, la fonction exacte du locus 33 reste inconnue. On ne peut savoir s'il s'agit seulement d'une halte très courte, comme on en connaît en Rhénanie centrale (Street, Baales, 1997, 1998 ; Baales, 2000), ou bien d'une occupation prenant place dans un plus vaste établissement du type de celui qu'on a pu reconstituer par exemple à Rekem (De Bie, Caspar, 2000, p. $280 \mathrm{sqq}$.). Au Cornet, quoi qu'il en soit, restes de taille, outils et armatures évoquent, par leur nombre et leur diversité, la réalisation d'activités variées : débitage, fabrication et réparation des armes de chasse, traitement du gibier et de ses produits, etc. Cette polyvalence ainsi que la faible densité en vestiges sont tout à fait conformes à ce que l'on connaît de la plupart des autres unités attribuées aux groupes nettement azilianisés du Bassin parisien (Fagnart, 1997, p. 135 ; Bodu dir., 1998). Par son faible degré d'organisation, la structure de combustion F2 pourrait très bien s'apparenter aux foyers connus dans ce contexte. Malheureusement, la documentation est insuffisante pour qu'on puisse certifier que telle était sa fonction. Rappelons en effet que, sur le niveau supérieur du Closeau, certaines structures analogues ont été interprétées, après étude minu- tieuse, comme les reliquats probables de souches d'arbres naturellement consumées, ayant altéré ou non des vestiges anthropiques (Wattez in Bodu dir., 1998, p. 140-166).

\section{ACTIVITÉS DE RETOUCHE ET DE DÉBITAGE DANS LE LOCUS 33 AU CORNET}

Le locus 33 a livré près de 800 silex taillés représentant plus de $14 \mathrm{~kg}$ (tabl. I) et près de $50 \%$ proviennent, nous l'avons vu, du niveau en place. Parmi tous ces éléments, 57 ont pu être intégrés dans 16 remontages, qui associent chacun entre deux et dix pièces.

\begin{tabular}{|l|c|c|}
\hline & Nombre & Poids $(\mathbf{k g})$ \\
\hline Lames & 193 & 1,934 \\
\hline Éclats et éclats allongés & 508 & 8,939 \\
\hline Nucléus & 21 & 3,483 \\
\hline Outils et armatures & 69 & 0,602 \\
\hline Total & $\mathbf{7 9 1}$ & $\mathbf{1 4 , 9 5 8}$ \\
\hline
\end{tabular}

Tabl. I - Décompte général de lïndustrie lithique.

\section{LES OUTILS ET ARMATURES RETOUCHÉS}

Près de la moitié des 69 pièces retouchées du locus 33 sont des pièces à bord abattu aux calibres divers (tabl. II). Parmi les autres éléments retouchés, les grattoirs, les burins et les pièces tronquées sont bien représentés, comme c'est le cas dans la plupart des assemblages nettement azilianisés de la moitié septentrionale de la France. On rappellera que, parmi les 256 objets retouchés recueillis en surface sur l'ensemble du site, les pièces à bord abattu sont également nombreuses $(28 \%)$, comme les grattoirs (28\%) et les burins (20\%) (Fosse et al., 1997, p. 247).

\begin{tabular}{|l|c|}
\hline & Nombre \\
\hline Pièces à bord abattu & 34 \\
\hline Grattoirs & 9 \\
\hline Burins & 6 \\
\hline Pièces tronquées & 4 \\
\hline Lames à retouche marginale & 9 \\
\hline Divers & 7 \\
\hline Total & $\mathbf{6 9}$ \\
\hline
\end{tabular}

Tabl. II - Outils et armatures retouchés. 


\section{GRATTOIRS, BURINS ET PIÈCES TRONQUÉES}

Parmi les 9 grattoirs du locus 33, il n'y a qu'un seul exemplaire long sur lame; les autres sont nettement courts (fig. 4, $\mathrm{r}^{\mathrm{os}} 1$ et 2 ) et ils ont souvent été aménagés sur des éclats. Ces outils possèdent tous un front large, aménagé par retouches parallèles plutôt que convergentes. Au moment de l'abandon, ces fronts présentaient un angle plutôt ouvert, compris entre $60^{\circ}$ et $85^{\circ}$. Cet aspect redressé n'est pas la conséquence de ravivages intenses mais plutôt l'héritage d'un mode particulier d'aménagement, qui les distinguent des grattoirs magdaléniens (Valentin, 1995, p. 530 ; De Bie, Caspar, 2000, p. 185).

Les 6 burins sont fabriqués sur des lames ou sur des éclats allongés, souvent épais (fig. $4, \mathrm{n}^{\text {os }} 3$ à 6 ). La plupart (5) sont des burins sur troncature. La troncature, généralement oblique et aménagée par retouches semi-abruptes, prolonge parfois un bord nettement abattu (fig. $4, \mathrm{n}^{\text {os }} 3$ et 5). On notera qu'un burin porte deux encoches profondes et dissymétriques dans sa moitié proximale et que les bords de son talon sont très fortement émoussés, aussi bien sur l'avers que sur le revers (fig. $4, \mathrm{n}^{\circ} 6$ ). On peut considérer prudemment ces modifications comme des aménagements facilitant un emmanchement de l'outil.

L'assemblage comporte aussi 4 pièces allongées uniquement modifiées par une troncature transversale, rectiligne ou légèrement concave (fig. $4, n^{\circ *} 7$ à 9 ).

\section{LES PIÈCES À BORD ABATTU}

La série contient 34 pièces, dont l'aménagement principal consiste en un abattage plus ou moins intense de l'un des deux bords. Ce lot peut être subdivisé en plusieurs catégories morphologiques et dimensionnelles, aux limites parfois un peu floues.

Le groupe le plus important (10 exemplaires) est composé d'éléments entiers ou fragmentés, dont le bord abattu, partiellement rectiligne jusqu'à la moitié ou aux deux tiers de la pièce, s'infléchit pour former une pointe à la rencontre d'un bord tranchant toujours rectiligne (fig. 5, $\mathrm{n}^{\text {os }} 1$ à 5). Sur ces "monopointes asymétriques" (ou Federmesser), l'apex a été indifféremment placé sur la partie proximale ou distale du support. Les bords abattus sont plutôt épais et diminuent donc assez fortement la largeur initiale du support. Ils forment ainsi de véritables dos, plutôt très légèrement anguleux que régulièrement courbes, aménagés indifféremment sur le bord droit ou gauche du support. La retouche est très abrupte, voire véritablement verticale, et sa direction est variable: sur 6 exemplaires suffisamment longs pour que ces observations soient significatives, on note que cette retouche est totalement directe dans un cas, qu'elle est successivement inverse et directe dans un autre cas, directe puis croisée en partie apicale dans les quatre autres cas. Ces monopointes sont des pièces étroites et légères, dont le poids - quand elles sont entières - ne dépasse pas $2 \mathrm{~g}$.

Un deuxième groupe comporte au moins 3 éléments assurément non pointus, assimilables donc à des lamelles à bord abattu. Ces pièces portent un bord abattu abrupt et rectiligne, aménagé par une retouche marginale dans un cas (fig. 5, $\mathrm{n}^{\circ} 6$ ), plus envahissante dans les deux autres (fig. 5, $\mathrm{n}^{\circ} 7$ ). Le premier élément, réduit à un fragment mésio-distal non appointé, prćscntc unc ćtroitesse et une finesse $(6 \mathrm{~mm} \times 3 \mathrm{~mm})$ qui le distinguent des monopointes. Les deux autres éléments, fabriqués sur des supports plus larges et plus épais au départ, portent à leurs extrémités deux troncatures transversales et rectilignes.

Seize autres fragments relèvent de l'une ou l'autre des deux catégories précédentes, sans qu'on puisse préciser laquelle, puisqu'on ne peut pas déterminer s'ils furent appointés ou non. Parmi eux, on trouve 14 fragments mésiaux à bord abattu rectiligne, fins (fig. $5, n^{\text {os }} 8$ et 9 ) ou épais (fig. $5, \mathrm{nI}^{\mathrm{os}} 10 \mathrm{et} 11$ ), et deux fragments portant une seule troncature rectiligne et transversale (fig. $5, \mathrm{n}^{\circ}$ 12). Un des éléments à bord épais porte un stigmate d'usage macroscopique : un enlèvement burinant indique qu'il fut utilisé comme armature de projectile (fig. $5, \mathrm{n}^{\circ} 11$ ).

Enfin, une troisième et dernière catégorie est composée de 5 pièces à bord abattu plutôt courbe, aménagées sur des supports nettement plus larges et plus épais que tous les précédents (fig. $5, \mathrm{n}^{\mathrm{os}} 13$ à 15). Sur la plupart de ces pièces robustes, le bord abattu, parfois partiel, rejoint le bord tranchant pour former une pointe. Le bord abattu est toujours aménagé par une retouche directe et d'incidence oblique, qui peut devenir croisée lorsque le dos traverse la largeur du support pour former la pointe. La base, qui correspond généralement à l'extrémité proximale du support, en conserve alors le talon. Les éléments entiers de cette catégorie pèsent entre $10 \mathrm{et} 15 \mathrm{~g}$.

En bref, la meilleure distinction s'établit entre ces 5 pièces robustes et les 29 pièces graciles (parmi lesquelles figure au moins une armature de projectile). La fonction des pièces robustes n'est pas explicite, mais on soulignera qu'elles présentent toutes un long tranchant plutôt recti- 

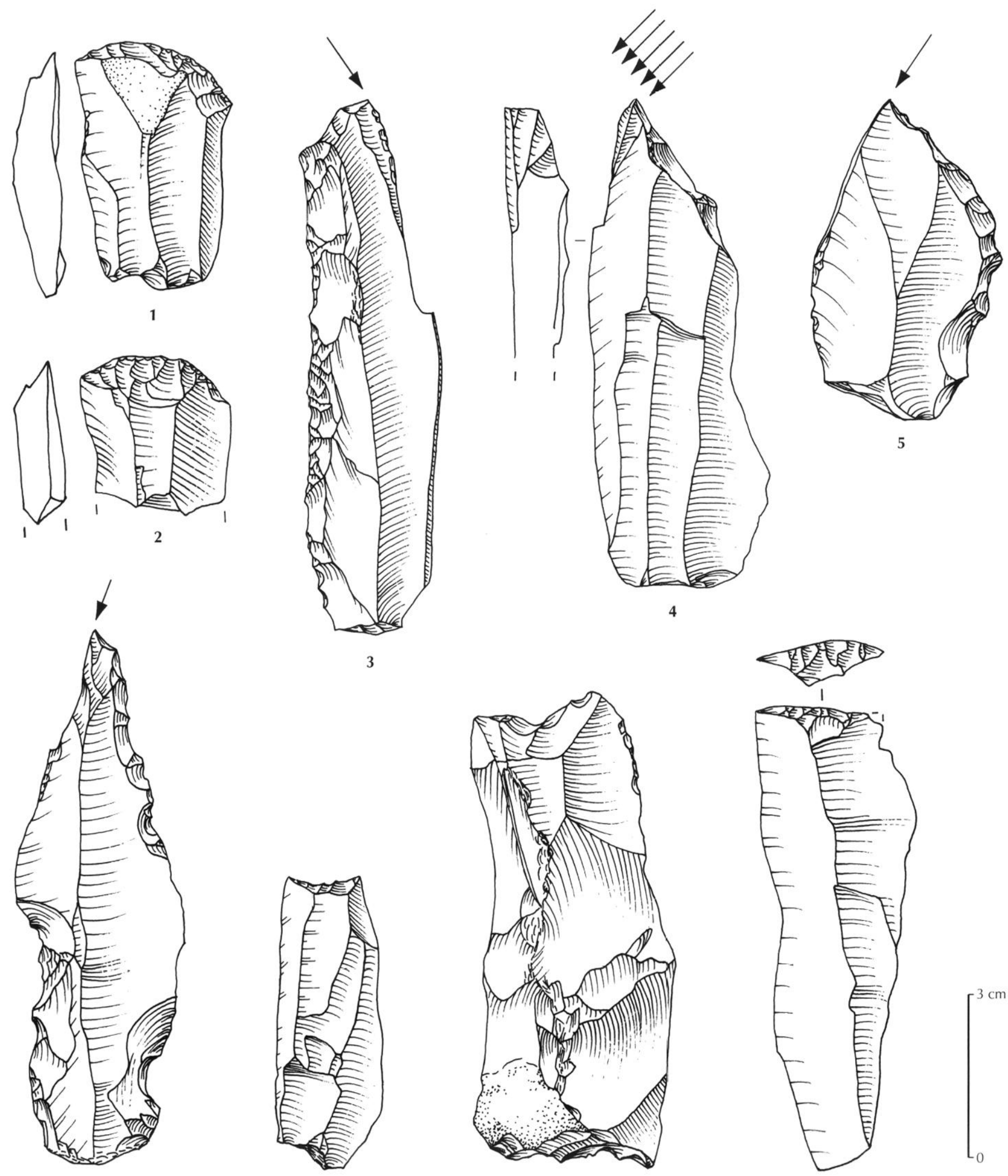

6
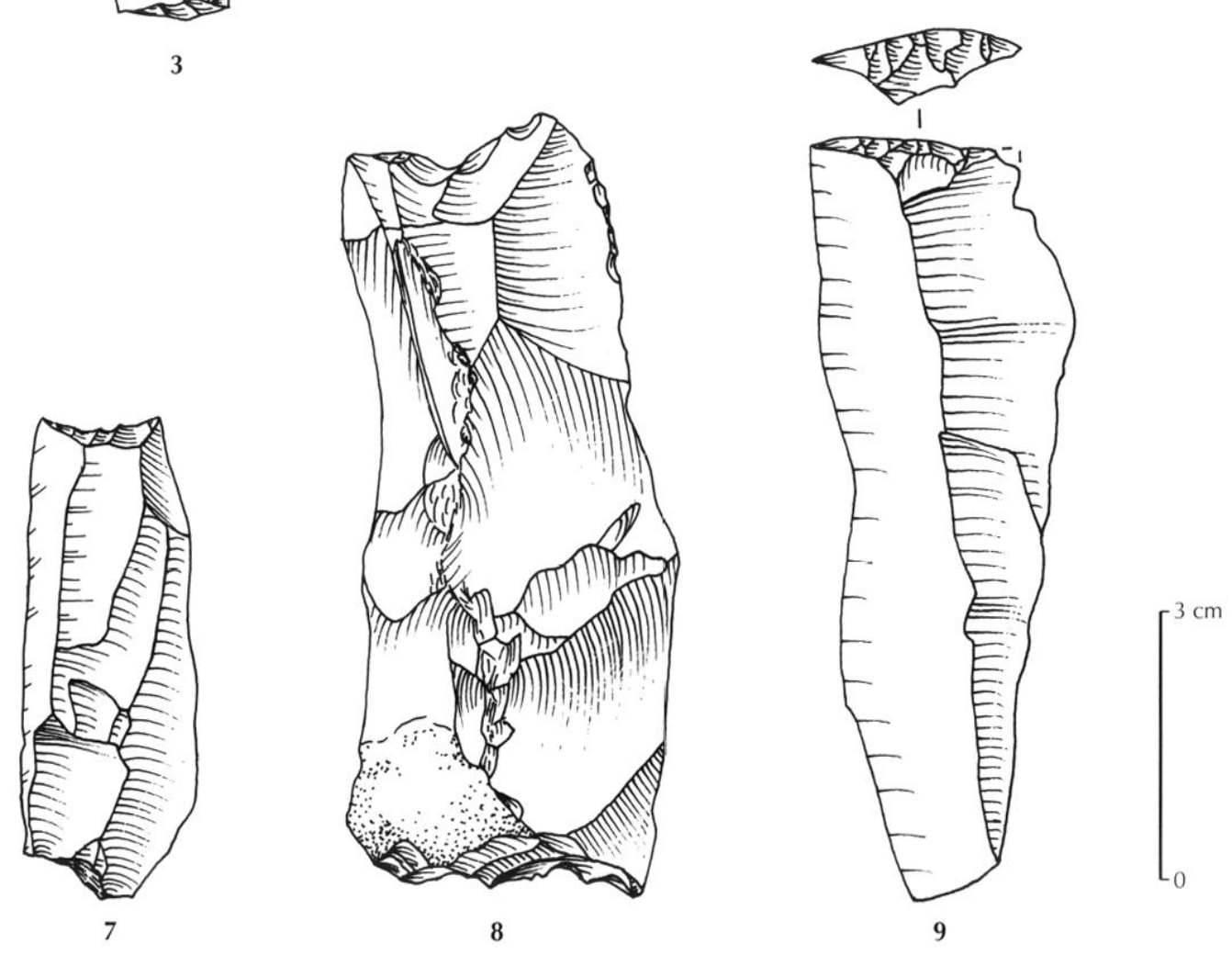

Fig. 4 -Outils : 1, 2, grattoirs ; 3-6, burins ; 7-9, pièces tronquées (dessins (.. Billard d'après E. Mantel). 

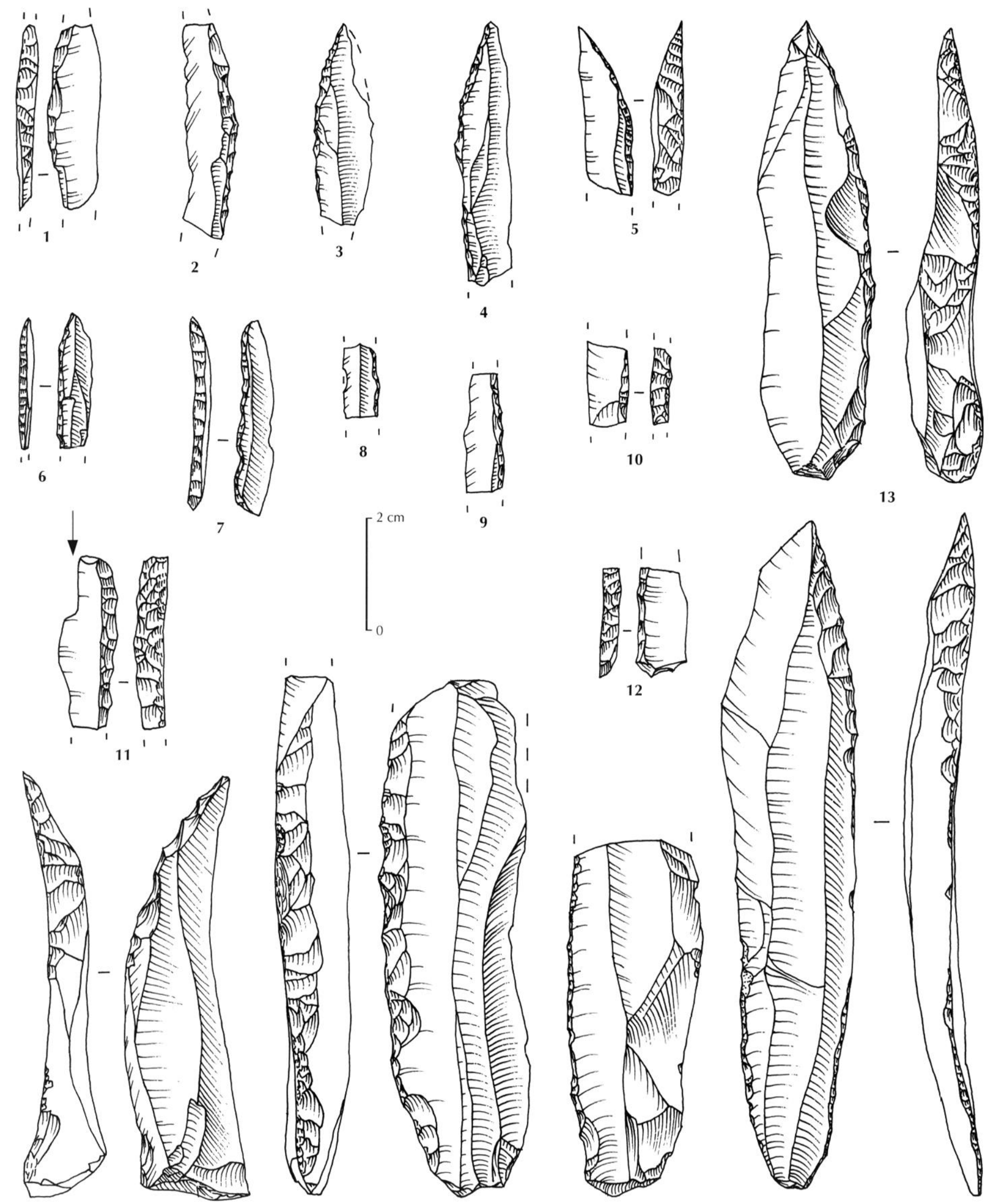

15

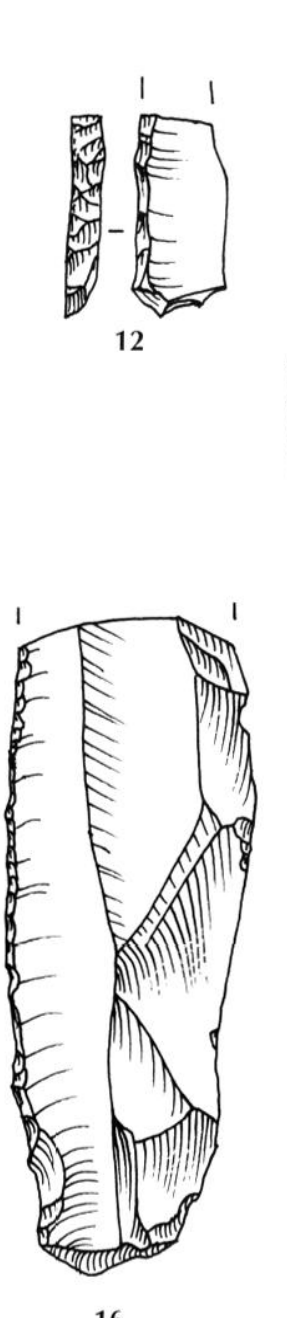

13

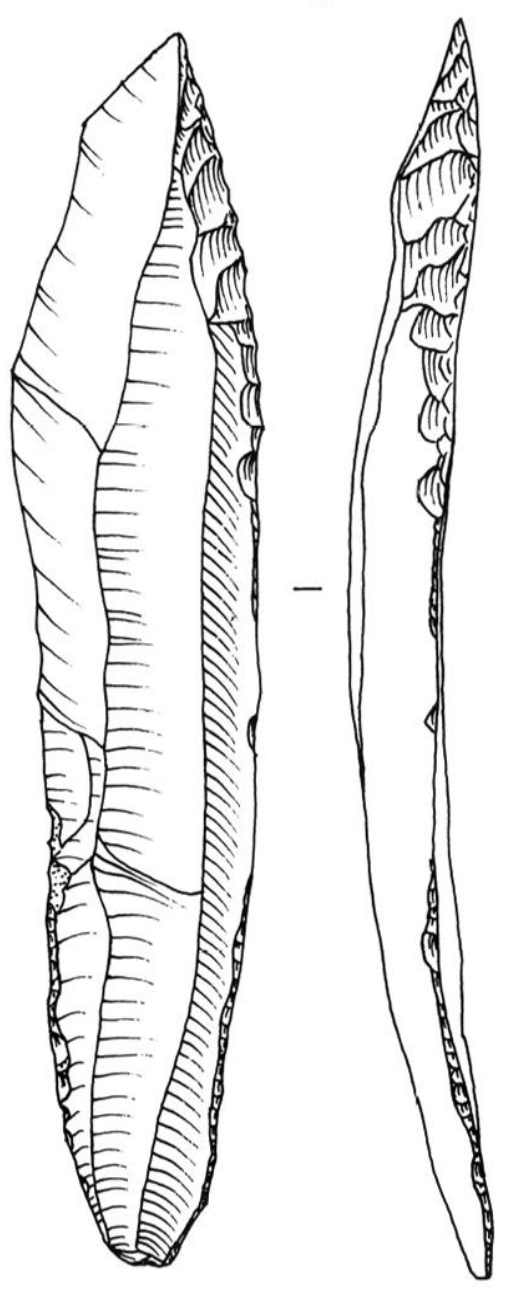

17

Fig. 5 - Armalures et outils : 1-5, monopointes; 6, 7, lamelles à bord abattu; 8-12, fragments de monopointes ou de lamelles à bord abattu ; 13-15, "couteaux à dos "; 16, 17, lames à retouche plutôt marginale (dessins (. Billard d'après E. Mantel). 
ligne. Nous les désignerons prudemment comme " couteaux à dos ", en vertu de quelques résultats tracéologiques acquis sur d'autres sites à propos d'outils similaires (voir notamment De Bie, Caspar, 2000, p. 131). Signalons qu’au Cornet, un élément analogue a reçu un aménagement par véritable coup de burin (fig. 4, n" 3 ).

Quant aux 29 pièces graciles, on trouve donc parmi elles plusieurs monopointes asymétriques, c'est-à-dire de probables armatures de projectile très caractéristiques des assemblages nettement azilianisés. Quand elles sont réduites à l'état de petits fragments, elles se distinguent mal des lamelles à bord abattu qui figurent souvent, mais en proportion inconstante, dans de tels assemblages.

\section{LAMES À KE"IUUCHE MARGINALE ET AUTRES OUTILS}

La série contient un autre lot de 9 lames, parfois d'excellente régularité mais de largeur variable, qui portent une retouche oblique, continue ou discontinue et plutôt marginale (fig. 5, $n^{\text {os }} 16$ et 17). Par leur gabarit et leurs qualités de tranchant, ces éléments peuvent être rapprochés des " couteaux à dos " que nous venons d'évoquer.

Parmi les 7 outils " divers ", on a regroupé quelques éclats courts ou allongés qui portent des retouches généralement irrégulières et discontinues. On trouve également un tiès gros éclat de mise en forme qui présente un bord légèrement denticulé, aménagé par des retouches profondes et d'incidence oblique.

Aux 69 éléments volontairement retouchés s'ajoutent enfin quelques outils a posteriori. On remarque d'abord un éclat allongé $(62 \mathrm{~mm} \times 43 \mathrm{~mm} \times 11 \mathrm{~mm})$ qui porte sur son tranchant le plus robuste un esquillement très limité, formé par des enlèvements inverses, courts et rasants. Trois nucléus présentent également des endommagements particuliers sur leurs bords de plan de frappe : dans deux cas, ces traces n'affectent qu'un seul plan de frappe (fig. 6) ; dans le troisième, elles concernent les deux. C'es stigmates, par leur ampleur, ne peuvent pas être assimilés au résultat d'une abrasion volontaire pour préparer l'extraction des produits. Ils résultent d'un véritable écrasement, qui s'accompagne d'esquillements et de fissurations, auxquels s'additionne un émoussé intense. Les endommagements observés sur ces nucléus évoquent donc ceux qui ont été identifiés sur certains éléments mâchurés "belloisiens » et qui ont été rapportés à un usage sur matériaux minéraux durs et abrasifs (Valentin, 1995, p. 668 ; Fagnart, Plisson, 1997).

\section{LES OBJECTIFS DU DÉBITAGE : DES PRODUITS ALLONGÉS ET NOTAMMENT DES LAMES}

Précisons d'abord que nous utiliserons le terme de " lame " dans un sens technologique strict. Par conséquent, ce qualificatif tient compte du module - quand la pièce n'est pas fragmentée - mais surtout de la régularité et du parallélisme des bords et des nervures, qui sont les meilleurs indices d'une intention laminaire et de sa récurrence. A contrario, plusieurs pièces ont été considérées comme des "éclats allongés " en raison de leur irrégularité, alors que leur module est supérieur au seuil théorique fixé pour une définition strictement morphométrique des lames (Long. > larg. $\times 2$ ) (par exemple fig. 4, $n^{\circ} 5$ ).

Parmi les produits de la taille, les éclats, courts ou allongés, sont majoritaires $(68 \%$ ) (fig. 7). Mais ce sont surtout des lames ( $74 \%$ ) qui ont été choisies pour fabriquer les outils retouchés et les armatures. Toutefois, on ne peut en déduire automatiquement que ces lames constituaient l'objectif économique essentiel. Il est impossible en effet de reconstituer ce que fut la production utilitaire réelle (incluant éventuellement des supports non retouchés) : l'assemblage ne se prête pas à des études fonctionnelles et les remontages ne sont pas assez complets pour que l'on puisse décrire la circulation des produits dans l'espace fréquenté. Compte tenu de cette réserve et considérant la proportion non négligeable d'outils retouchés sur éclats (15\% sur des éclats courts et $11 \%$ sur des éclats allongés), peut-on considérer alors que la production d'éclats constituait un objectif du débitage au même titre que la fabrication de lames? Pour les éclats courts, il n'existe aucune évidence de débitages autonomes sur des nucléus qui n'auraient assumé que cette vocation, ni même d'une éventuelle phase terminale de production de ces supports sur certains volumes. Au contraire, les remontages indiquent que les éclats courts ont été essentiellement détachés pendant les opérations de mise en forme ou d'entretien de nucléus qui étaient tous destinés à fournir des supports allongés. Parmi les ensembles remontés, il n'en existe pas non plus qui attesteraient indubitablement une production exclusive d'éclats allongés sur certains volumes. Des lames vraies ont toujours pu s'intercaler pendant les différentes séquences d'exploitation. Notons toutefois que la quantité de lames est assez variable d'un débitage à l'autre et qu'elle est toujours inférieure à celle des éclats allongés.

En somme, s'il est clair que la production d'éclats courts ne constituait pas un objectif à part entière, il reste assez. 


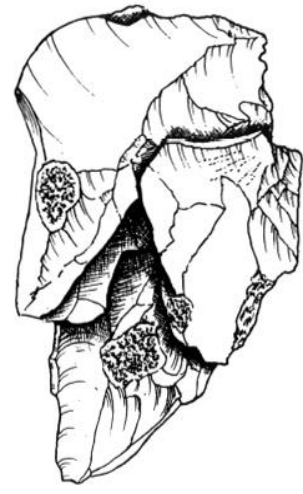

vue latérale droite

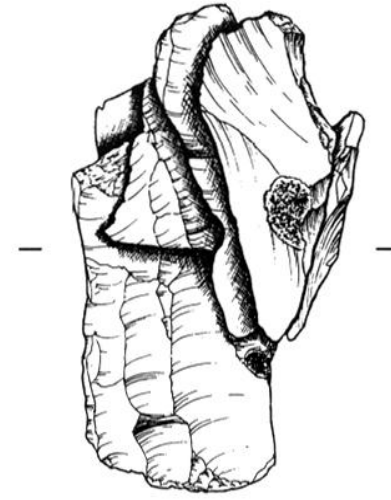

vue antérieure

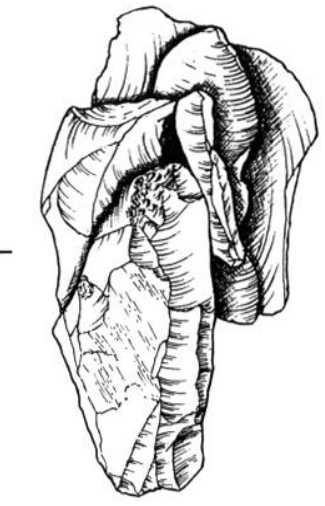

vue latérale gauche

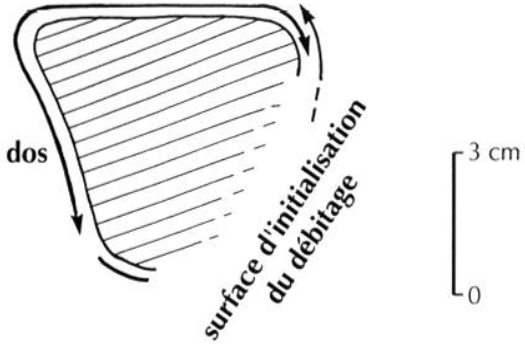

— surface naturelle de cassure enlèvements extraits à partir d'une crête

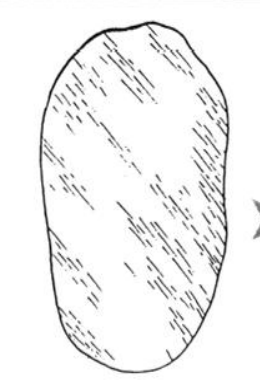

vue lat. gauche

1

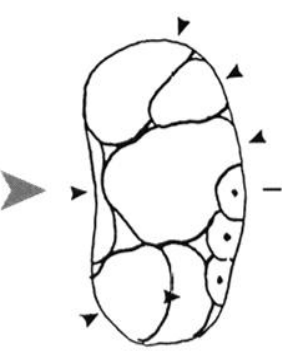

vue lat. droite

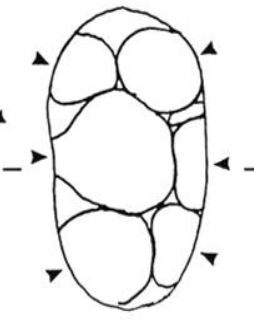

vue ant.

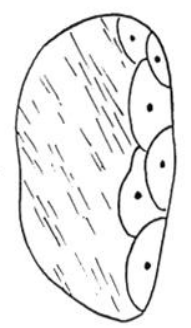

vue lat. gauche

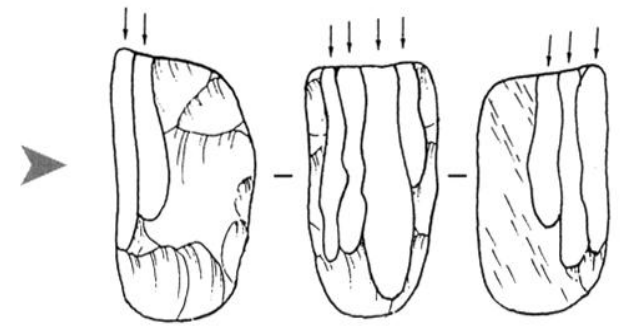

vue lat. droite vue ant.

3

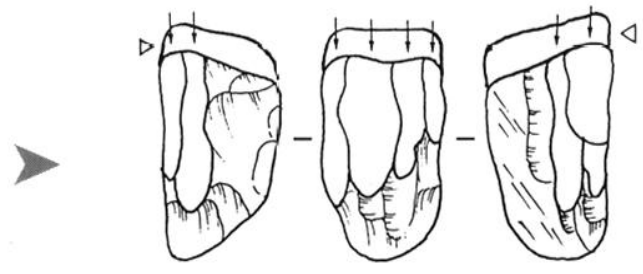

vue lat. droite

vue ant.

4

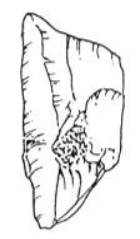

vue lat. droite

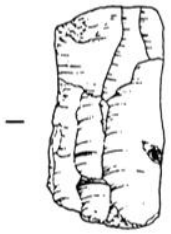

vue ant. vue lat. gauche

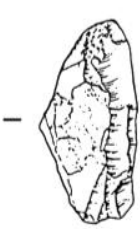

vue lat. gauche

6

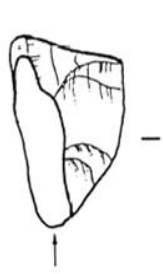

vue lat. droite

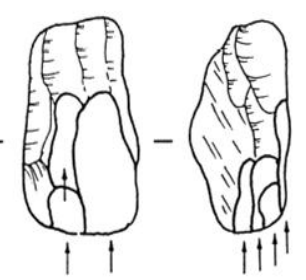

vue ant. vue lat. gauche

5

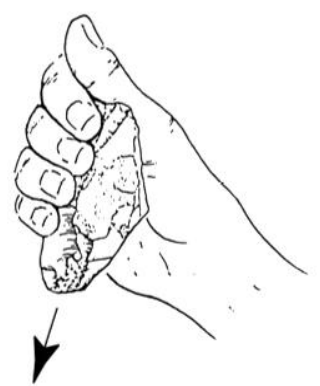

7

Fig. 6 - L'exploitation d'un bloc : l, sur le volume sélectionné (> $100 \mathrm{~mm} \times>60 \mathrm{~mm} \times 60 \mathrm{~mm}$ ), la hauteur de la surface d'initialisation a été installée dans la plus grande dimension; 2, le bloc a été mis en forme à partir d'une crête latérale antérieure et d'une crête latérale postérieure; 3, une série associant éclals allongés et lames larges a été extraite à partir du premier plan de frappe; 4, après ravivage du premier plan de frappe, le tailleur a produit une autre série associant éclats allongés et lames plus étroites; 5, à partir du second plan de frappe, le tailleur a détaché une série associant éclats allongés et lames étroites ; 6 , le débitage a été interrompu après un aplatissement longitudinal et transversal excessif de la table; 7 , le nucléus a été réutilisé : le bord de son premier plan de frappe est mâchuré (dessins et schéma dynamique interprétatif $D$. Molez). 


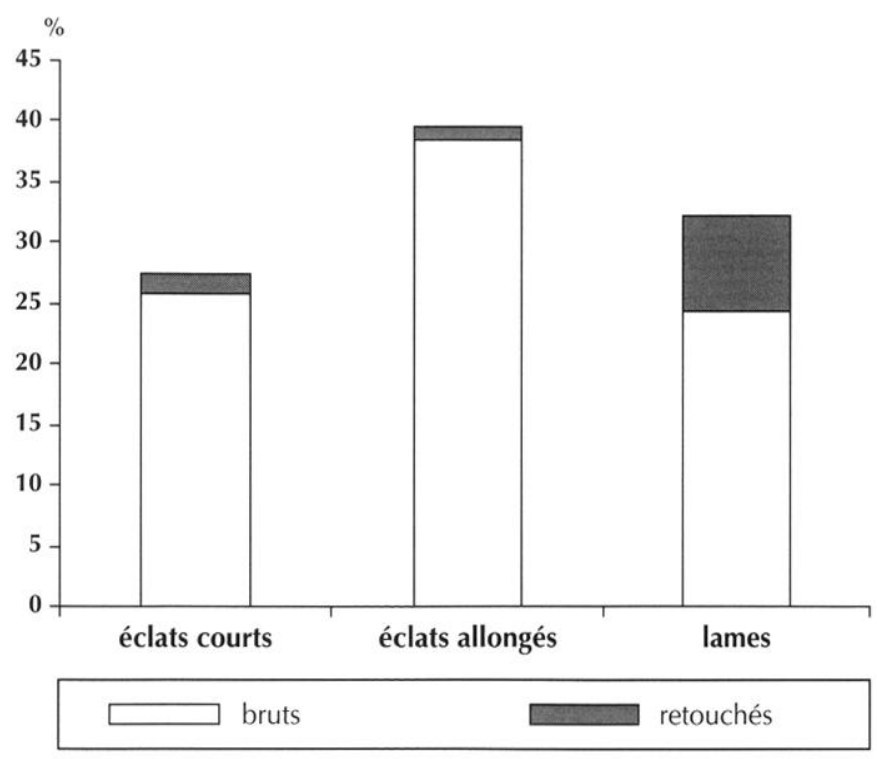

Fig. 7 - Proportion des différents produits de débitage et part transformée en outils et armatures retouchés.

difficile de séparer dans les intentions productives, éclats allongés et lames vraies. À propos de cette distinction, deux faits méritent tout de même d'être soulignés. D'une part, les lames ont donc été manifestement privilégiées pour être transformées par la retouche ; d'autre part, leur production, qui est attestée sur tous les volumes ou presque, a exigé, comme on le verra, un soin particulier qui confère à cet objectif une certaine priorité dans la hiérarchie des intentions techniques.

Si l'on en juge par les supports qui ont été préférentiellement retouchés, les lames recherchées se partagent grosso modo en deux calibres. On trouve d'abord des supports de régularité variable, généralement assez peu allongés quand ils sont entiers (60 à $120 \mathrm{~mm}$ de long pour 16 à $30 \mathrm{~mm}$ de large), et toujours épais (la plupart entre 7 et $13 \mathrm{~mm}$ ). Avouons que ces lames robustes ne se distinguent pas toujours très nettement des supports que nous avons qualifiés comme "éclats allongés ». En revanche, ces éclats allongés se démarquent plus clairement d'une autre catégorie de lames généralement régulières, qui sont également plus courtes, plus étroites et plus fines (40 à $60 \mathrm{~mm}$ de long pour 8 à $16 \mathrm{~mm}$ de large et 2 à $7 \mathrm{~mm}$ d'épaisseur). Ces derniers supports ont exclusivement été utilisés pour fabriquer les monopointes et quelques possibles lamelles à bord abattu épais. Les remontages attestent que les deux calibres de lames ont souvent été produits sur les mêmes volumes, parfois pendant les mêmes séquences (fig. 8), et éventuellement dès le début de l'exploitation. Un seul petit volume n'a servi à produire que des lames courtes et étroites (fig. 9).

Bien que certaines lamelles à bord abattu aient été fabriquées sur des supports très étroits $(<10 \mathrm{~mm})$ et particulièrement fins $(<4 \mathrm{~mm})$, la plupart des nucléus ne portent pas d'évidence d'un véritable projet que l'on pourrait qualifier comme « lamellaire». Le seul nucléus qui pourrait résulter d'une exploitation dans cette intention est resté pratiquement improductif et son exploitation a été conduite avec beaucoup de maladresse. Les quelques " lamelles ", retouchées ou non (les restes de taille bruts en contiennent à peine une dizaine restées brutes), ont donc été probablement produites en position intercalée, au cours du débitage des lames. Il n'est d'ailleurs pas certain que cette production répondait seulement à un objectif économique, car des enlèvements de ce module peuvent parfaitement avoir été détachés dans une intention d'entretien (recentrage d'une " nervure-guide » par exemple).

En bref, l'objectif des débitages réalisés au Cornet fut une production de lames et d'éclats allongés de dimensions et de régularité variées. Seuls les supports étroits et légers d'armatures ont fait l'objet d'une certaine exigence qualitative. Ces produits, ainsi que les supports plus larges réservés aux outils retouchés, ont été détachés sur les mêmes volumes et selon la même méthode. Ces exploitations ont également généré quelques rares lamelles et des éclats courts, dont une petite part a été retouchée en outils.

\section{UN APPROVISIONNEMENT EN SILEX SANS GRANDE EXIGENCE QUALITATIVE}

Tous ces produits ont été débités dans des silex de qualité souvent médiocre, dont l'origine précise n'a pas pu encore être précisément déterminée. Comme nous l'avons signalé plus haut, le silex contenu localement dans les argiles du plateau est un matériau peu propice à la taille, qui ne semble donc pas avoir été exploité par les occupants du Cornet. L'approvisionnement a dû plutôt s'effectuer à un kilomètre environ dans la vallée de la Risle, probablement sur des formations détritiques (alluvions ou dépôts de pente) car les blocs sont généralement altérés : leurs cortex sont lavés et les surfaces de cassure naturelle, que portent beaucoup d'entre eux, sont patinées. D'après des critères strictement macroscopiques (grain, couleur, opacité du silex et aspect des cortex), on peut estimer à trois ou quatre les variétés de silex débités. Nous ignorons si cette variabilité est liée à une réelle diversité des provenances ou si elle découle 


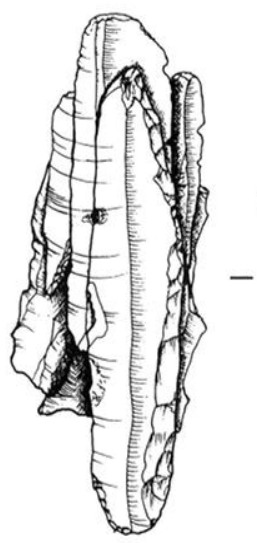

vue antérieure

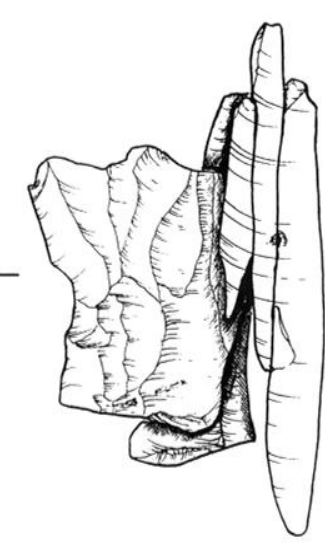

vue latérale gauche

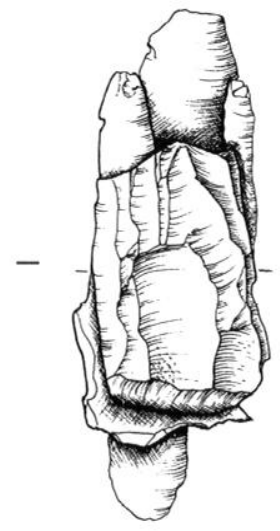

vue postérieure
" couteau à dos"
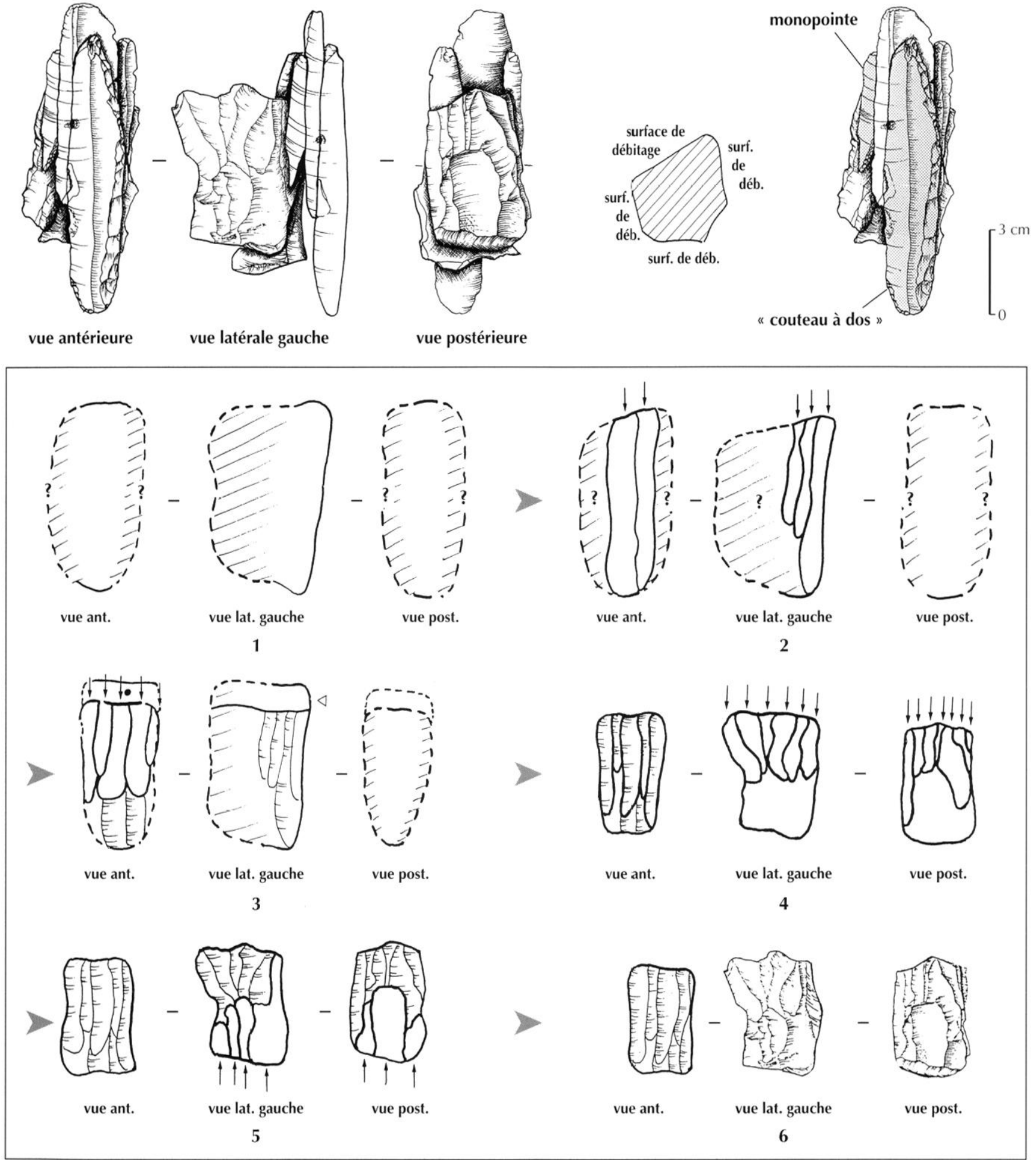

Fig. 8 - Lexploitation d'un bloc: 1, sur le volume sélectionné (dimensions initiales impossibles à restituer), la hauleur de la surface d'initialisation a probablement élé installée dans la plus grande dimension (les modalités de mise en forme el d'initialisation n'omt pas pu être reconstituées); 2, une série associant probablement éclats allongés et lames larges a été extraite à partir du premier plan de frappe (une lame de cette série porte un borl abattu) - à ce stade, l'élat du dos initial ne peut pas être restitué: 3, une autre série associant éclats allongés el lames plus étroites a été extraite à partir du premier plan de frappe, après son ravivage (une laméétroile de cette série a été transformée en monopointe) - à ce slade, l'état du dos initial ne peut toujours pas être restitué; 4, des séries associant érlats allongés el lames étroiles ont élé extraites à partir du premier plan de frappe sur le flanic gauche, le flanc droil et le dos; 5, à partir du second plan de frappe, le tailleur a détaché sur le flane gauche et le dos des séries associant éclats allongés et lames étroites; 6, le débitage a été interrompu après le détachement d'éclats courts el larges (par suile d'un élalement accidentel des enlèvements) et le nucléus a été abandonné à ce siade (dessins el schéma dynamique interprétatif D. Molez). 


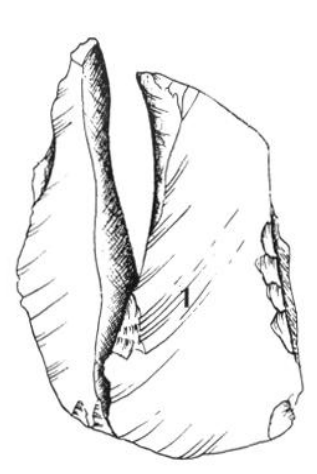

vue latérale droite

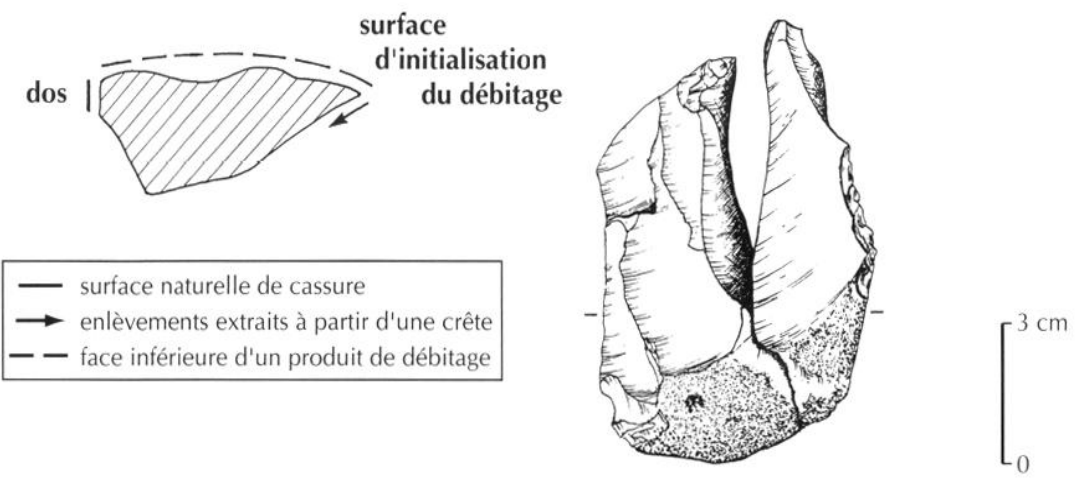

vue latérale gauche

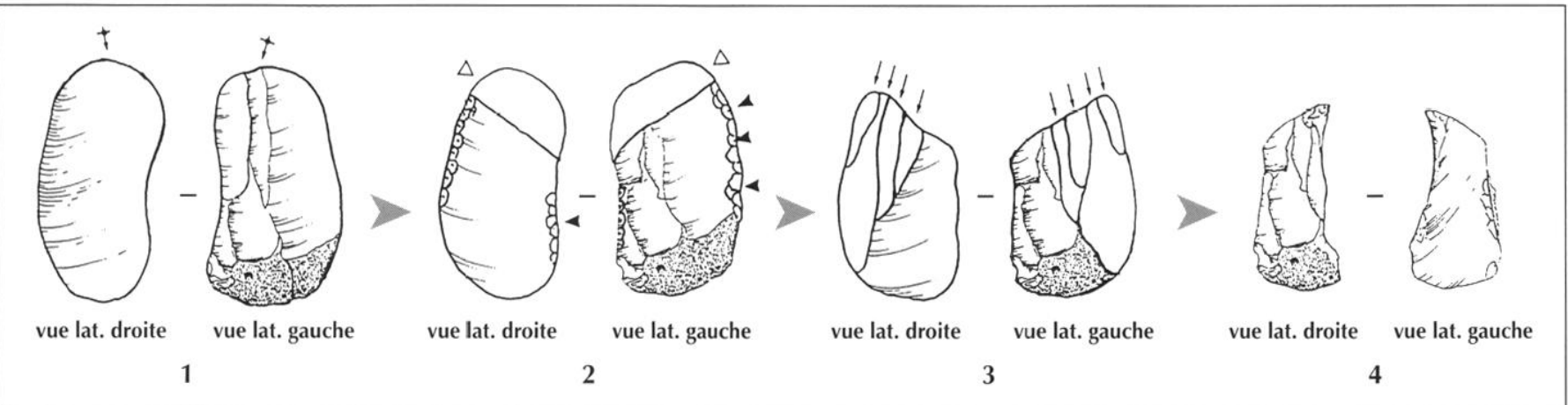

Fig. 9 - L'exploitation d'un éclat débité: 1, sur le volume sélectionné (> $95 \mathrm{~mm} \times>63 \mathrm{~mm} \times 25 \mathrm{~mm}$ ), la hauteur de la surface d'initialisation a élé installée dans la plus grande dimension et sa largeur a été placée dans la plus petite (épaisseur de l'éclat débité); 2, à l'emplacement de la future surface d'initialisation, une crôte partielle a servi à régulariser le dièdre formé par la rencontre de la face inférieure et de la face supérieure de l'éclat - Ie dos a également accueilli une crête partielle sans vocation technique explicite (adoucissement d'une arête vulnérante'?); 3 , après outerture d'un plan de frappe, un éclat d'entame épais a ensuite été extrait le long de la surface d'initialisation, puis une série associant quelques éclats allongés et peut-être quelques rares lames courtes et étroites a été extraite à partir de l'unique plan de frappe; 4, le nucléus a été abandonné après des réfléchissements occasionnés par un aplatissement longitudinal de la table (dessins et schéma dynamique interprélatif l). Molez).

de la variété des matériaux sur un unique lieu d'approvisionnement.

Dix-neuf nucléus entiers et un autre cassé ont été retrouvés dans l'unité 33 . Ils attestent le débitage de 17 blocs, de deux produits de taille et d'un gélifract. On compte aussi un bloc, non exploité et resté au stade de la mise en forme. Deux autres blocs au moins ont été exploités, mais leurs nucléus ont disparu de la zone fouillée. Au total, les tailleurs de l'unité 33 ont donc sélectionné 23 volumes (20 blocs et 3 fragments taillés ou naturels), et parmi ces volumes, un seul bloc n'a pas été exploité (fig. 10).

Parmi les 20 blocs qui ont été rapportés dans l'unité 33, la plupart (16) étaient grossièrement parallélépipédiques (fig. 10). Grâce aux remontages, on a pu estimer le module originel de plusieurs d'entre eux. La plus grande dimension de ces blocs parallélépipédiques s'établissait autour de $100 \mathrm{~mm}$ en moyenne (les plus grands atteignant $150 \mathrm{~mm}$ ).
Leurs autres dimensions étaient comprises entre 60 et $100 \mathrm{~mm}$. S'ajoute à ce lot un petit groupe de quatre rognons à section ovalaire nettement plus resserrée : une de leurs dimensions originelles (autour de $40 \mathrm{~mm}$ ) était nettement plus réduite que les deux autres (entre 60 et $100 \mathrm{~mm}$ ). Tous ces blocs portaient un cortex épais, dont la surface dessinait des creux et des bosses. Par ailleurs, les zones corticales étaient souvent limitées par des surfaces planes et patinées, correspondant à d'anciennes diaclases naturelles. L'intersection de ces surfaces diaclasiques et des zones corticales formait des arêtes qui ont facilité l'ouverture des surfaces de travail (plans de frappe et surfaces de débitage). À coeur, le matériau était rarement faillé par le gel, mais il contenait souvent des zones au grain plus grossier ainsi que des géodes profondes et d'étendue variable, qui ont pu gêner gravement la conduite du débitage (fig. 11 et 12). Il est notable que, dans quatre cas au moins, ces géodes 


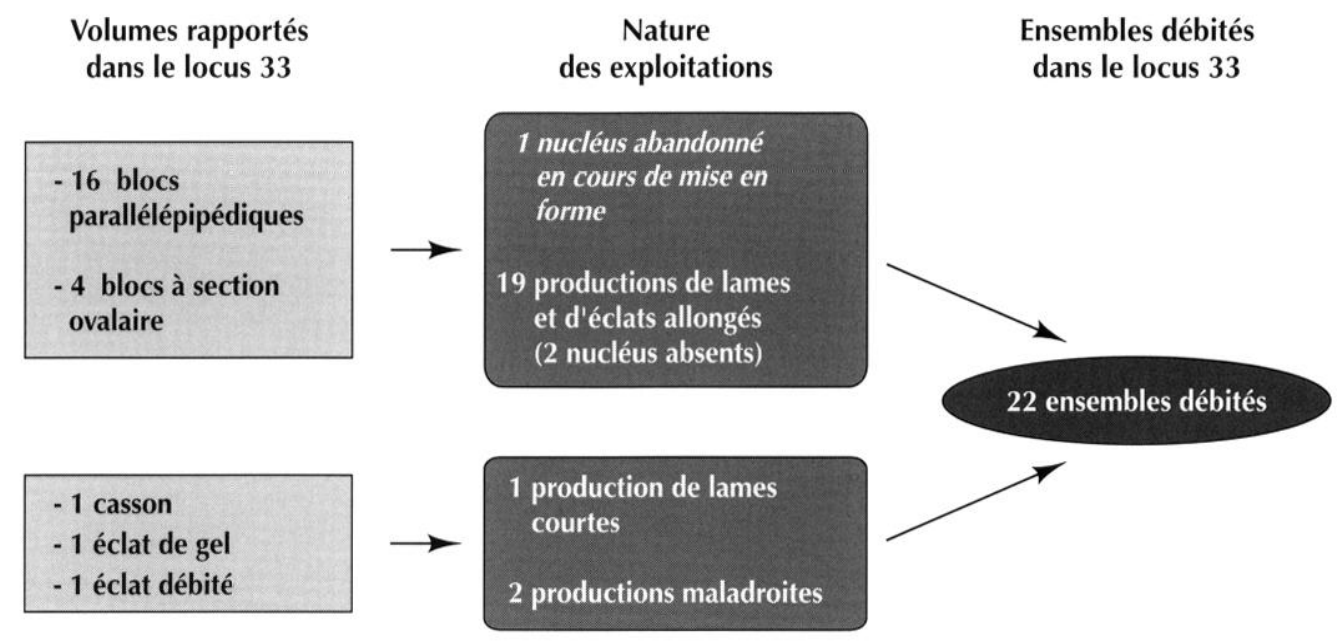

Fig. 10 - Morphologie initiale des volumes sélectionnés et nombre d'ensembles débités.

étaient visibles ou prévisibles lors du ramassage (fig. 11). Cette sélection peu rigoureuse est difficile à imputer à des tailleurs inexpérimentés, car ce sont parfois les blocs les plus irréguliers qui ont fait l'objet des exploitations exigeant le plus de savoirfaire. Nous sommes donc tentés d'y voir le premier indice de la grande souplesse et du faible souci de rentabilisation, qui caractérisent l'ensemble du processus de taille au Cornet.

Les trois fragments qui ont servi comme nucléus (un gélifract, un " casson " et un éclat de mise en forme) étaient des volumes assez réguliers $(55$ à $85 \mathrm{~mm}$ dans leur plus grande dimension, pour 40 à $60 \mathrm{~mm}$ dans leur dimension moyenne et 30 à $45 \mathrm{~mm}$ dans leur plus petite). Parmi les autres restes de taille, on trouve quelques gros éclats aux dimensions analogues qui n'ont pas été utilisés comme nucléus, sans doute parce qu'ils étaient couverts d'un cortex trop épais.

\section{LES ACTIVITÉS DE DÉBITAGE PRATIQUÉES DANS LE LOCUS 33}

La présence d'éléments provenant de toutes les étapes de la chaine opératoire ainsi que l'abondance d'esquilles et de lames cassées au débitage permettent d'affirmer que des activités de taille assez complètes ont eu lieu dans le locus 33. On constate cependant une assez nette surreprésentation des lames et des éclats allongés au détriment des éclats courts (fig. 7). En outre, dans toutes les catégories de produits, on note un faible pourcentage de pièces dont la face supérieure est entièrement brute (cortex ou surface diaclasique) (fig. 13). Enfin, les vrais éclats d'entame (face supérieure et talon entièrement naturels) sont particulièrement rares. Tous ces indices suggèrent que les éléments extraits lors des premières étapes du débitage se trouvent en partie en dehors du locus fouillé. Cette hypothèse est confortée par les remontages qui, à quelques exceptions près, associent surtout des éléments appartenant aux séquences finales du débitage. Il n'est donc pas exclu que quelques opérations de taille se soient déroulées sur les lieux de l'approvisionnement. Mais, si tel fut le cas, ces opérations se sont probablement limitées au test des blocs, dont les dimensions originelles ne nécessitaient pas d'allégement particulier pour le transport. Il reste que cette hypothèse de tests préalables s'accorde asse $z$ mal avec les faibles exigences qualitatives qui ont guidé la collecte. Il est donc plus vraisemblable que les éléments de mise en forme absents de l'unité 33 ont été regroupés dans d'autres secteurs du site (soit que la préparation ait été réalisée sur d'autres postes de taille, soit que les produits de cette opération aient été rejetés en dehors du locus 33).

\section{LA MISE EN FORME ET L'INITIALISATION DU DÉBITAGE : DES SÉQUENCES SOUVENT CONFONDUES}

\section{Principes Volumétriques gÉNÉrauX}

Au Cornet, la distribution des différentes surfaces de travail dans les volumes ne répondait pas à des règles très strictes.

Les tailleurs inscrivaient plutôt la hauteur de la future surface d'initialisation du débitage dans la plus grande 


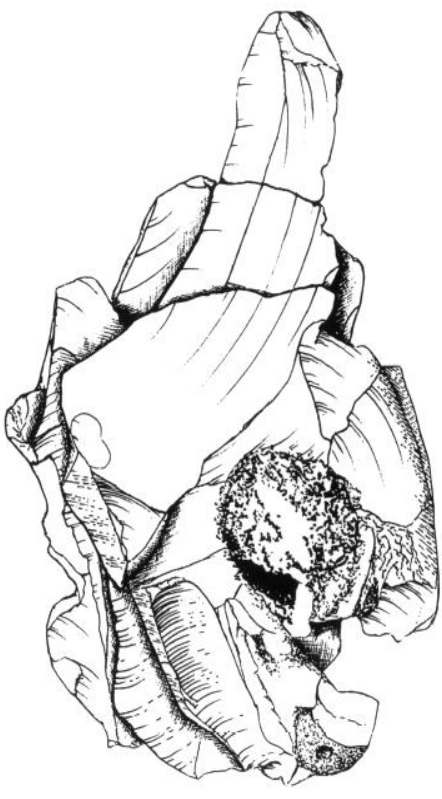

vue antérieure

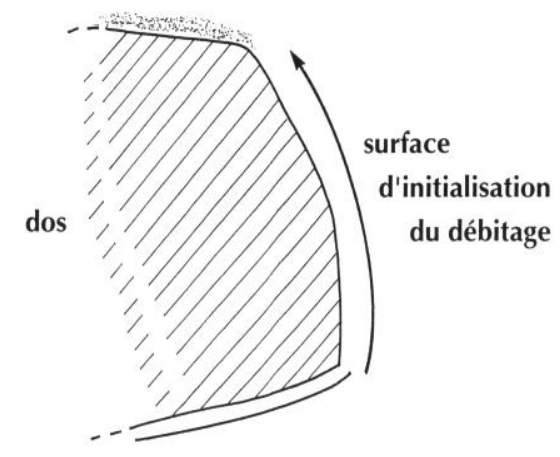

s.:Purface corticale

enlèvements extraits à partir d'une crête

— - face inférieure d'un produit de débitage

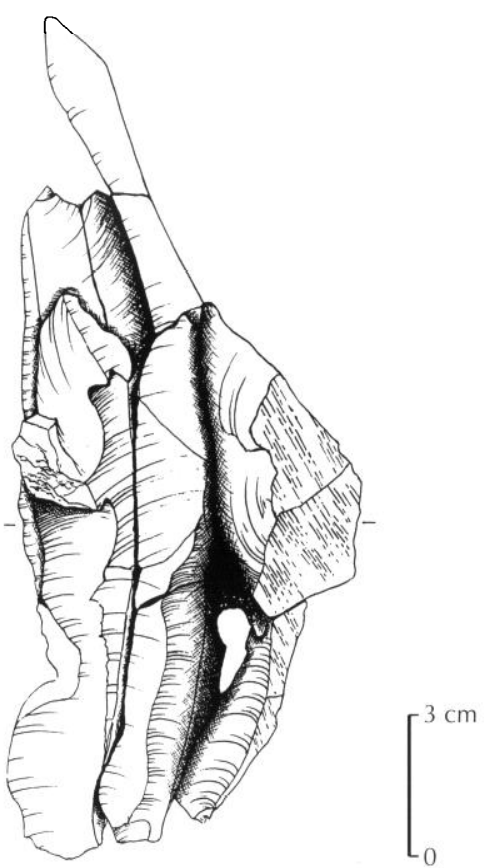

vue latérale gauche

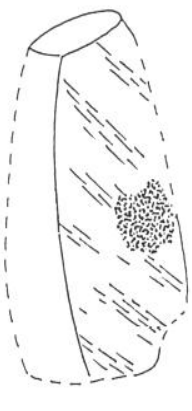

vue ant.

1

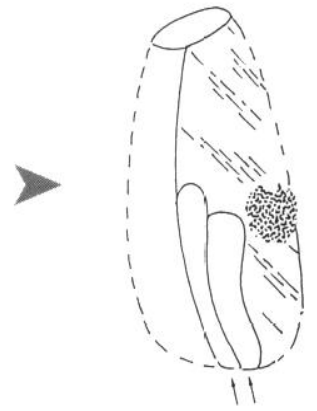

vue ant.

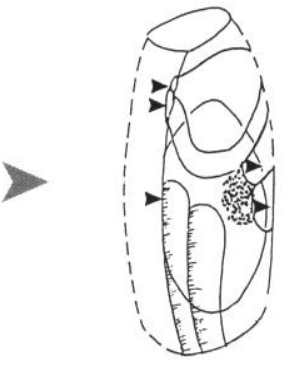

vue ant.

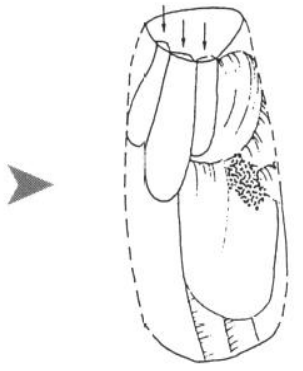

vue ant.

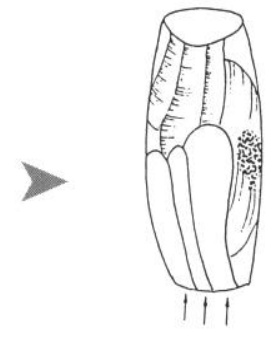

vue ant.

4

5

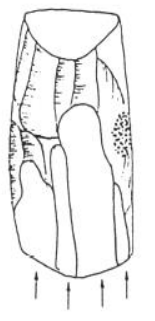

vue ant.
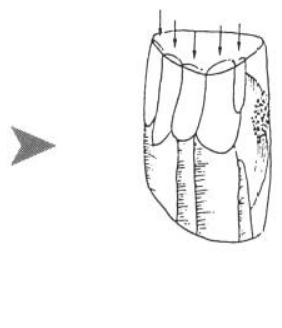

vue ant.

Fig. 11 - L'exploitation d'un bloc: 1, sur le volume sélectionné (> $174 \mathrm{~mm} \times>92 \mathrm{~mm} \times>75 \mathrm{~mm}$ ), la hauteur de la surface d'initialisation a été installée dans la plus grande dimension; 2 , après ouverture d'un plan de frappe, quelques lames ont été extraites le long d'une surface de cassure naturelle; 3, cette surface déformée par une géode profonde a été régularisée par une crête cuverte à partir du flanc gauche ; 4, à partir d'un second plan de frappe opposé au premier, le tailleur a extrait une série associant éclats allongés et lames larges; 5 , à partir du premier plan de frappe, le tailleur a détaché une autre série associant éclats allongés et lames larges ; 6-8, trois autres inversions dans le sens du débitage ont eu lieu au cours de la production de séries associant éclats allongés et lames étroites; 9, le nucléus est absent et la suite de l'exploitation ne peut pas être reconstituée (dessins et schéma dynamique interprétatif $D$. Molez). 


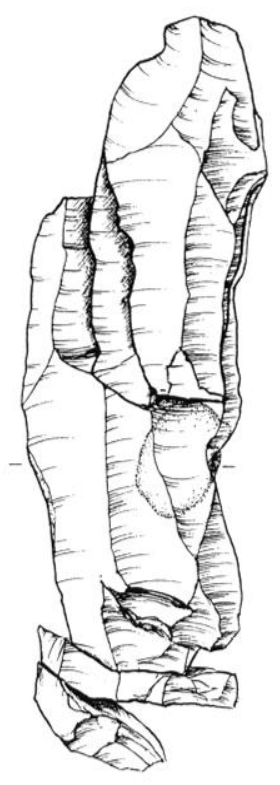

vue antérieure

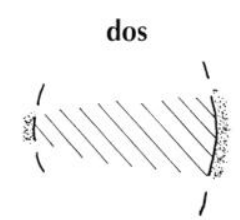

surface de débitage

[.:Pi: surface corticale

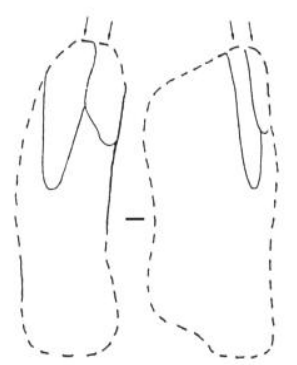

vue ant vue lat. gauche 2

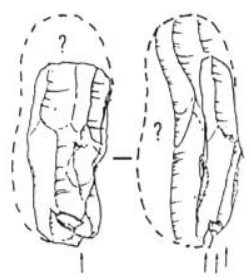

vue ant. vue lat. gauche

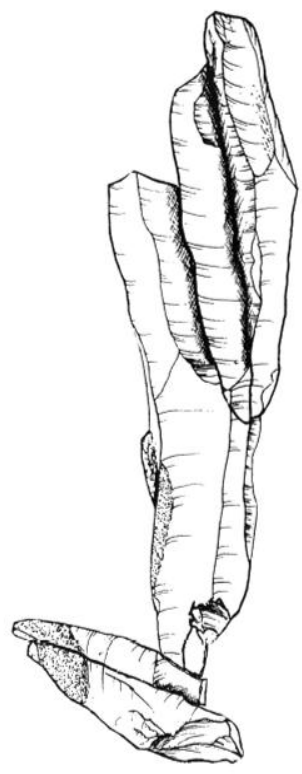

vue latérale gauche
1

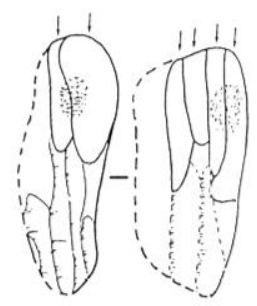

vue ant. vue lat. gauche

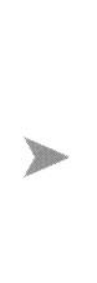

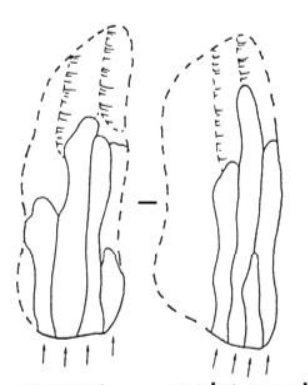

vue ant.

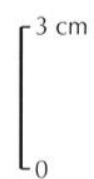

3

6

Fig. 12 - L'exploitation d'un bloc: 1, sur le volume sélectionné (> $156 \mathrm{~mm} \times>57 \mathrm{~mm} \times 47 \mathrm{~mm}$ ), la hauteur de la surface d'initialisalion a sans doute été installée dans la plus grande dimension (les modalités de mise en forme el d'initialisation ne peuvent pas être reconstituées car le nucléus est absent) ; 2, une série associant éclats allongés et lames larges a été extraite à partir du premier plan de frappe; 3, à partir du second plan de frappe, le tailleur a détaché une série associant éclats allongés et lames larges; 4, à partir du premier plan de frappe et après son ravizuge, le tailleur a extrait une autre série associant éclats allongés et lames plas étroites - elle a vónélé une géode profonde qui a occasionné plusieurs réfléchissements ; 5, à partir du second plan de frappe, un éclat allongé très épais a été extrait pour nettoyer la surface laminaire ; 6, le nucléus étant absent, la suite de l'exploitation ne peut pas être reconstituée (dessins el schéma dynamique interprétatif l). Molez). 


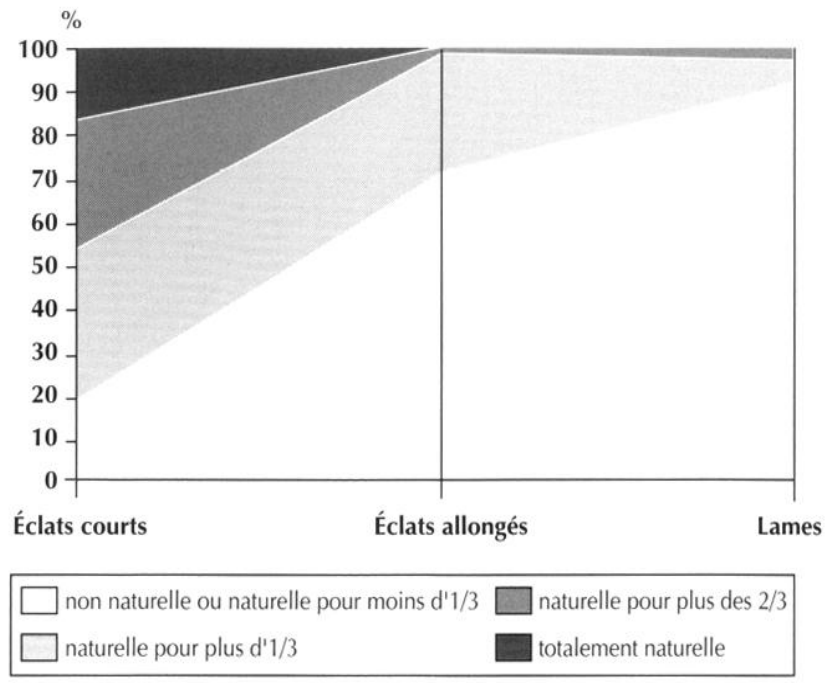

Fig. 13 - Aspect de la face supérieure sur les differents produits de débitage.

dimension des blocs, mais cette tendance a souffert au moins une exception notable. En effet, sur un bloc bordé de surfaces diaclasiques régulières, le tailleur a d'abord choisi sa dimension moyenne et il a profité de ses arêtes naturelles pour guider les premiers enlèvements. Par suite d'un aplatissement transversal de cette première table, il a retourné le bloc pour placer la hauteur de la nouvelle table dans la plus grande dimension du bloc, cette fois (fig. 14).

Pour sa part, la largeur de la surface d'initialisation a été diversement placée selon les circonstances. Sur les rares volumes à section ovalaire, elle a été disposée dans la plus petite dimension. Sur les autres volumes, qui ne sont pas naturellement resserrés, c'est généralement la présence d'une grande arête naturelle, formée par l'intersection de zones corticales ou diaclasiques, qui a guidé l'implantation de la surface d'initialisation.

Les tailleurs ont conçu par ailleurs un ou deux plans de frappe autonomes, dans des plans globalement perpendiculaires à la surface d'initialisation. Ces plans de frappe sont restés généralement permanents, sauf dans le cas précédemment évoqué, où la première surface de plan de frappe fut investie par le débitage, après retournement du bloc (fig. 14).

Une fois cette distribution décrétée, l'initialisation du débitage ainsi que des séquences éventuellement conjointes de mise en forme ont configuré certaines surfaces plus systématiquement que d'autres. Le seul impératif était de régulariser progressivement la surface de débitage et d'y dégager des "nervures-guides " asse\% rectilignes. La carène de cette surface est restée généralement faible. Nous arons mesuré son intensité sur quelques surfaces d'initialisation ainsi que sur quelques crêtes d'entame non remontées, en calculant un indice qui rapporte à la hauteur de la surface de débitage considérée, la flèche de sa convexité (fig. 15). Cet indice avoisine en général 0,05 alors qu'il se situe autour de 0,15 dans les séries magdaléniennes où nous l'avons estimé (Valentin, 1995, p. 171 et 334). Le cintre global de la surface d’initialisation était également réduit. Ainsi, le dièdre formé par la rencontre des deux pans divergents résultant de certains aménagements par crêtes formait un angle très ouvert, compris entre $85^{\circ}$ et $120^{\circ}$, tandis que cet angle se situe généralement entre $80^{\circ}$ et $90^{\circ}$ en contexte magdalénien (ibid.). Au Cornet, les flancs, qui encadraient ccttc surface initiale peu carénée et peu cintrée, ont pu rester partiellement naturels et n'ont alors été régularisés qu'en cours de débitage. Quant aux plans de frappe, ils formaient un angle assez ouvert avec la surface d'initialisation : cet angle est compris entre $80^{\circ}$ et $90^{\circ}$ sur les blocs peu exploités et sur les lames d'entame sur lesquels nous avons pu l'estimer. Pour sa part, le dos initial ne constituait pas nécessairement une zone inaccessible pour le débitage, mais sa régularisation a rarement été conçue dès le départ. Elle a pu n'avoir lieu que pendant le début ou même le plein temps du débitage, pour faciliter les ravivages de plan de frappe. Par ailleurs, dans d'assez nombreux cas, le dos est resté entièrement naturel pendant toute l'exploitation.

\section{DES MODALITÉS DE MISE EN FORME ET D'INITIALISATION DU DÉBITAGE QUI TÉMOIGNENT D'UNE GRANDE SOUPLESSE}

\section{La mise en forme des blocs}

Pour les blocs, la reconstitution des modalités de mise en forme est délicate, compte tenu de la sous-représentation relative des produits de cette étape, qui limite les possibilités de remontage. Dans 8 cas seulement sur 20 (quatre blocs abandonnés précocement ainsi que quatre ensembles remontés et relativement complets), les modalités de mise en forme peuvent être assez précisément décrites (fig. 16).

- Sur trois blocs peu ou presque pas exploités, la préparation s'est essentiellement limitée à l'extraction d'enlèvements allongés le long des surfaces naturelles (fig. 16, $\mathrm{n}^{\circ \aleph} 1$ à 3). C'est le cas sur un petit rognon à section ovalaire qui présentait, à l’intersection de surfaces diaclasiques, des arêtes naturelles régulières qui ont servi à guider les premiers enlèvements (fig. 16, n' 1 ; fig. 17). Son dos cortical régulier n'a fait l'objet d'aucune préparation: les 


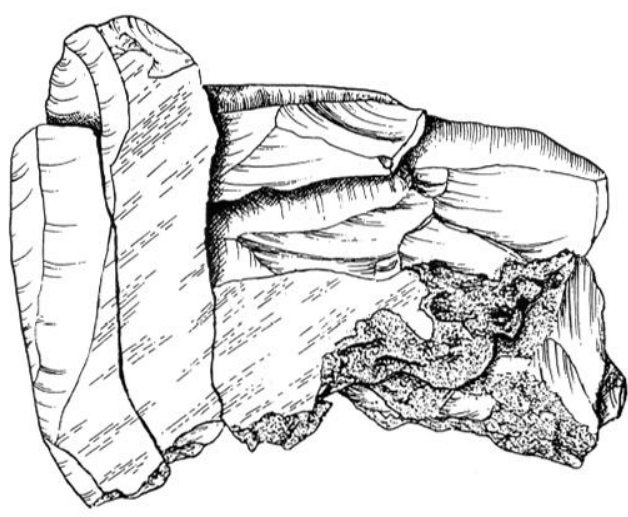

Phase 1, vue latérale droite

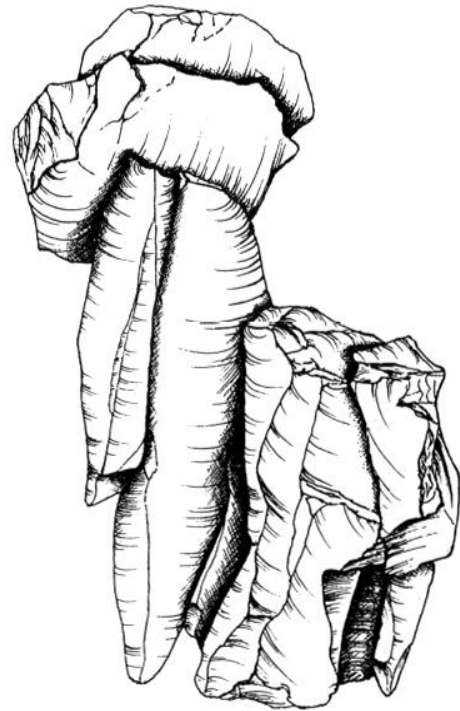

Phase 2, vue antérieure

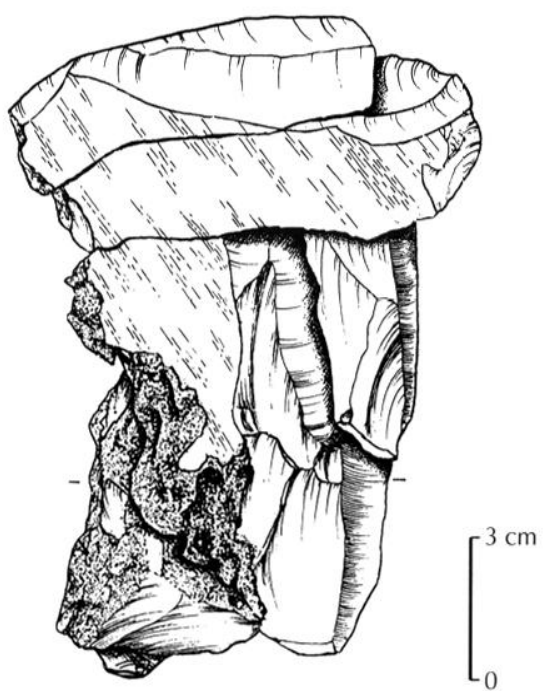

Phase 2, vue latérale gauche

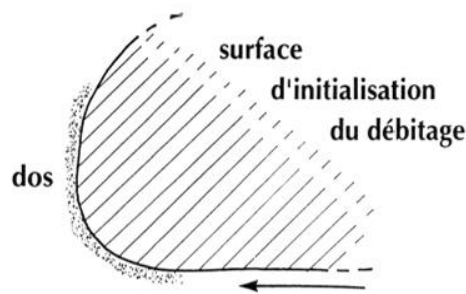

Phase 2

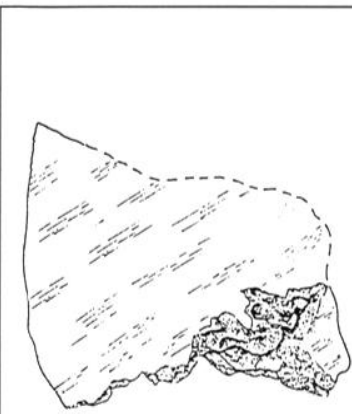

vue lat. droite

1

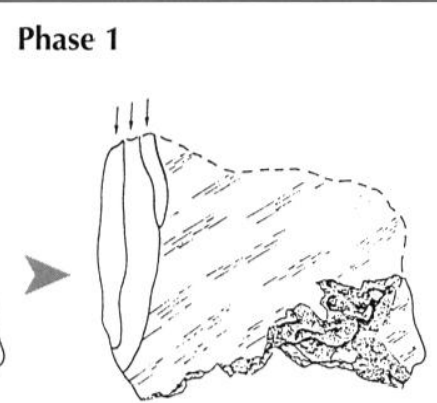

vue lat. droite

2

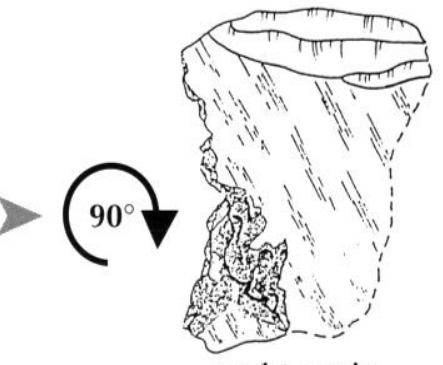

vue lat. gauche

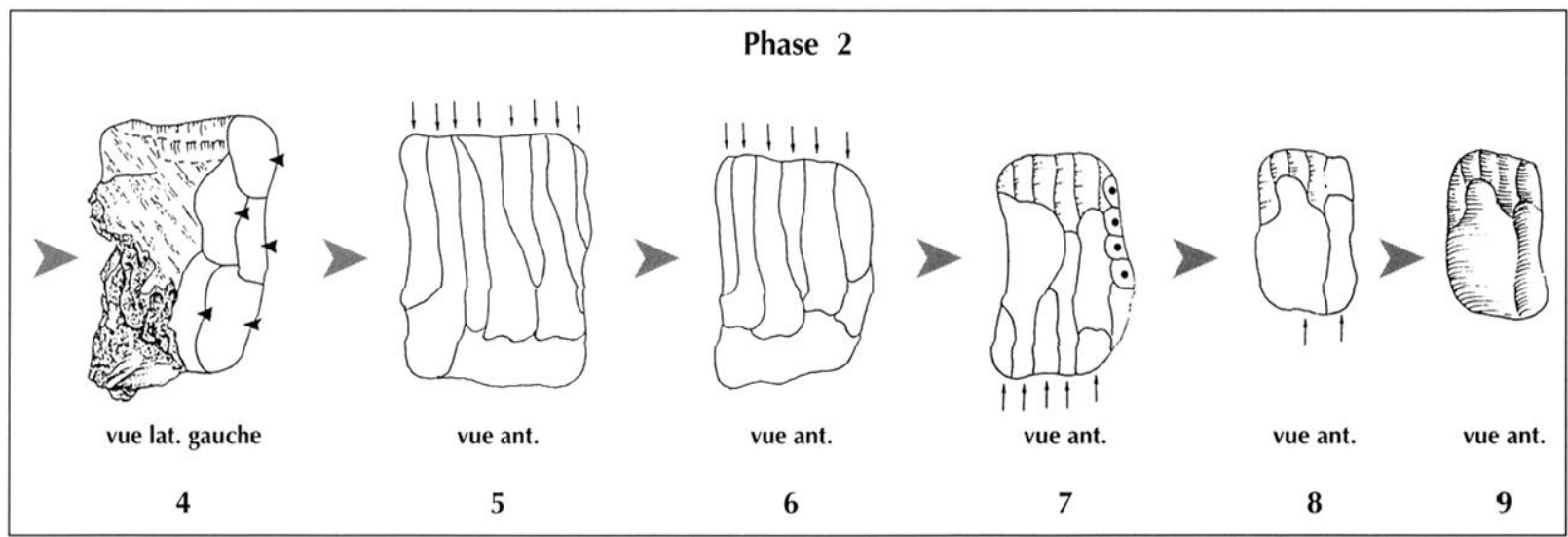

Fig. 14 - L'exploitation d'un bloc: 1, première phase - sur le volume sélectionné (> $132 \mathrm{~mm} \times>103 \mathrm{~mm} \times>95 \mathrm{~mm}$ ), la hauteur de la première surface d'initialisation a été installée dans la dimension moyenne; 2 , après ouverture d'un plan de frappe, le tailleur a extrait des lames assez larges (et des lames étroites intercalées ?) le long d'un dièdre formé par la rencontre de deux surfaces de cassure nalurelles; 3, l'aplatissement longitudinal de celte première table a conduit le tailleur à l'abandonner et à retourner le bloc à $90^{\circ} ; 4$, seconde phase - le premier plan de frappe a été utilisé comme nouvelle surface de débilage et cetle surface a été mise en forme par une crête antérieure, 5, 6, sur cette nouvelle table, le tailleur a produit au moins deux séries de lames et d'éclats allongés, entrecoupées par le détachement d'une lablette; 7, 8, après l'aménagement d'une néocrête partielle, au moins deux séries d'entèvements ont été détachées à partir d'un plan de frappe opposé; 9, le nucléus a été abandonné à ce slade (dessins el schéma dynamique interprétatif D. Molez). 


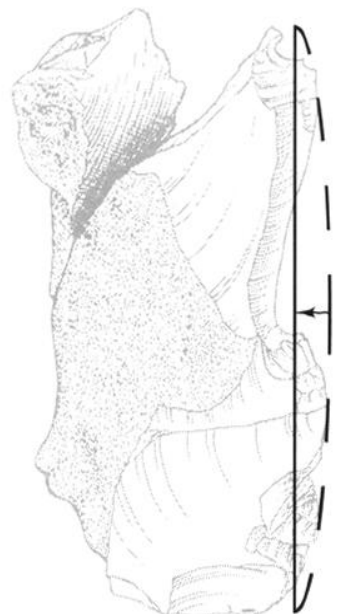

rapport flèche/hauteur $=0,05$

1

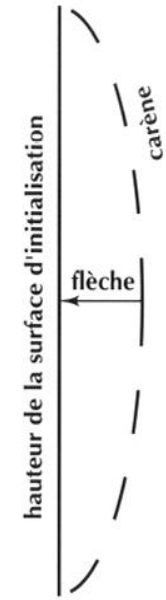

rapport flèche/hauteur $=0,15$

2
Fig. 15 - Estimation de la carène des surfaces d'initialisation: 1, rapport flèche/hauteur moyen des surfaces d'initialisation observées au Cornet ; 2, le même rapport observé sur quelques séries magdaléniennes du Bassin parisien.

convexités naturelles ont facilité le détachement des ouvertures et des ravivages de plan de frappe. Sur le deuxième bloc (fig. 16, n²), très vite abandonné après le début d'une mise en forme maladroite, la surface d'initialisation a également été aménagée par des enlèvements détachés directement à partir du plan de frappe, le long des arrondis corticaux. À ce stade, la partie dorsale est restée brute. Sur le troisième rognon (fig. $16, n^{\circ} 3$ ), dont le débitage a aussi été interrompu précocement, la mise en forme a également été amorcée par l'extraction de grandes lames corticales détachées à partir du plan de frappe. Assez vite, deux crêtes latérales partielles ont été ouvertes pour achever la régularisation de la table et mettre en forme le dos.

- Sur deux autres blocs, on observe une exploitation immédiate le long des convexités naturelles, mais elle ne semble pas avoir eu de véritable finalité préparatoire (fig. 11 et 14). Sur ces volumes qui comportaient des irrégularités apparentes, les tailleurs ont d'abord voulu utiliser le potentiel immédiat et ils ont choisi d'extraire directement quelques lames le long d'anciennes surfaces de cassure (deux courtes lames dans un cas; quatre ou cinq lames de longueur moyenne dans l'autre). C'est seulement après le détachement de ces premières séries que les artisans ont procédé à une véritable mise en forme (fig. 16, $n^{\text {*s }} 4$ et 5 ). À cette occasion, de nouvelles tables laminaires ont été ouvertes sur des surfaces au potentiel plus élevé que celles qui avaient été initialement exploitées. La régularisation de ces nouvelles tables, rendue nécessaire par la présence de géodes profondes, a été réalisée par de grands éclats épais détachés au percuteur de pierre dure ${ }^{1}$. Ces éclats ont été extraits perpendiculairement à l'axe des futures tables, à partir d'une ancienne zone de cassure qui bordait ces surfaces. Ces mises en forme n'ont été que partielles et elles ont laissé subsister des irrégularités sur les flancs des deux blocs. Ensuite, ces irrégularités n'ont été corrigées que progressivement par l'extraction d'éclats allongés à partir du plan de frappe. Le traitement de la surface postérieure ne peut être observé que sur un de ces deux blocs (fig. 14 ; fig. 16, n" 5). Sa régularisation n'a été réalisée qu'en cours de débitage, à partir d'une petite crête postéro-latérale partielle, d'où quelques petits enlèvements ont été extraits pour faciliter les ravivages de plan de frappe. Cette crête ne participe donc qu'à un entretien très local du volume.

- Sur un sixième bloc, il ne subsiste aucun indice d'une première phase éventuelle de débitage le long des convexités naturelles (fig. 6 ; fig. $16, \mathrm{n}^{\circ} 6$ ). La régularisation de la surface d'exploitation semble avoir été entièrement réalisée au moyen d'éclats larges et épais, détachés au percuteur de pierre à partir de deux crêtes latérales irrégulières. L'une de ces crêtes, en position postérieure, a également participé à l'aménagement du dos. Cette préparation dispendieuse a fait perdre au bloc un tiers environ de son volume initial avant que la production ne commence.

- Deux autres blocs enfin portent le témoignage d'une mise en forme initiale de la surface antérieure par une crête médiane à deux versants et ce sont les seuls blocs traités de la sorte (fig. 16, no 7 ; fig. 18). Il s'agit de deux rognons à section ovalaire, dont l'étroitesse naturelle a facilité l'ouverture de crêtes partielles, principalement destinées à régulariser les flancs. L'aménagement de ces crêtes antérieures médianes n'a été réalisé que par deux générations d'enlèvements. La première, consistant en éclats larges et épais détachés au percuteur de pierre dure, a laissé subsister de profonds contre-bulbes, à peine rectifiés par une seconde génération d'éclats plus fins de régularisation. À l'issue de cette préparation, les crêtes ont une délinéation sinueuse et leur carène est relativement faible (fig. 15). Sur l'un de ces

1. Pour toutes les interprétations concernant les stigmates de percussion, nous nous référons aux critères définis par J. Pelegrin (exposés wès en détail dans Pelegrin, 2000). 


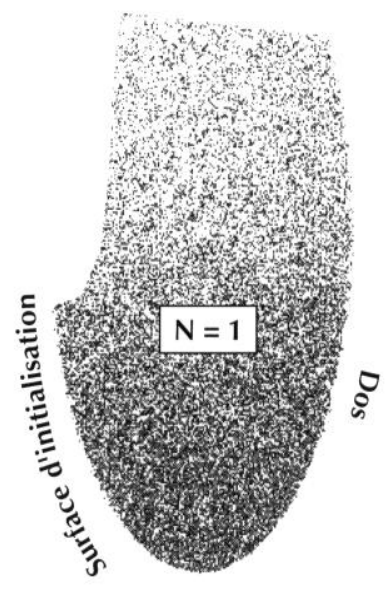

1

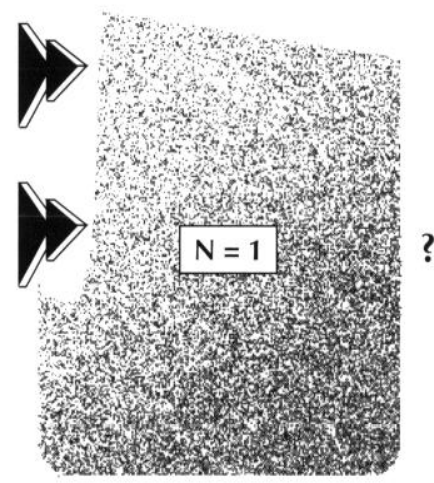

4

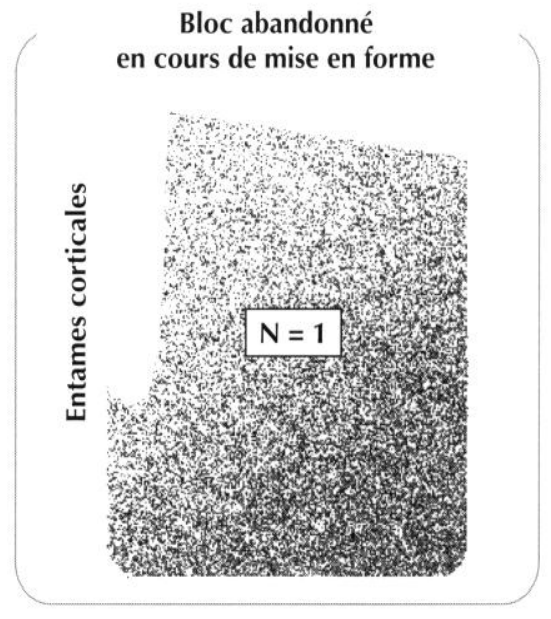

2

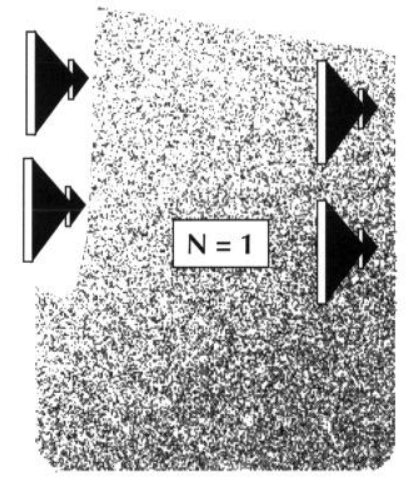

5

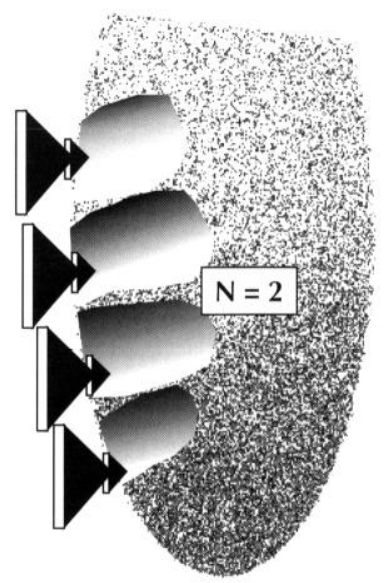

7

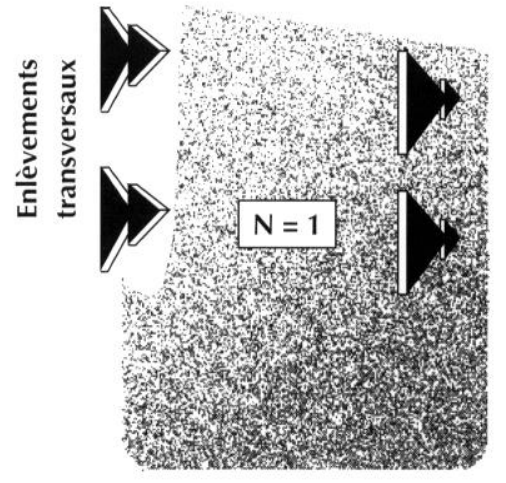

3

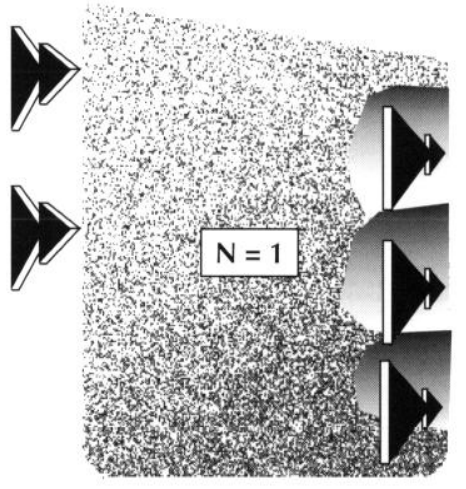

6

Fig. 16 - Modalilés de mise en forme observiés sur 8 blocs débités (sur 20) : 1, 2, entames conticales; 3, entames corticales puis crête antérolatérale el crête postéro-latérale à un versant; 4, entames corticales puis crôte antéro-latérale à un versant; 5 , entames corticales puis crête antéro-latérale et crôte postéro-latérale à un versant; 6, crête antéro-latérale et crête postéro-latérale à deux versants; 7 , crête antérieure médiane à deux versants. 


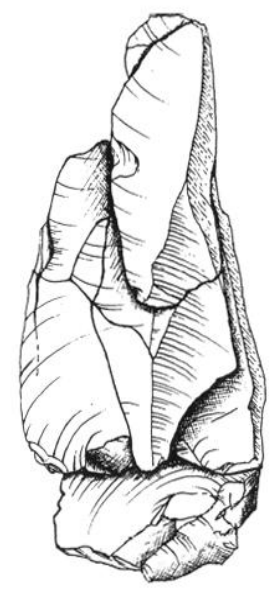

vue antérieure

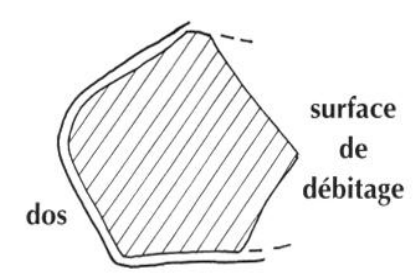

surface naturelle de cassure

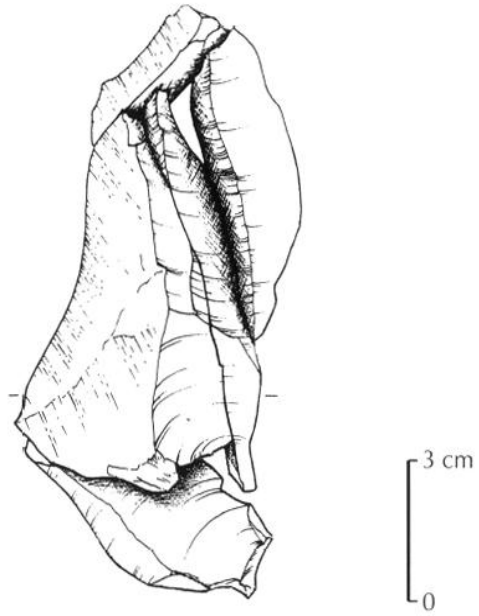

vue latérale gauche

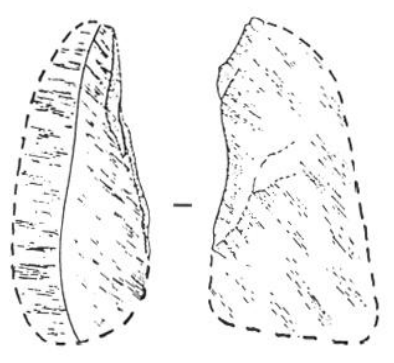

vue ant.

vue lat. gauche

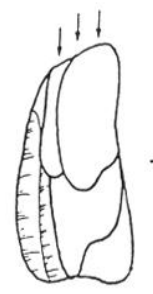

vue ant.

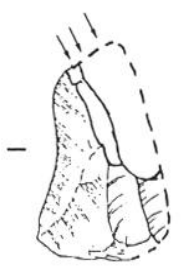

vue lat. gauche

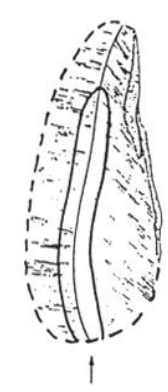

vue ant.

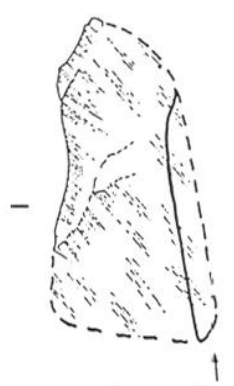

vue lat. gauche

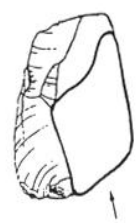

vue ant.

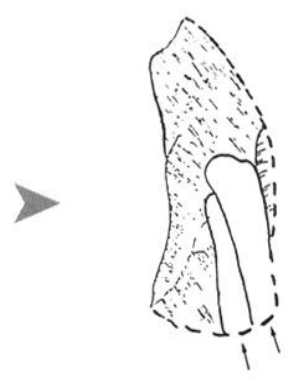

vue lat. gauche

3

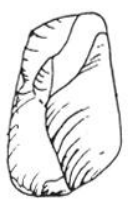

vue ant.

6

Fig. 17 - L'exploitation d'un bloc: 1, sur le volume sélectionné (130 $\mathrm{mm} \times>60 \mathrm{~mm} \times 54 \mathrm{~mm}$ ), la hauleur de la surface d'initialisation a été installée dans la plus grande dimension et sa largeur a élé placée dans la plus petite; 2 , après ouverture d'un plan de frappe, l'initialisation s'est limitée à l'extraction d'une lame d'entame le long d'un dièdre formé par la rencontre de deux surfaces de cassure naturelles; 3 , après cette. extraction, quelqués éclats allongés ont été détachés à partir du premier plan de frappe; 4, par suite d'un aplatissement longitudinal de la table, le bloc a été retourmé pour extraire quelques éclats allongés (et des lames étroites ?) à partir d'un plan de frappe opposé; 5, un nouveau retournement à permis d'extraire un éclat allongé à partir du premier plan de frappe; 6, le nucléus a été abandonné à ce stade (dessins et schéma dynamique interprétatif I). Molez). 


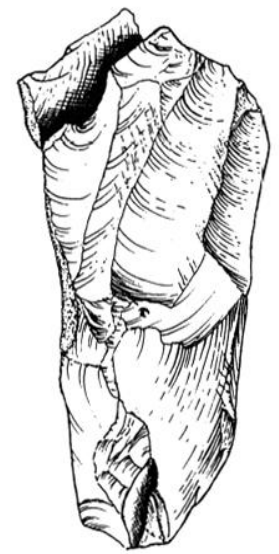

vue antérieure

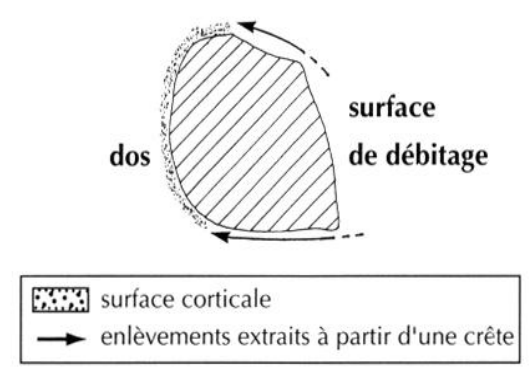

$\rightarrow$ enlèvements extraits à partir d'une crête

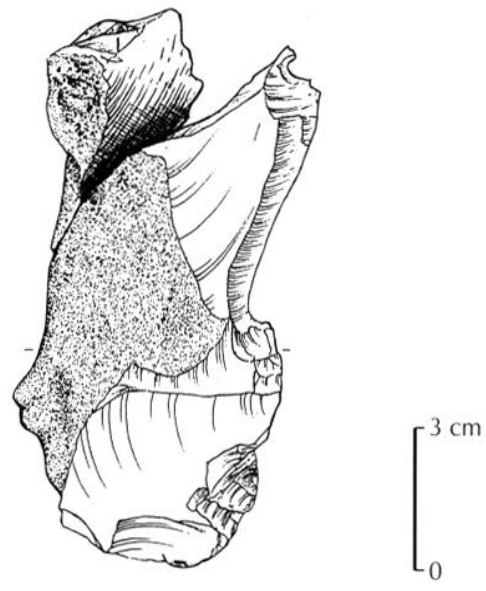

vue latérale gauche

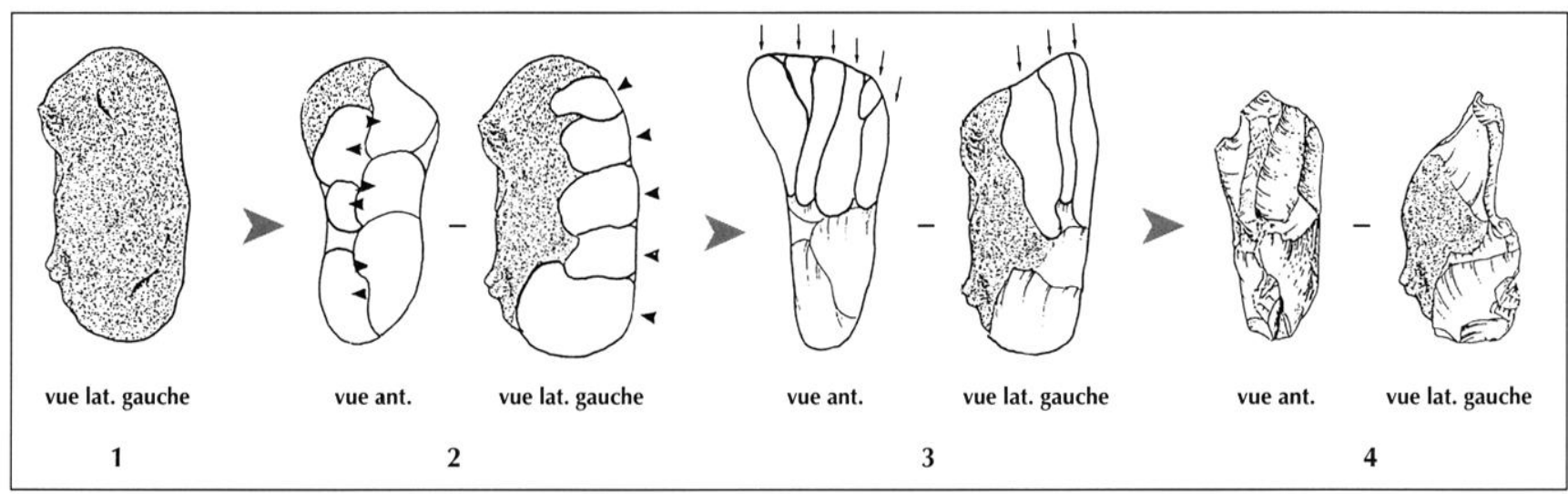

Fig. 18 - L'exploitation d'un bloc: 1 , sur le volume sélectionné $(115 \mathrm{~mm} \times>55 \mathrm{~mm} \times 41 \mathrm{~mm})$, la hauteur de la surface d'initialisation a été installée dans la plus grande dimension et sa largeur a été placée dans la plus petite; 2 , le bloc a été mis en forme à partir d'une crête antérieure à deux versants, le dos restant cortical; 3, des éclats allongés et des lames courtes ont été extraits à partir d'un seul plan de frappe, les derniers enlèvements sont profondément réfléchis ; 4, le nucléus a été abandonné à ce stade (dessins et schéma dynamique interprétatif 1 ). Molez).

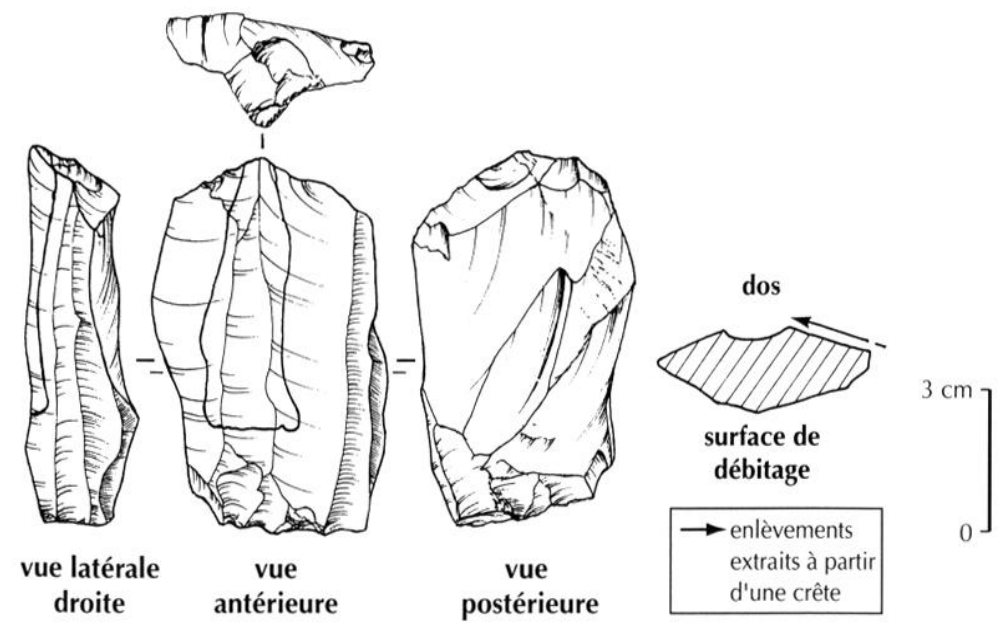

1

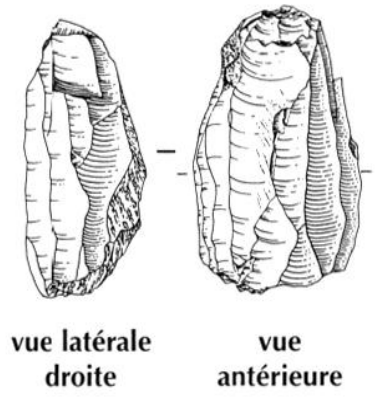

2

Fig. 19 - Deux nucléus abandonnés après la production de lames courtes et étroites. La dermière lame produite est remontée sur le $n^{\prime \prime} 1$. Sur le plan de frappe du $n^{\circ} 1$, on observe, sur le bord antérieur droit, un grattage unilatéral additionné au facettage (dessins $D$. Molez). 
blocs peu débité, le dos est resté brut car il était suffisamment régulier pour guider les enlèvements de plan de frappe (fig. 18). Sur l'autre bloc, le dos est resté naturel dans une première phase; il a été régularisé ensuite, à partir d'une crête antéro-latérale, lorsqu'il a été investi par le débitage.

Parmi les 20 blocs débités, on compte douze autres ensembles peu ou pas remontés, sur lesquels l'évolution du débitage masque totalement les négatifs qui pourraient révéler les modalités de mise en forme de la surface d'exploitation. Trois blocs seulement portent sur leurs flancs des traces de petits enlèvements transversaux à l'axe du débitage et provenant de la partie antérieure du nucléus. Comme ces enlèvements ont un petit module, il est impossible de déterminer à quel moment du débitage ils ont été détachés : ils peuvent avoir été extraits dès le début de la mise en forme ou lors d'une opération de réaménagement. En revanche, sur six de ces douze ensembles, on peut observer les modalités éventuelles de préparation de la partie dorsale car elle n'a pas été investie par le débitage. Le dos a été aménagé dans cinq cas sur six. Dans trois cas, cet aménagement, qui a laissé subsister d'importantes plages corticales, s'est limité au détachement, à partir d'une crête latérale, de quelques éclats destinés à faciliter les réfections de plan de frappe. Sur les 2 autres nucléus, la préparation, conduite à partir d'une crête postérieure, médiane ou latérale, a été béaucoup plus intense et elle n'a laissé subsister aucun résidu cortical (fig. 19, n⿳1 1). Sur ces 2 blocs, il est donc probable que la préparation du dos a participé à une mise en forme assez globale du volume.

L'examen des restes de taille isolés soutient cette reconstitution des modalités de mise en forme. L'assemblage contient en effet plusieurs éclats larges et épais partiellement recouverts de cortex, qui ont été détachés, pour la plupart, avec un percuteur de pierre dure au cours de séquences de préparation. Or, ces éclats portent fréquemment sur leur face supérieure des négatifs d'autres enlèvements, de direction perpendiculaire ou presque (fig. 20). Cette observation confirme que les mises en forme de la future table réalisées à partir d'une crête à deux versants en position médiane sont peu fréquentes. Ce mode de mise en forme aurait plutôt généré, en effet, des éclats portant des négatifs de direction parallèle. Parmi les restes de taille, il n'existe d'ailleurs que 2 lames (sur 193) qui portent la trace d'un aménagement de la table par crête médiane. Sur beaucoup de blocs, la mise en forme consistait donc plutôt en une combinaison d'éclats extraits à partir d'une ou plusieurs crêtes, souvent en position latérale, et d'enlè- vements détachés à partir du plan de frappe. On retrouve ces derniers parmi les éclats allongés et les lames épaisses, relativement irrégulières et partiellement corticales. Ces produits portent souvent des négatifs d'éclats transversaux de provenance latérale, ce qui constitue un indice supplémentaire à propos de cet usage des crêtes latérales pour la mise en forme (fig. 20).

Les modalités de mise en forme appliquées aux blocs révèlent donc une assez grande souplesse opératoire. Ainsi, dans la plupart des cas, mise en forme et initialisation du débitage se sont confondues. Sur les blocs dont les convexités naturelles étaient régulières, la mise en forme a été réalisée, directement après l'ouverture d'un plan de frappe, par des enlèvements extraits le long des surfaces naturelles. Quand les blocs étaient volumineux et irréguliers, cette mise en forme simplifiée a pu être complétée par des éclats détachés, conjointement ou postérieurement, à partir d'une ou deux crêtes plutôt en position latérale. Ces enlèvements transversaux, souvent larges et épais, extraits pour la plupart au percuteur de pierre dure, ont consommé beaucoup de matière première. Leur vocation essentielle était de régulariser la future surface d'exploitation et de lui assurer éventuellement un léger cintrage plutôt que d'en aménager la carène, laissée faible dès le départ. Le dos et les flancs n'ont pas toujours été traités immédiatement, mais ils ont pu être régularisés, par la suite, en cours de débitage. Sur toutes ces surfaces, la mise en forme a souvent laissé subsister des irrégularités que les tailleurs n'ont supprimées que progressivement. Ces irrégularités n'étaient pas toujours prévisibles mais, quand elles l'étaient, les tailleurs ont souvent choisi de tirer parti du potentiel immédiat plutôt que d'achever tout de suite la régularisation des volumes. On relèvera d'ailleurs que la mise en forme de certains volumes a pu être parfois précédée par une exploitation opportuniste, indépendante de la préparation.

\section{La mise en forme des fragments taillés ou naturels qui ont servi de nucléus}

Sans surprise, la mise en forme de ces trois petits volumes a été extrêmement simplifiée. Le premier nucléus, fait sur un éclat débité, est le seul dont le débitage a été productif (4 à 5 supports utiles). Un plan de frappe a été ouvert, à partir duquel des petites lames ont été extraites le long d'un bord de l'éclat aménagé par une crête partielle (fig. 9). Une seconde crête partielle a été aménagée sur l'autre bord de l'éclat, constituant le dos du nucléus. La raison technique de 
Sur les volumes parallélépipédiques, la mise en forme fut souvent réalisée par des lames d'entames relayées par des éclats transversaux
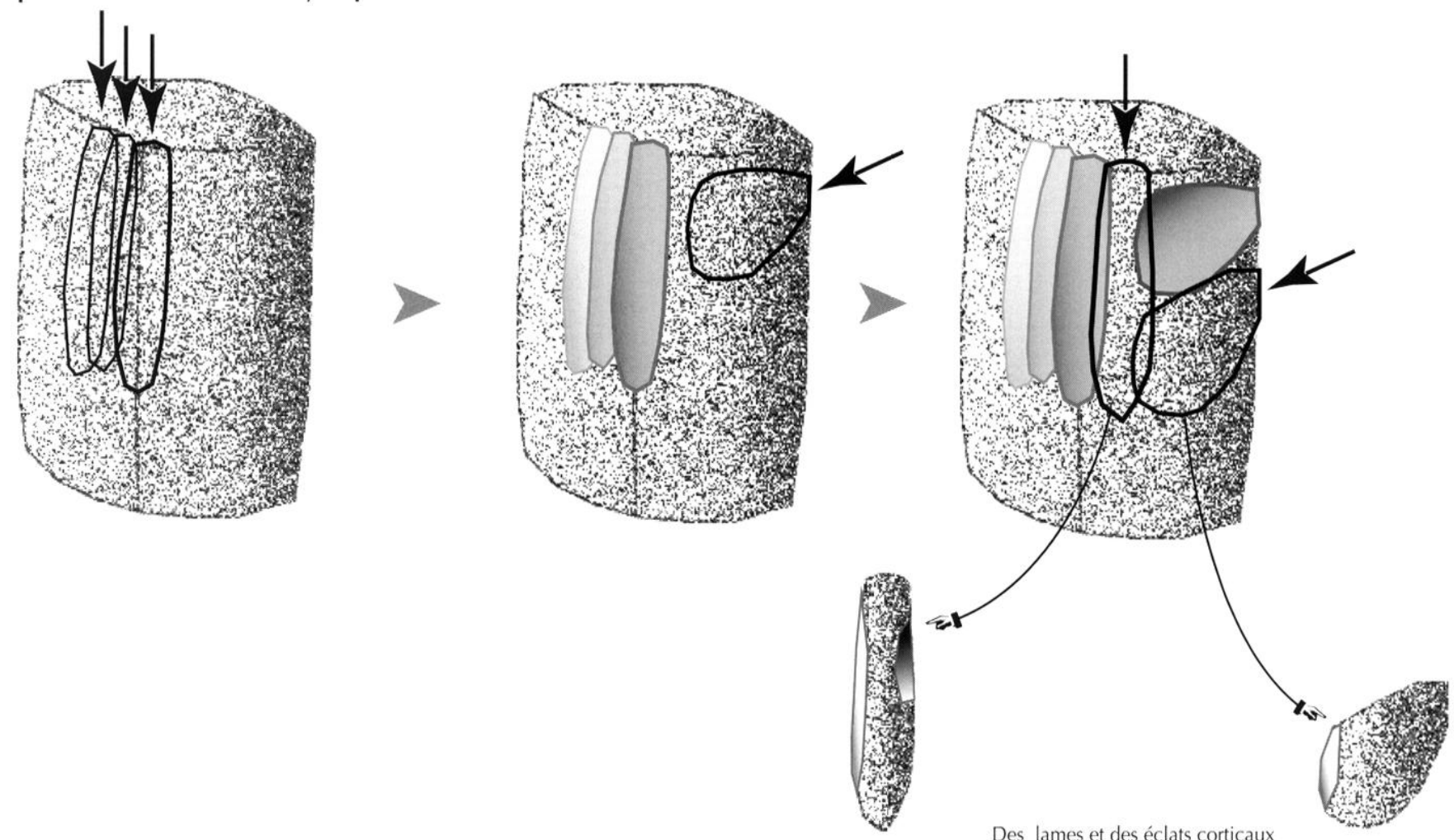

Des lames et des éclats corticaux

portant des négatifs transversaux, perpendiculaires ou presque, sont les témoins de cette modalité de mise en forme

Fig. 20 - Mise èn forme des volumes parallélépipédiques et produits caractéristiques résultants.

cet aménagement n'est pas explicite : cette crête postérieure n'a ni réellement participé à une régularisation du volume ni particulièrement facilité les ravivages éventuels de plan de frappe. À notre avis, cet aménagement avait surtout pour vocation d'adoucir une des arêtes aiguës et vulnérantes de l'éclat transformé en nucléus.

Le deuxième nucléus, non productif donc, résulte d'une tentative d'exploitation sur un " casson ", c'est-à-dire sur un éclat informe extrait d'un volume faillé par le gel. C'est le long d'un de ses bords qu'on a tenté d'extraire quelques lamelles, la préparation se réduisant à l'aménagement d'un plan de frappe au moyen d'un simple petit enlèvement.

Le troisième nucléus résulte de l'exploitation d'un éclat naturel détaché par le gel. Une surface naturelle a été choisie comme plan de frappe et seuls quelques petits enlèvements irréguliers en ont été extraits le long de la face supérieure corticale de l'éclat. Pour ces deux derniers débitages, le très faible potentiel productif des volumes sélectionnés, la simplification extrême de leur exploitation et leur absence totale de productivité conduisent à douter de la compétence de leurs auteurs.

\section{LA PRODUCTION DES LAMES ET DES ÉCLATS ALLONGÉS}

\section{LES PREMIĖRES SÉQUENCES DU DÉBITAGE}

Ces premières séquences ont généré de grands éclats allongés, souvent larges et épais, qui achevaient la régularisation de la surface de débitage. Ces produits ont des talons épais (plus de $5 \mathrm{~mm}$ ) et généralement peu préparés (lisses ou grossièrement facettés, et parfois non abrasés). Comme l'attestent quelques remontages ainsi que les négatifs observés sur certains de ces produits irréguliers non remontés, l'intersection de ces enlèvements larges a pu dégager les nervures favorables à l'extraction de quelques lames plus régulières et plus étroites, mais encore épaisses. On verra que les quelques lames entières de ce gabarit ont presque toutes été transformées en outils. 
Sur cette première génération de lames, les talons sont également épais (plus de $5 \mathrm{~mm}$ ). Leur morphologie souvent triangulaire est déterminée par la profondeur des contre-bulbes des enlèvements précédents. Ces talons ont été soigneusement aménagés par un facettage légèrement convexe, presque toujours accompagné par un micro-facettage secondaire (fig. 21). Ce facettage inframillimétrique résulte d'un " grattage " qui visait à renforcer le bord de plan de frappe en supprimant la corniche, tout en isolant et en reculant la future zone d'impact, pour régler l'épaisseur du produit. Ce grattage a presque toujours été conduit unilatéralement, mais sans latéralisation préférentielle, à partir d'un des bords externes du talon triangulaire (fig. 19, n'1). L'observation de lames raccordées appartenant à la même série indique clairement que ce procédé a été réalisé localement, avant le détachement de chaque produit, et non d'un seul coup sur une large portion du bord de plan de frappe. L'un des objectifs visés par ces dégagements unilatéraux pouvait être de décaler légèrement la zone d'impact par rapport à la nervure-guide de la future lame. Ce décentrement permettait alors de régler la largeur des lames; ce faisant, il contribuait à les déporter légèrement vers un des flancs pour ne pas trop diminuer le cintrage déjà faible de la surface d'exploitation (fig. 22).

Les lames et éclats allongès de ces premières séquences ont été détachés au percuteur de pierre, c'est ce qu'éroquent leur robustesse, leur profil rectiligne et leur relative irrégularité ainsi que la forte épaisseur et l'angle de chasse

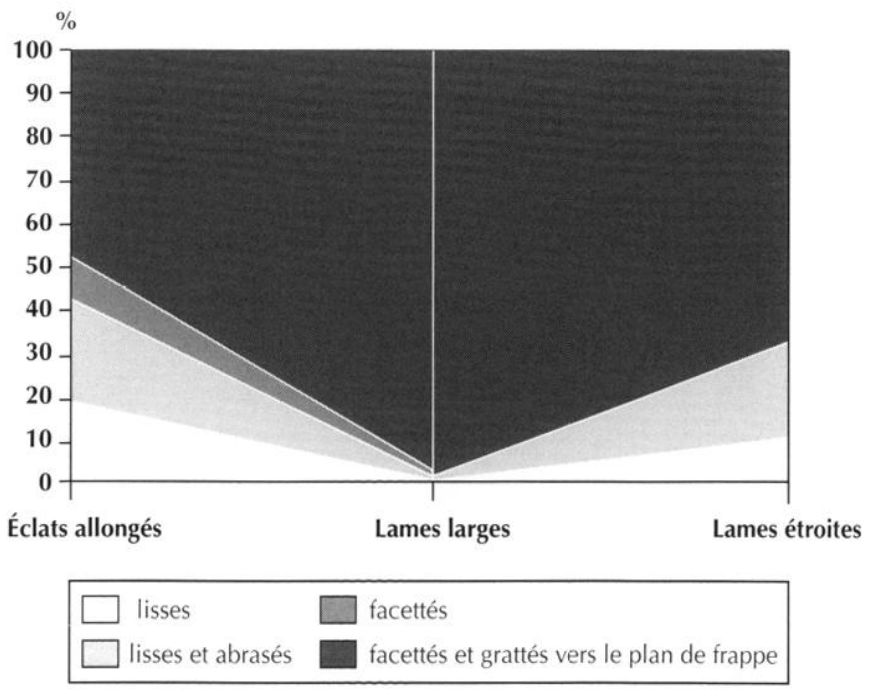

Fig. 21 - Aspert des talons sur les produits détachés le long des surfaces d'exploitation.

toujours très élevé de leurs talons (proche de 90 ). C'est d'ailleurs ce que confirme la présence de stigmates ciocateurs sur la moitié environ de ces produits.

Entre les enlèvements allongés de ces premic̀res séquences, quelques éclats courts, extraits à partir des crêtes

Une simple abrasion du bord de plan de frappe
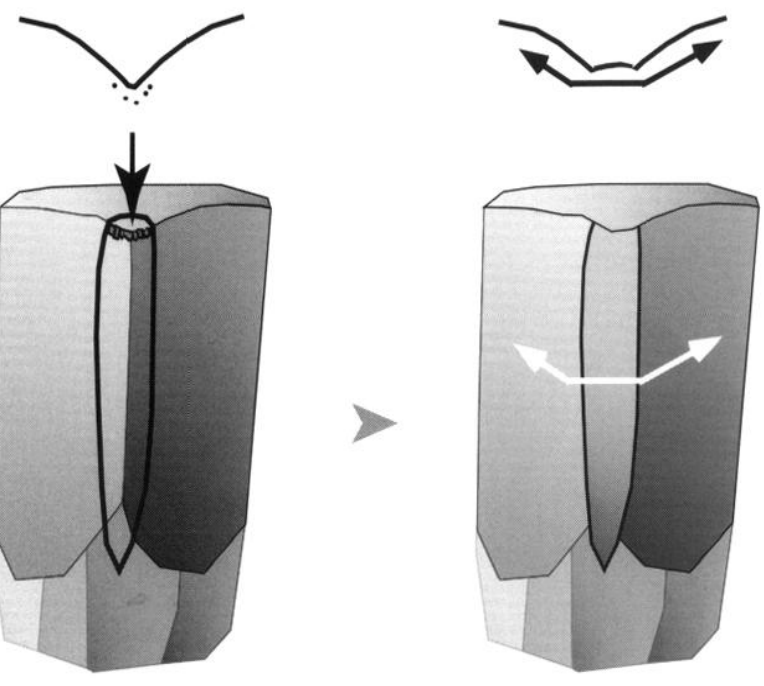

la lame est centrée sur la nervure-guide et le cintrage diminue après son extraction

Un grattage unilatéral permet de décaler la zone d'impact
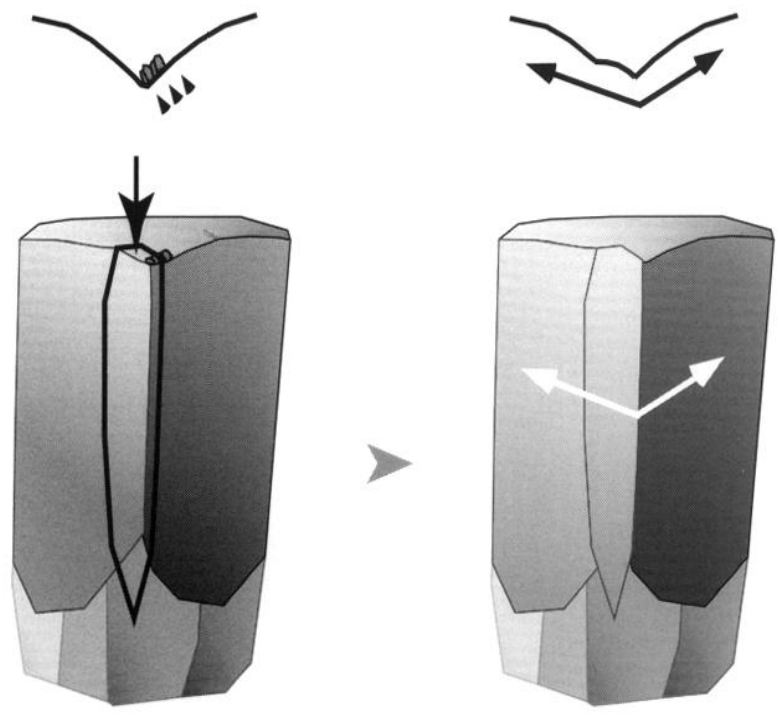

la lame est un peu décalée par rapport à la nervure-guide et le cintrage diminue peu après son extraction

Fig. 22 - Objectif possible des grattages unilatéraux on bord de plan de frappe. 
latérales, ont pu parfois encore s'intercaler pour parfaire la mise en forme du volume.

\section{LA PROGRESSION DU DÉBITAGE ET SON ENTRETIEN}

Au cours de la diminution des nucléus, le débitage, progressant de façon semi-tournante, investissait progressivement les flancs. Cette progression a été conduite en respectant un agencement qui faisait alterner des éclats allongés ou des lames épaisses entretenant le cintrage du volume et des lames plus régulières, guidées par les nervures dégagées par les enlèvements précédents. Parmi ces lames régulières détachées précocement, on trouve parfois des supports nettement étroits (largeur comprise entre 8 et $12 \mathrm{~mm}$ ) (fig. 8).

Tous ces produits ont probablement été débités avec un percuteur de pierre plutôt tendre, comme l'indique la présence de stigmates diagnostiques: points d'impact visibles mais partiellement détourés, fissurations du talon pouvant conduire à l'esquillement du bulbe, rides fines sur les premiers millimètres du bulbe (Pelegrin, 2000, p. 78-80). Les talons restent assez épais (2 $\mathrm{mm}$ en moyenne quand ils n'ont pas éclaté sous l'impact), ils sont faiblement inclinés et ne présentent généralement pas de lèvre : ces aspects, qui s'approchent parfois de ceux de la percussion à la pierre dure, laissent penser que le percuteur a été manié avec un geste rectiligne et plutôt rentrant, plutôt que curviligne et tangentiel (ibid., p. 77). C'est cet usage, grâce auquel le tailleur pouvait facilement faire varier la largeur et l'épaisseur des enlèvements, qui a permis de tirer parti de surfaces partiellement régularisées (ce qui explique le faible soin apporté parfois à la mise en forme). Ce maniement assez. rentrant permettait aussi d'entretenir facilement le cintrage de la surface de débitage et de réajuster aisément l'espacement entre les nervures-guides. Mais l'emploi de ce mode de percussion accroît très vite la rectitude longitudinale de la table, ce qui a entraîné une multiplication des réfléchissements parfois dommageables à la poursuite du débitage. Ainsi, un tiers environ des lames brutes dont la partie distale est conservée présentent un assez fort réfléchissement. C'est aussi le cas pour la moitié des éclats allongés.

Les tailleurs ont eu recours à plusieurs procédés pour prévenir ou pour supprimer ces réfléchissements, qui pouvaient endommager la surface de débitage.

- L'usage des crêtes d'entretien (autrement dit, de " néocrêtes ") était très courant à tous les stades du débitage et permettait également de débarrasser les blocs des irrégularités pouvant subsister sur leurs flancs (fig. 14). L'application de cette modalité peut être observée sur $29 \%$ des lames larges des premières séquences, sur $19 \%$ des lames étroites et sur $24 \%$ des éclats allongés. Il s'agit le plus souvent d'aménagements partiels, mais les enlèvements transversaux peuvent parfois être envahissants et laisser des négatifs relativement profonds. Voilà un aspect qui distingue ces néo-crêtes de leurs équivalents magdaléniens, généralement aménagés avec beaucoup de soin pour diminuer le moins possible le potentiel restant à débiter.

- Comme autre procédé d'entretien, les tailleurs du Cornet ont également eu recours à des enlèvements robustes, détachés à partir d'un plan de frappe. Ces éclats allongés très épais peuvent couvrir toute la longueur de la table - voire toute sa largeur - en outrepassant légèrement. Ils portent des talons larges et épais, souvent peu ou pas préparés (fig. 21). Le recours à cette modalité a bien sûr toujours entraîné une diminution importante du volume résiduel à débiter.

- L'emploi d'un second plan de frappe - sans doute ouvert précocement en prévision de cet usage - est aussi une modalité d'entretien très courante, attestée sur seize des dixhuit ensembles réellement productifs. Ce plan de frappe a servi couramment à extraire des petits produits à la base de la table pour lui conférer une très légère carène. Parfois, des enlèvements volumineux ont pu également être extraits à partir de ce plan de frappe pour supprimer les réfléchissements qui endommageaient la surface de débitage (fig. 12). Ce procédé a souvent inauguré un renversement du sens de débitage. De secondaire, le second plan de frappe est alors devenu préférentiel pour la séquence

\begin{tabular}{|l|c|c|c|c|}
\hline & $\begin{array}{c}\text { 1 ou 2 négatifs à } \\
\text { I'extrémité distale }\end{array}$ & $\begin{array}{c}\text { 1 ou 2 négatifs envahissant } \\
\text { les 2/3 de la face supérieure }\end{array}$ & $\begin{array}{c}\text { 1 ou 2 négatifs envahissant } \\
\text { le 1/3 de la face supérieure }\end{array}$ & $\begin{array}{c}\text { Pas de } \\
\text { négatifs opposés }\end{array}$ \\
\hline Lames larges $(\mathrm{I}>16 \mathrm{~mm})$ & $4 \%$ & $8 \%$ & $24 \%$ & $64 \%$ \\
\hline Lames étroites $(\mathrm{I} \leq 16 \mathrm{~mm})$ & $3 \%$ & $11 \%$ & $12 \%$ & $74 \%$ \\
\hline Éclats allongés & $14 \%$ & $20 \%$ & $49 \%$ & $17 \%$ \\
\hline
\end{tabular}

Tabl. III - Négatifs opposés visibles sur différentes catégories de produits. 
productive qui suivait. Ces changements d'orientation - qui n'étaient pas systématiques puisqu'il existe deux exploitations unipolaires (fig. 9 et 18) - ont une fréquence inconstante : de un à trois changements qui interviennent parfois dès les premières séquences et font se succéder des séries de 2 à 5 produits (fig. $6,8,11,12,14$ et 17). Il ne s'est donc jamais agi d'un véritable débitage alternatif, mais d'un débitage successif au cours duquel les plans de frappe, considérés comme préférentiels à tour de rôle, ont pu échanger leur vocation. Cet échange des rôles est confirmé par la relative fréquence des négatifs opposés sur la face supérieure des lames larges et des éclats allongés non raccordés (tabl. III).

En cours de débitage, les plans de frappe ont été entretenus, si nécessaire. Le facettage et le grattage déjà évoqués contribuaient à des aménagements localisés. Occasionnellement, les tailleurs ont aussi détaché des éclats de ravivage ou de véritables tablettes (entre 5 et $10 \mathrm{~mm}$ d'épaisseur en moyenne), à partir de la table ou des flancs. Ces ravivages n'ont pas été très fréquents : la série ne contient qu'une quarantaine de tablettes, une quantité qu'il faut rapporter à un total de 34 plans de frappe actifs observés sur 16 ensembles productifs à deux plans de frappe et sur 2 ensembles portant un unique plan de frappe. Cette basse fréquence - comparée par exemple aux assemblages magdaléniens - ne surprend pas, car l'usage du percuteur de pierre au cours du débitage autorise des interventions sur des angles ouverts (proches de $90^{\circ}$ ) et retarde l'urgence des ravivages. De ce fait, même si les flancs ont été souvent progressivement investis par le débitage, l'inclinaison globale du plan de frappe ne devait pas être réajustée aussi souvent que pendant un débitage mené sur des angles fermés (fig. 23). En fait, les ravivages observés nous paraissent surtout motivés par le désir de nettoyer occasionnellement des surfaces endommagées par les réfléchissements occasionnés par les facettages successifs. Cet entretien est resté assez soigneux jusqu'à la fin de l'exploitation (rares sont les nucléus dont le plan de frappe est abîmé à ce stade) et il a souvent été facilité par des régularisations limitées du dos en cours de débitage.

\section{LES DERNIÈRES SÉQUENCES DU DÉBITAGE ET SON INTERRUPTION}

Parmi les 18 nucléus productifs, quatorze ont encore fourni de vraies lames, juste avant leur abandon. Sur quatre d'entre eux, ces dernières lames ont une largeur comprise

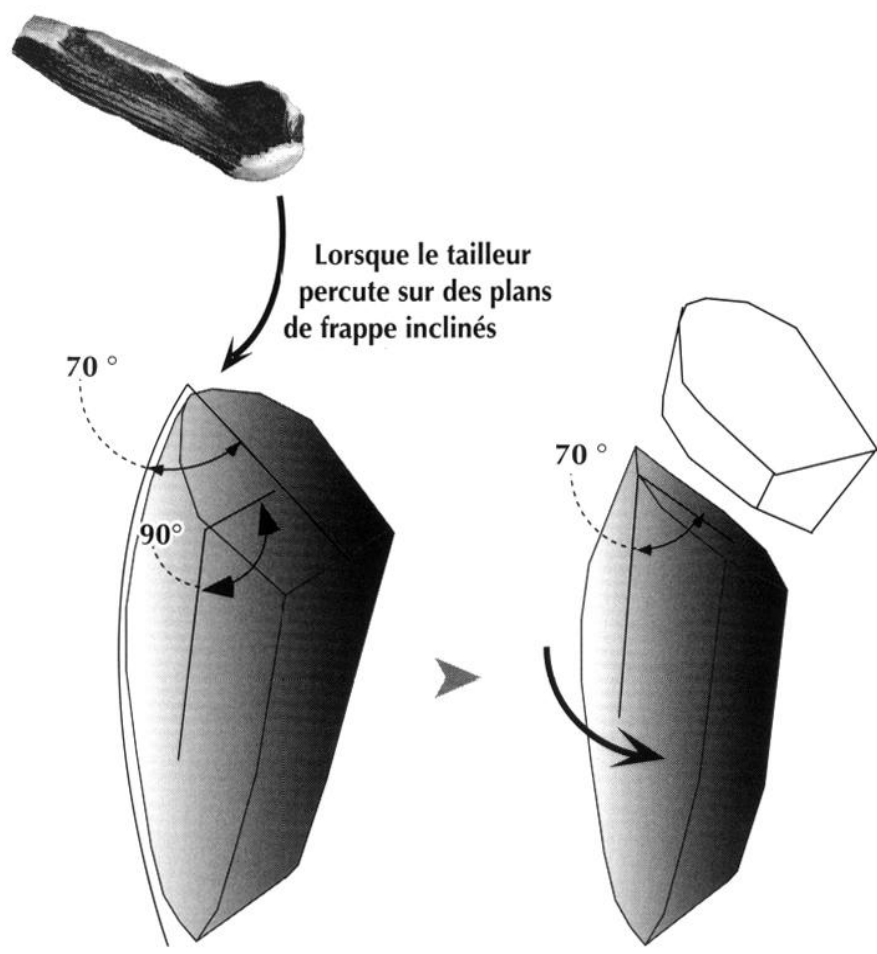

une progression semi-tournante exige des ravivages importants

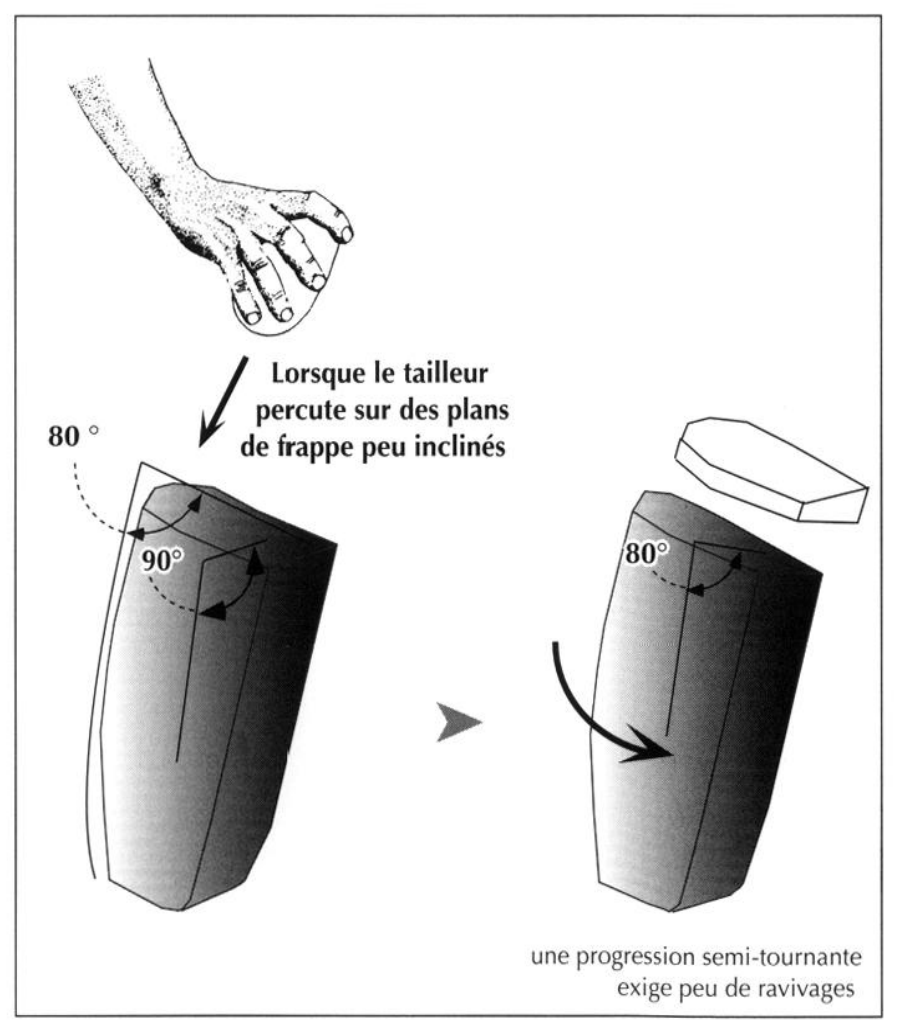

Fig. 23 - Des ravivages peu fréquents, malgré la progression semitoumante du débitage : une commodité due à l'usage du percuteur de pierre (photo et dessin de percuteurs d'après Inizan et al., 1995). 


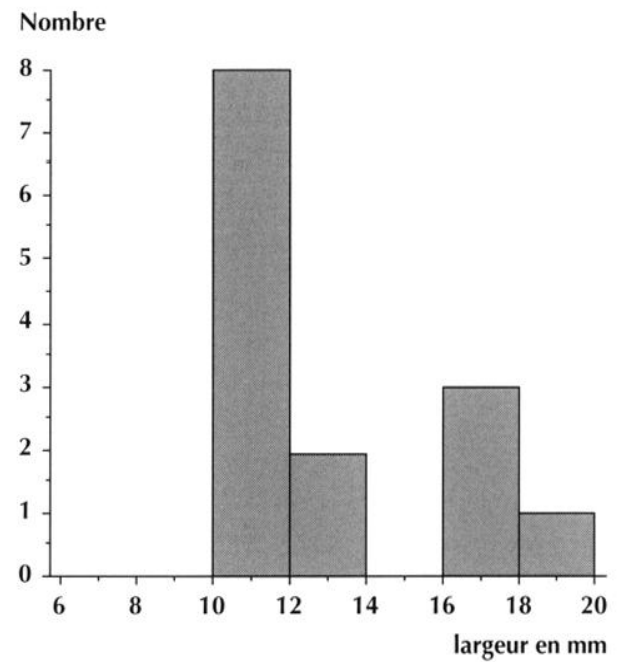

Fig. 24 - Largeur des derniers négatifs laminaires observés sur 14 nucléus.

entre 16 et $20 \mathrm{~mm}$ (fig. 24). Sur ces blocs, l'interruption du débitage fut assez précoce et elle semble toujours avoir été motivée par de graves accidents intervenus sur la surface d'exploitation (fissuration dans un cas et réfléchissements dans les trois autres). Sur 10 autres nucléus, le module des derniers enlèvements correspond à des petites lames dont la largeur est comprise entre 10 et $14 \mathrm{~mm}$ et la longueur entre 40 et $60 \mathrm{~mm}$ : voilà où se situaient les véritables seuils économiques d'interruption.

Parfois déjà produites en situation intercalée dès les premières séquences, comme nous l'avons vu, ces lames courtes et étroites semblent surtout avoir été obtenues en fin de débitage sur les nucléus diminués. Rappelons que dans un seul cas, elles l'ont été sur un éclat débité, exploité à cet unique effet (fig. 9). La plupart des talons de ces petites lames ont été soigneusement aménagés par un facettage plat qui s'accompagne presque toujours d'un grattage unilatéral (fig. 21). Même en fin de débitage, ces produits s'intercalent toujours entre des enlèvements plus larges destinés à entretenir le cintrage du volume et à dégager des nervures régulières. À ce stade, l'alternance dans l'usage des plans de frappe est encore assez fréquente (tabl. III).

Sur la plupart des nucléus productifs, le débitage n’a que partiellement envahi les flancs (14 cas). Dans trois cas, le débitage a également investi le dos, mais partiellement (fig. 19, n"2) ; sur un autre, il l'a totalement envahi pour profiter des dernières convexités (fig. 8). Les exploitations envahissantes sont donc assez exceptionnelles et semblent plutôt tirer profit d'opportunités occasionnelles, contrai- rement à ce que l'on observe par exemple dans les industries «belloisiennes ». Ces progressions envahissantes ont été facilitées par l'usage de la pierre tendre qui permet de régulariser facilement des surfaces qui ne l'ont pas été en début de débitage, et qui autorise en outre, comme on l'a signalé, des débordements latéraux sans ravivages fréquents des plans de frappe.

En fin d'exploitation, les dernières tables de 4 nucléus (sur les 18 productifs) ne présentent plus que des négatifs d'éclats, souvent réfléchis et parfois courts (fig. 8, 9 et 17). Comme nous l'avons annoncé d'emblée, nous ne pensons pas que ces négatifs puissent correspondre à un objectif final et spécifique du débitage. Au Cornet, en effet, le détachement de ces derniers éclats est conduit dans le sens de la table principale et, surtout, il s'inscrit dans la logique du débitage précédent. Il faut donc plutôt y voir des échecs liés à un aplatissement excessif de la surface de débitage, entrầnant le réfléchissement ou l'étalement des produits.

\section{LA VOCATION ÉCONOMIQUE DES DÉBITAGES}

\section{Tentative d'estimation de LA PRODUCTIVITÉ}

À propos de la productivité brute, on peut proposer une simple moyenne, en rapportant le nombre minimal" de lames et d'éclats allongés, raccordés ou non, au nombre de volumes susceptibles d'en avoir fourni. La série contient un nombre minimal de 122 lames et de 202 éclats allongés pour 18 volumes productifs. La moyenne s'établit donc autour de 7 lames et 11 éclats allongés par volume.

L'analyse des ensembles remontés permet d'atteindre une estimation plus nuancée de la seule productivité laminaire. Parmi les 18 ensembles remontés et productifs, 12 seulement se prêtent à une estimation de cette productivité. Sur 3 ensembles, cette productivité atteint une quinzaine de lames par blocs ; 3 autres ensembles ont foumi chacun entre 4 et 7 lames et les 6 derniers ensembles ont fourni de 1 à 3 lames ${ }^{3}$.

Il ressort de ces observations encore imprécises que la productivité en supports allongés varie assez fortement d'un

2. Cette estimation a ćté calculée en prenant en compte, pour les outils et les lames brutes, le nombre d'exemplaires entiers additionné au nombre de fragments proximaux.

3. Cette évaluation est approximative et sans doute un peu sous-estiméc. car elle se fonde sur des ensembles toujours incomplets. Au nombre de lames remontées, on a donc ajouté le nombre de lames absentes, evaluć a minima en fonction du volume que le remontage permet de reconstituer virtuellement. 
ensemble à l'autre. Cette variabilité est fonction bien évidemment du stade d'interruption des exploitations, mais elle dépend également beaucoup de l'intensité des régularisations qui ont été nécessaires en cours de débitage. Notons que la faible productivité laminaire est compensée par un taux de cassure assez limité (sur 122 lames au minimum, 61 sont entières). Elle est surtout rééquilibrée par une productivité utilitaire élevée puisque les éclats sont assez souvent transformés en outils retouchés.

Sur cette productivité utilitaire, les remontages n'apportent que des informations anecdotiques: un seul ensemble à productivité laminaire brute probablement élevée contient des supports retouchés, un " couteau à dos " et une monopointe (fig. 8). À titre indicatif, on rappellera qu'aux 18 ensembles productifs correspondent, au minimum, 52 lames, 7 éclats allongés et 10 éclats courts transformés en outils et armatures retouchés.

\section{LA TRANSFORMATION DES SUPPORTS EN OUTILS : CARACTÈRES GÉNÉRAUX DES SUPPORTS SÉLECTIONNÉS}

Toutes les données chiffrées qui suivent sont exclusivement fondées sur l'étude des 69 outils retrouvés dans le locus 33. Précisons que les tendances qui ont été perçues se trouvent largement confirmées par l'analyse complémentaire d'un lot d'une soixantaine d'outils analogues, trouvés en surface à proximité du sondage principal (Valentin, 1995 , p. 487-521).

On notera pour commencer que, dans le locus 33, la proportion de supports retouchés ou portant des traces macroscopiques d'usage est élevée (près de $9 \%$ ). Signalons qu'en contexte magdalénien, ce taux dépasse très rarement $5 \%$ sur les sites de plein air du Bassin parisien (ibid., p. 682).

Les différentes catégories de produits du locus 33 n'ont pas été transformées dans les mêmes proportions. Parmi les lames (pièces entières et fragments), 21,5\% ont été retouchées. Ce n'est le cas que pour $4,5 \%$ des éclats courts et $2,5 \%$ des éclats allongés.

\section{Quelles lames?}

Toutes les lames transformées en outils, sauf une (fig. 4, $\mathrm{n}^{\prime \prime} 8$ ), ont été produites pendant des séquences autres que l'initialisation.

Les lames larges qui ont été extraites pendant les premières séquences ont été asse $z$ intensément transformées. De ce fait, parmi les lames de ce gabarit non retouchées, il subsiste surtout des petits fragments. Les rares supports entiers et restés bruts sont des lames, qui se signalent soit par une asse\% grande irrégularité de leurs bords ou de leur section, soit par leur faible épaisseur. On peut en conclure que les critères qui ont orienté la sélection des lames les plus larges sont donc tout autant qualitatifs (régularité des tranchants et des sections) que dimensionnels (longueur d'au moins $60 \mathrm{~mm}$ et épaisseur d'au moins $8 \mathrm{~mm}$ ).

Pour leur part, les lames étroites retouchées sont exclusivement dérivées des séquences de plein débitage et elles ont été essentiellement dévolues à la fabrication des armatures. Au moment de la sélection de ces supports, ce sont d'abord des critères qualitatifs qui semblent avoir orienté les choix : régularité d'au moins un bord, équilibre des sections et rectitude du profil. À propos de ce dernier critère qualitatif, il faut préciser qu'il n'y a pas de supports vraiment arqués parmi les restes de taille restés bruts, ce qui est logique étant donné la technique de détachement. Mais quelques-uns sont tors et ils ont manifestement été rejetés au moment du choix des supports destinés à être transformés. Quant aux critères dimensionnels qui ont orienté le choix des lames étroites, ils concernent au premier titre la longueur : elle ne devait pas être inférieure de beaucoup à $50 \mathrm{~mm}$, si l'on en juge d'après la diminution consécutive à la retouche.

\section{Quels éclats?}

Presque tous les éclats allongés transformés en outils ont été produits pendant l'exploitation des surfaces de débitage. Les critères de sélection de ces éclats allongés paraissent nettement moins stricts que pour les lames. Pour ces supports, une relative régularité des tranchants semble constituer le principal critère de choix. ('est d'ailleurs sans doute pour cette raison que les éclats sélectionnés sont plutôt des éléments détachés en cours de plein débitage. A contrario, les produits plus irréguliers des premières séquences ainsi que ceux qui participaient à une remise en forme partielle des volumes en cours de débitage ont donc souvent été négligés.

Les éclats non allongés sont surtout issus des séquences de mise en forme. Un seul éclat vraiment volumineux (115 mm $\times 98 \mathrm{~mm} \times 22 \mathrm{~mm}$ ) a été choisi pour y aménager un bord légèrement denticulé. Les autres éclats retouchés en grattoirs sont nettement plus petits. Leur plus grande dimension est comprise entre 20 et $50 \mathrm{~mm}$ et leur épaisseur dépasse rarement $15 \mathrm{~mm}$. Dans l'ensemble, les éclats non allongés les plus irréguliers semblent avoir été rejetés et c'est probablement pour cette raison qu'une minorité 
parmi les produits transformés présente une face supérieure en partie naturelle.

\section{LA TRANSFORMATION DES SUPPORTS EN OUTILS : QUELS SUPPORTS POUR QUELLES MODALITÉS DE TRANSFORMATION ?}

Quels supports pour les armatures?

Les monopointes ont donc été aménagées sur des lames courtes et plutôt étroites. Les lames choisies sont généralement régulières, au regard de la production globale. Leurs épaisseurs sont comprises entre 3 et $6 \mathrm{~mm}$, tandis que leurs largeurs originelles (restituées d'après l'ampleur de l'abattage) varient entre 10 et $20 \mathrm{~mm}$, c'est-à-dire asse $z$ fortement. C'est donc surtout l'intensité variable de l'abattage qui assurait aux largeurs résiduelles une certaine constance. Les quelques lamelles à bord abattu épais ont été fabriquées sur les mêmes supports que les monopointes, tandis que les microlithes à bord fin ont été aménagés sur des supports très étroits $(5$ à $10 \mathrm{~mm}$ ) et très fins (2 à $3 \mathrm{~mm}$ ), qui ne semblent pas, nous l'avons dit, constituer un véritable objectif du débitage.

\section{Quels supports pour les « couteaux à dos " ?}

Les autres éléments à bord abattu épais, qui ne sont pas assimilables par leurs dimensions aux monopointes, ont été aménagés sur des supports souvent issus des premières séquences de débitage : leurs longueurs sont variables (50) à $100 \mathrm{~mm}$ ) et ils sont toujours larges (18 à $29 \mathrm{~mm}$ ) et épais (7 à $12 \mathrm{~mm}$ ). La plupart sont des lames qui présentent un bord tranchant rectiligne.

Par leurs dimensions, les lames à retouche marginale s'inscrivent dans les marges de variation décrites pour ces " couteaux à dos ", mais elles sont généralement plus régulières et c'est probablement en raison de cette régularité originelle qu'elles ont été plus marginalement retouchées.

\section{Quels supports pour les grattoirs?}

Les grattoirs ont plus souvent été aménagés sur des éclats (5 cas) que sur des lames (4 cas). Les grattoirs sur éclats sont tous nettement courts (20 à $40 \mathrm{~mm}$ dans leur plus grande dimension). Trois pièces sur lames cassées sont assimilables à cette catégorie d'outils conçus comme courts. La première, qui a été aménagée sur un fragment de lame outrepassée, ne fait pas de doute car le front est opposé à la terminaison distale. Sur les deux autres grattoirs sur lame, le front est opposé à une cassure, si bien qu'on pourrait également considérer ces pièces comme des outils fracturés.
On notera toutefois que leur module résiduel coïncide parfaitement avec celui des grattoirs dont le caractère court est certain. Parmi les 4 exemplaires sur lames, un seul grattoir particulièrement long et étroit $(69 \mathrm{~mm}$ sur $24 \mathrm{~mm}$ ) s'individualise donc véritablement.

\section{Quels supports pour les burins et les pièces tronquées ?}

Les burins ont été aménagés sur des lames (4 cas) ou sur des éclats allongés ( 2 cas). Tous ces supports sont assez larges (23 à $32 \mathrm{~mm}$ ) et épais ( 8 à $12 \mathrm{~mm}$ ). Les lames, d'assez. bonne régularité, proviennent plutôt des premières séquences du débitage.

Les produits qui ont été choisis pour fabriquer les quatre pièces tronquées sont toujours allongés, mais leur robustesse et leur régularité sont variables : on trouve une lame à crête et un éclat allongé épais ainsi que deux lames nettement plus fines.

\section{BILAN ÉCONOMIQUE}

Au Cornet, les lames les plus régulières extraites pendant les premières phases du débitage ont donc été intensément transformées. Elles ont surtout servi à fabriquer des " couteaux à dos " et plusieurs burins. Des lames plus étroites, obtenues lors de la diminution des volumes, ont également été transformées en " couteaux à dos ", en burins, en pièces tronquées et exceptionnellement en grattoir. Les lames les plus courtes, les plus étroites et les plus régulières, débitées soit en cours de débitage et en position intercalée, soit à la fin, ont exclusivement servi de supports à des armatures légères. Par ailleurs, plusieurs éclats ont été transformés. Les éclats les plus courts ont été utilisés pour fabriquer plusieurs grattoirs, tandis que les éclats allongés ont servi de supports à quelques burins et " couteaux à dos".

Enfin, quelques déchets de débitage portent des traces évidentes de réutilisation : fragments de lames transformés en grattoirs courts ou nucléus utilisés a posteriori (fig. 6).

\section{BILAN ET DISCUSSION}

\section{L'INDUSTRIE DU CORNET (LOCUS 33) : UN ASSEMBLAGE NETTEMENT AZILIANISÉ}

En somme, les techniques pratiquées dans le locus 33 sont simples et caractérisées par une grande souplesse conceptuelle et opératoire, perceptible dès le moment de 
l'approvisionnement. Cette grande "liberté ", qui a pu mettre ces débitages à la portée de presque tous les savoirfaire, nous paraît étroitement liée à l'usage qui a été fait du percuteur de pierre tendre. Tel qu'il a été manié, selon un geste rectiligne et plus ou moins rentrant, permettant donc de faire varier la largeur et l'épaisseur des enlèvements, son usage autorise en effet une certaine improvisation. Ainsi, la collecte des volumes à débiter s'est faite sans sélection vraiment attentive, sans écarter par exemple ces volumes déformés par des géodes. Ensuite, la mise en forme de ces volumes a été réduite, si possible, au minimum, se confondant alors avec l'initialisation, ou bien elle a été conçue comme une opération très progressive et, par conséquent, partiellement intégrée à l'exploitation. Cette exploitation s'accompagne aussi d'opérations constantes d'entretien, qui peuvent occasionnellement s'apparenter à de véritables « remises " en forme. Dans un tel contexte, la notion même d'“ entretien " est d'ailleurs d'un usage presque problématique puisque les débitages semblent avoir été menés selon une logique plutôt tactique, c'est-à-dire sans beaucoup d'anticipation. Cette improvisation est quand même tempérée par le soin relatif accordé à la préparation des zones d'impact, qui témoigne au moins d'un réglage assez attentif de l'épaisseur des produits.

Toute cette souplesse a une rançon : la fabrication de lames asse $\%$ nomalisées fait encore partie des objectifs, mais la productivité des débitages en supports de ce type est inconstante et plutôt faible, comparée à la quantité des autres produits (éclats divers et lames irrégulières). Cette assez faible rentabilité qualitative a pour corollaire une véritable "économie du débitage ", qui structure les choix appliqués aux supports destinés à être transformés en outils. Les concepts qui guident ces choix demeurent assez rigides pour les armatures et les " couteaux à dos ". Mais, ces concepts sont nettement moins exigeants pour les grattoirs, aménagés sur des éclats de mise en forme et sur des fragments de lames, c'est-à-dire sur des produits que les Magdaléniens auraient considérés comme de banals déchets.

Cette requalification des déchets de taille attestée au Cornet n'est qu'une des ruptures profondes, mais non des moindres, avec la tradition magdalénienne, dont l'unité, telle qu'elle s'exprime dans le Bassin parisien, est aujourd'hui très bien définie. Citons à ce propos ce que nous pouvions en dire dans une synthèse récente (Valentin, Pigeot, 2000, p. 132-133) : "Sur tous les gisements magdaléniens, la taille du silex satisfait deux objectifs principaux et le plus souvent disjoints dans leur réalisation : la production de supports étroits et fins pour les armatures et la confection de lames plus longues et plus larges pour les outils de transformation (grattoirs, burins, becs...). La production des lames s'accompagne d'exigences qui restent très stables d'un gisement à l'autre (recherche de longueur, de normalisation et de productivité) et qui justifient partout la réalisation d'un certain nombre de débitages élaborés [...]. Si nécessaire, lorsque les volumes naturels sont irréguliers, ces débitages peuvent inclure une phase de mise en forme complexe destinée à conférer aux préformes une configuration optimale. Cette phase, alors clairement séparée des séquences de plein débitage et garantissant une prédétermination à long terme, assure au débitage réalisé au percuteur tendre les conditions d'un déroulement optimal. L'exigence de longueur et de normalisation est garantie en outre par le respect d'un certain nombre de principes : usage d'un plan de frappe préférentiel voire unique ; maintien d'une angulation fermée entre le plan de frappe et la surface de débitage; préparation soigneuse des zones d'impact (confection d'éperons par exemple) ; entretien des convexités latérales par la progression régulière du débitage. Le coût de ces options fut assez élevé: elles exigent une sélection attentive des matières premières locales et supposent une somme de connaissances et un degré de savoir-faire élevés qui n'ont pu être réunis qu'au prix d'un apprentissage progressif et d'une pratique régulière ".

Le Cornet affiche également un net contraste avec les occupations du Bassin parisien antérieures à l'Allerød, où se manifestent diversement les premiers signes de l'azilianisation (fig. 25). Sur les trois gisements actuellement connus, les panoplies d'armatures changent plus ou moins par rapport à celles du Magdalénien. À la grotte du Cheval à Gouy et sur le niveau inférieur du Closeau, datés entre $12360 \pm 60$ et $12050 \pm 130 \mathrm{BP}$, la distinction est nette car les lamelles à dos sont absentes et le seul modèle attesté consiste en bipointes symétriques et élancées, inconnues au Cornet (Valentin 1995 ; Bodu, Valentin, 1997 ; Bodu, 1998 ; 2000a). Sur le niveau inférieur d'Hangest III.1, daté entre $11660 \pm 110$ et $11630 \pm 90 \mathrm{BP}$, mais antérieur à la pédogenèse Allerød, l'assemblage associe diverses pointes axiales et lamelles à dos et reste donc assez similaire à celui que l'on trouve sur plusieurs gisements magdaléniens (Fagnart, 1993 ; 1997 ; Fagnart, Coudret, 2000). Sur ces trois gisements, tout se passe comme si les principales exigences qui guidaient les débitages laminaires magdaléniens avaient été conservées, malgré une transformation notable concernant le mode de détachement, l'usage dorénavant fréquent 


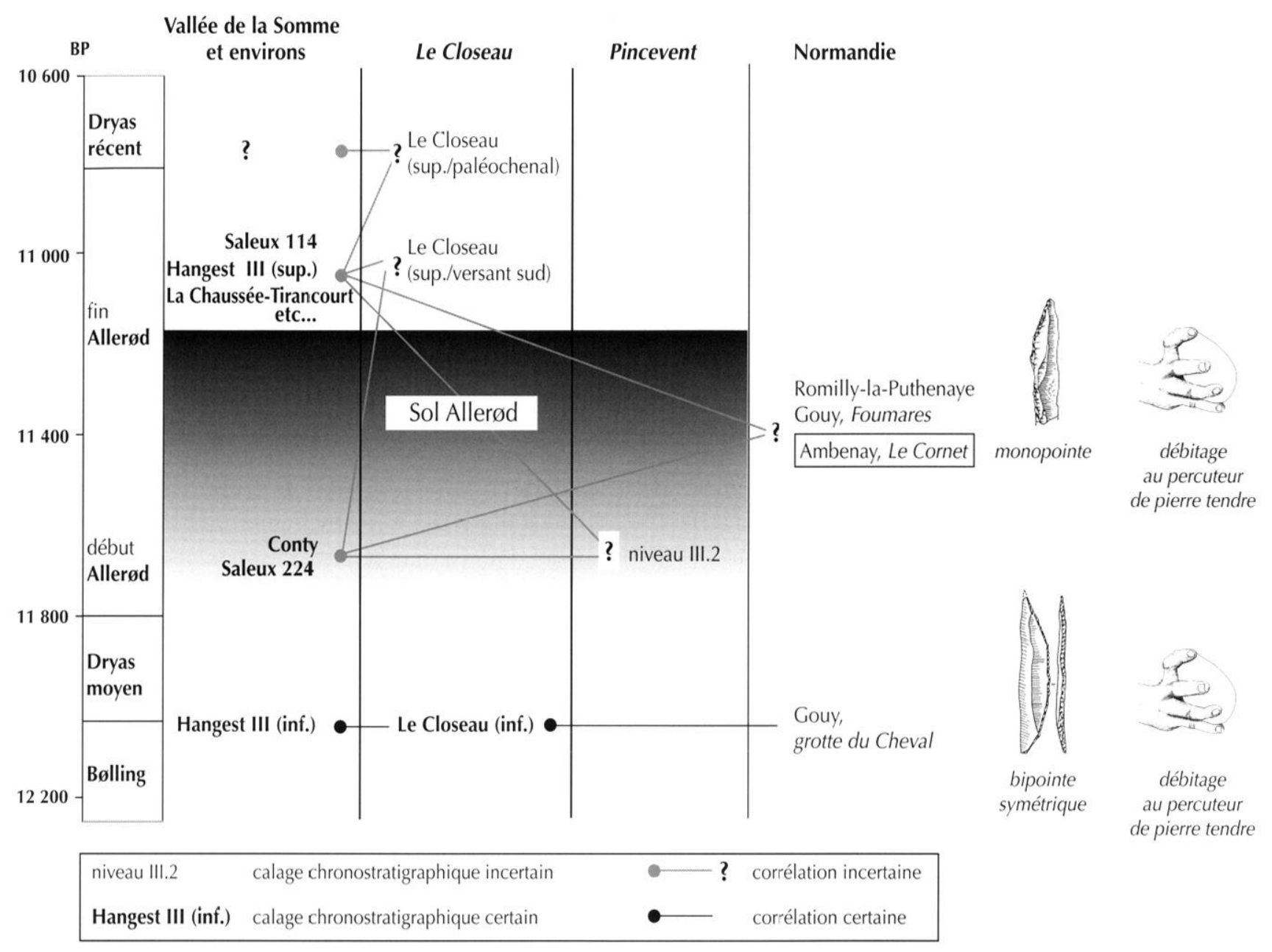

Fig. 25 - L'azilianisalion dans le Bassin parisien el ses alentours : difficulté des comrélations (dessin de percuteur d'après Inizan et al., 1995).

du percuteur de pierre tendre. Cet usage est exclusif à la grotte du Cheval et au Closeau; des observations récentes suggèrent qu'il est peut-être encore combiné avec celui du percuteur tendre organique à Hangest (Fagnart, Coudret, op. cit., p. 119), ce qui rapprocherait alors cet assemblage de certaines industries magdaléniennes du faciès "Cepoy/ Marsangy" (Valentin, 1995, p. 441-445; 1999). Enfin, il faut préciser que, dans ces 3 gisements, la pierre tendre est maniée selon une version tangentielle, très peu utilisée au Cornet, où domine, comme on l'a vu, une autre version plus rentrante et donc beaucoup moins contraignante car elle n'exige pas le même degré de soin lors de la préparation des zones d'impact (Pelegrin, 2000, p. 77-78; Valentin, 2000).

L'assemblage du Cornet doit donc logiquement être rapproché des industries plus nettement azilianisées du Bassin parisien.

\section{PEUT-ON CORRELER PLUS PRECISEMENT L'INDUSTRIE DU CORNET ?}

\section{Confrontation aVEc les SÉQuences} DE LA VALLÉE DE LA SOMME

Dans la Somme, ces industries nettement azilianisées sont attribuées actuellement à deux principales phases (Fagnart, 1997 ; Fagnart, Coudret, 2000). La première est rapportée au début de l'Allerød, en vertu des dates obtenues à Conty, entre $11890 \pm 50$ et $11410 \pm 80 \mathrm{BP}$. La seconde est placée à la fin de cet épisode, d'après les dates de la section 114 à Saleux $(11010 \pm 80$ et $10800 \pm 140 \mathrm{BP}$ ) et celle du niveau supérieur d'Hangest III.1 (10 920 $\pm 90 \mathrm{BP}$ ). Entre ces deux phases, les panoplies de pièces retouchées ne semblent pas changer et sont analogues à celle du Cornet : parmi les armatures, ce sont des monopointes qui dominent. Ce sont donc 
les calages chronostratigraphiques qui fournissent les principaux arguments de cette nouvelle sériation proposée par J.-P. Fagnart, qui décèle en outre des contrastes portant sur les modes d'approvisionnement et de débitage. Dans la Somme, la phase fin Allerød s'individualiserait en effet par le choix de silex de qualité inférieure à celle des matériaux sélectionnés durant les deux précédentes phases de l'azilianisation et pendant le Magdalénien. En Normandie, ce critère est malheureusement d'un faible secours. Si les qualités de silex exploitées au Cornet sont -à quelques notables expressions près - globalement médiocres, c'est peut-être seulement l'expression d'une forte limite de l'environnement géologique naturel, ressentie également sur les sites voisins de Blaru et de Romilly-la-Puthenaye (Fosse, 1993, 1997). A contrario, c'est dans un bon silex qu'est fait l'assemblage, analogue à celui du Cornet, recueilli en surface à Foumares sur le plateau de Gouy (Valentin, 1995, p. 536; Fosse et al., 1997, p. 254). Faute d'approches microrégionales aussi intensives que dans la Somme, les contrastes lithologiques perçus entre sites normands semblent donc pour le moment recouper une diversité plus générale des sources d'approvisionnement, à l'échelle régionale. L'autre critère de sériation intrinsèque mis en avant par J.-P. Fagnart concerne les styles de débitage. Ceux de la fin de l'Allerød se distingueraient par la faible normalisation de leur production laminaire, imputable à des mises en forme très simplifiées et à l'usage d'un percuteur de pierre plutôt dure appliqué sans préparation systématique des zones d'impact (l'abrasion et le facettage étant donc très inconstants). Des débitages aussi simplifiés sont connus au Cornet (fig. 14, première phase ; fig. 17) et il suffit, dans ce contexte, que la percussion soit assez rentrante pour qu'on hésite légitimement entre pierre dure et pierre tendre. Mais il existe aussi des débitages plus productifs en lames normalisées résultant parfois d'une mise en forme plus soigneuse (fig. 6 et 8). Ces derniers produisent alors des caractères stylistiques plus proches de ceux qui sont retenus dans la Somme pour individualiser la phase début-Allerød.

En bref, aucun argument ne nous permet de rapprocher l'occupation du Cornet de l'une plutôt que de l'autre des deux phases distinguées actuellement pour l'Allerød, dans la vallée de la Somme. La relative mixité des caractères observés sur le site normand conduit en retour à s’interroger sur la possibilité, quand les informations chronostratigraphiques font défaut, d'étendre aux régions avoisinantes la sériation proposée dans la Somme.

\section{Confrontation aVec la séquence du Closeau}

Qu'apportent sur ce point les données recueillies au Closeau? D'un strict point de vue stratigraphique, on ne distinguc sur ce gisement exploré sur plus de $25000 \mathrm{~m}^{2}$ que deux niveaux (Bodu dir., 1998 ; Bodu, 1998; 2000a et b) : le plus ancien, sous-jacent à l'horizon sableux pédogénéisé pendant l'Allerød, a déjà été évoqué ; c'est le niveau qui se développe dans sa partie sommitale et qui est coiffé par les limons du Dryas récent qui nous intéresse maintenant. Il est matérialisé par plus de 70 locus disposés dans le centre et sur les deux versants d'un paléochenal. Sans pouvoir invoquer une réelle discrimination stratigraphique, $\mathrm{P}$. Bodu perçoit actuellement l'existence d'au moins trois tendances techniques, dans les industries de ces locus :

- une tendance sans doute très tardive, qui ne nous intéresse pas directement et que l'auteur rapproche du Laborien ;

- deux tendances nettement azilianisées et possiblement diachrones.

Parmi ces deux dernières tendances, celle qui est présumée la plus récente caractérise les assemblages les plus nombreux du niveau supérieur, plutôt situés au centre du paléochenal. Par leur outillage et leurs armatures, ces assemblages s'apparentent à ceux des deux phases Allerød de la Somme comme à celui du Cornet, mais ils s'en écartent assez. nettement par le style de débitage (Kildea, 1996 ; Bodu dir., 1998 ; Debout, 2000). Ici, les volumes en silex local, pourtant d'excellente qualité, ont toujours été traités de manière très expédiente, selon une méthode qui rappelle, par bien des aspects, celle qui a été décrite pour le Brommien scandinave (Madsen, 1983; 1992). Mise en forme et initialisation se confondent totalement sur ces volumes qui ne fournissent des lames épaisses qu'occasionnellement et qui produisent surtout des éclats, plutôt allongés. Les exploitations, souvent unipolaires, ont été exclusivement réalisées avec un percuteur de pierre particulièrement dur et toujours manié avec un geste très rentrant. Ici, la préparation préalable des zones d'impact semble encore plus rare que dans la phase fin-Allerød de la Somme. Par rapport à cette phase - et, a fortiori par comparaison avec le Cornet - un degré de simplification supplémentaire est donc franchi, selon l'avis de P. Bodu. Cette tendance, majoritaire sur le niveau supérieur du Closeau, représenterait-elle alors une phase ultime de l'azilianisation, non encore attestée dans la Somme? Est-elle réellement contemporaine des débuts du Dryas récent selon les toutes premières hypothèses fondées sur l'âge des charbons de bois trouvés en association? Depuis que ces premières dates 
ont été obtenues, de plus en plus d'évidences se sont accumulées qui évoquent une succession au Closeau d'incendies naturels. Il devient donc très dangereux d'utiliser les dates sur charbon pour fonder des sériations culturelles. Une fois ces résultats provisoirement exclus de la discussion, une fois écartées quelques dates sur os d'âge holocène qui témoignent de la taphonomie complexe du niveau supérieur, il ne reste pour le moment que deux dates sur os de $10840 \pm 110$ et $10410 \pm 50 \mathrm{BP}$. Dans ce contexte assez embrouillé, ces résultats ne peuvent être utilisés qu'avec prudence pour caler ces débitages systématiquement plus simplifiés que ceux du Cornet : l'attribution au début du Dryas récent reste donc une hypothèse.

Parmi les assemblages nettement azilianisés que recèle le niveau supérieur du Closeau, une deuxième tendance technique a donc pu être identifiée. Elle est attestée dans une dizaine de locus seulement, pour lesquels on ne dispose malheureusement d'aucune datation sur os. Leur répartition spatiale est asse\% nettement distincte des précédents et ils ne se signalent ni par une quelconque spécialisation fonctionnelle ni par l'emploi d'un silex de meilleure qualité. Dans ces assemblages de la rive sud du paléochenal, on retrouve sans difficulté les caractères mixtes observés au Cornet et l'embarras n'est pas moindre, sans datations, pour les rapprocher de l'une plutôt que de l'autre des deux phases Allerød distinguées dans la Somme.

Ainsi, ce détour par Le Closeau ne permet pas, tant s'en faut, de resserrer la fourchette chronologique proposée pour l'occupation du Cornet en comparaison des données acquises sur la Somme. Peut-être pourra-t-on bientôt exclure le début du Dryas récent, s'il se confirme que les assemblages du Closeau très simplifiés, et en assez nette rupture avec ceux du Cornet, sont aussi tardifs qu'on le suspecte pour le moment. L'Allerød, sans plus de précision, reste donc le moment le plus probable pour situer l'occupation du Cornet, comme celle des locus de la rive sud sur le niveau supérieur du Closeau.

\section{POURQUOI CES INCERTITUDES CHRONOLOGIQUES?}

Ce détour est surtout une invitation à la réflexion et à la prudence, qui signale le risque que l'on prendrait à extrapoler des modèles, fondés sur un cadre chronoenvironnemental détaillé, à d'autres régions, même proches, où ces calages font encore défaut. Quelques autres exemples permettent de souligner ce risque. À Pincevent (Seine-et-
Marne), le niveau III contient, en deux locus, des assemblages analogues à celui du Cornet (Bodu et al., 1996). Dans un des locus, l'occupation est associée à un sol rapporté à l'Allerød, mais sa position stratigraphique exacte n'est pas très claire en raison de la bioturbation. C'est donc en vertu d'une seule date sur os (11 870 $\pm 130 \mathrm{BP})$ que l'assemblage, pourtant nettement azilianisé, est attribué au début de l'Allerød. Malgré de forts contrastes en matière d'approvisionnement et de débitage avec le Magdalénien sous-jacent, on rappellera que cette occupation a livré l'indice d'une très forte parenté culturelle d'un autre ordre : une gravure sur le cortex d'un éclat de silex représentant une tête de cheval traitée dans un style très naturaliste (op. cit.; voir également la discussion dans Valentin, 1995, p. 789). Est-ce à dire que la simplification des techniques a été plus rapide en certains endroits, et ce malgré la permanence locale de certaines valeurs symboliques? C'est ce que nous suggérions déjà en 1995. Depuis, cette simplification rapide a été confirmée en Suisse par l'attribution chronologique de l'occupation azilienne de Champréveyres (Cattin, 2000). Son industrie ne déparerait pas dans une des phases Allerød de la Somme, et pourtant elle se trouve attribuée par la palynologie au Bølling et datée par les charbons d'un foyer entre $12550 \pm 130$ et $12120 \pm 170 \mathrm{BP}$. Peut-être faudra-t-il également invoquer ces décalages de rythme pour expliquer pourquoi en Rhénanie centrale les industries à Federmesser paraissent si homogènes et si simplifiées, bien qu'elles soient connues sur de nombreuses occupations aux positions stratigraphiques asse $z$ diverses et aux dates couvrant tout l'Allerød (Street, Baales, 1997 ; 1998 ; Baales, 2000 ; 2002, p. 40-45). Les mêmes décalages doivent peutêtre être invoqués pour expliquer les dates sur os assez diverses obtenues pour des niveaux d'azilien initial, aux industries si analogues à celles de la phase pré-Allerød du Bassin parisien : $12130 \pm 160$ et $11600 \pm 120 \mathrm{BP}$ à Pontd'Ambon, en Dordogne (Célerier dir., 1994), $11810 \pm 230$ et $11740 \pm 110 \mathrm{BP}$ à La Fru, en Savoie (Pion dir., 1990) et $11900 \pm 360$ BP à Saint-Thibaud-de-Couz, en Savoie également (Bintz dir., 1995). Mais peut-être faudrait-il plus simplement discuter la fiabilité de ces résultats obtenus en contexte karstique.

À travers cette discussion, nous avons affronté quelquesunes des importantes lacunes qui subsistent sur l'histoire de l'azilianisation. D'abord, il nous paraît plus urgent que jamais d'en établir la chronologie fine, région par région, en évitant de reproduire les erreurs commises quand on voulut, par exemple, extrapoler la sériation aquitaine du 
Magdalénien à d'autres contrées. Dans le contexte de l'azilianisation, des différences de rythmes sont d'autant plus prévisibles que l'usage systématique du percuteur de pierre tendre reconnu dans certaines régions ourrc la voie d'une simplification, non obligatoire certes, mais possiblement très rapide. De plus, pour l'étude de processus aussi versatiles que ceux qui furent pratiqués au Cornet, il nous reste beaucoup à apprendre, comme on l'a fait pour le Magdalénien, sur la marge de variabilité qui fut admise à l'échelle de chaque occupation. L'étude du petit locus du Cornet montre déjà une variabilité assez forte et c'est précisément elle qui nous a retenus pour préciser son attribution chronologique en référence aux sériations proposées pour les industries de l'Allerød dans la Somme. Une variabilité du même ordre a été reconnue à bcaucoup plus large échelle sur les $3000 \mathrm{~m}^{2}$ connus du campement de Rekem en Belgique (De Bie, Caspar, 2000). La plupart des 12 locus - dont un au moins est daté $11350 \pm 150 \mathrm{BP}-$ ont livré des assemblages très proches de ceux du Cornet. Les auteurs pensent pouvoir y discerner les indices d'une diversité des compétences, à travers une variabilité ici decryptée par de nombreux remontages, qui attestent par ailleurs une certaine cohérence temporelle de l'occupation. Nous les rejoignons à propos des cas les plus flagrants de maladresse et restons circonspects quand il s'agit, dans ce contexte de grande " liberté ", d'intcrpréter en ces termes les divergences relatives à la productivité laminaire. Sans exclure catégoriquement une variabilité liée au savoirfaire, on peut invoquer d'autres facteurs découlant de la diversité des activités pratiquées sur le site, et notamment de l'exigence particulière qui s'attache encore dans ce contexte à la production des supports d'armatures. Dans leurs interprétations finales, les auteurs affichent d'ailleurs cette prudence, au point même d'invoquer l'hypothèse d'une légère diachronie pour expliquer la simplicité répétitive observée dans deux locus que les remontages n'ont pas pu relier aux autres (De Bie, Caspar, op. cit., p. 113 sqq.). Cette monographie exemplaire d'un vaste campement de l'Allerød indique clairement la voie à suivre pour exploiter au mieux les données spatiales, fonctionnelles, économiques et sociales acquises sur des gisements dont les fouilles extensives révèlent la complexité.

Pour sa part, la publication du Cornet ne contribuera que modestement à l'éclaircissement de cette complexité, mais elle en aura au moins rappelé l'existence ainsi que la prudence qu'elle impose.

\section{Nota bene}

Nous adressons nos remerciements amicaux à Danièle Molez pour sa contribution décisive à l'iconographie et à Jean-Pierre Fagnart pour sa relecture attentive et ses conseils avisés. 


\section{BIBLIOGRAPHIE}

\section{BaAles $M$.}

2000: "Larchéologic du Palćolithique final en Rhénanie du Centre et du Nord", in

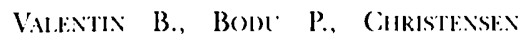
M. (i.lo.), I.Turope centrale et sepientrionale au Tardiglaciaire. (onfrontation des modieles régionaux de peuplement, p. 239-252 [référence complète infira].

2002: Der Spätpaläolithische Fundplatz Kettig, Mainz, Verlag des Römisch-(iermanischen Zentralmuseums (Monographien, 51), $333 \mathrm{p}$.

BARTON N

1992: Hengestbury Head Dorset -2- The Late Lpper Paleolithic and Early Mesolithic Sites, Oxford. University Committee for Archaeology (Monograph Series, 34), $299 \mathrm{p}$.

Barton N., Dumont S.

2000 : "Recolonisation and settement of Britain at the end of the Last Clacial ", in

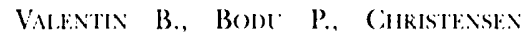

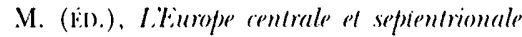
an Tardiglaciaime. Comfrontation dis modeles régionaux de peuplement, p. 151-162 [référence complete infra].

BINTZ P. (DIR.)

1995 : " Les grottes Jean-Pierre 1 et 2 à SaintThibaud-de-cour (Savoic). Palcoenvironnement et cultures du Tardiglaciaire à l'Holocène dauss les Alpes du Nord" (seconde partic), (iallia Prihistoire, 37 . p. 15.5-328.

Bodu P.

1995 : « Le site à Fordermesser du Closeau à Rucil-Malmaison (Hauts-de-Seine) ". I. ouvain, Notae Prohistoricue, 15, p. 45-49.

1998 : "Magdalenians-karly Azilians in the Centre of the Paris Basin : a filiation? The Fxample of I.e (Closeau (Rucil-Malmaison, France) ", in Mulakix S. (EDo.), The Organization of Lithic Terhnology in Late Glacial and Larly Postglucial of Eisroper. Oxford, BAR international series, 700 . p. $131-147$.

2000a : "Que sont devenus les Magdaléniens du Bassin parisien? Quelques eléments de réponse sur le gisement azilien du (loseau (Rucil-Malmaison. France) ", in

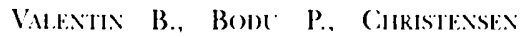
M. (i.1).), L.Turope centrale al sepientrionale au Tardiglaciairr. Confromtation dis modiples régionanex de peruplement, p. 315-339 [référence complete infra].

2000b : " L ces faciès tardiglaciaires à grandes lames rectilignes et les ensembles à pointes de Malaurie dans le sud du Bassin parisien : quelques réflexions à partir de l'exemple du Closeau (Hauts-de-Seine)", in CRotTl P. (Fo.), Eppipaléolithique at Mésolithique, Actes de la table ronde de Lausanne, 21-23 nov. 1997, Lausanne, Cahiers d'archéologie romande, 18, p. 9-28.

\section{BodU P. (DIR.)}

1998 : Le "Closerun". Deux années de fouille sur un gisement azilien et belloisien en bord de Seine, Document final de Synthèse de sauvelage urgent, Saint-Denis, SRA d'l̂le-deFrance/AFAN, 3 vol., $470 \mathrm{p}$.

Bodu P., Orliac M., Baffier D.

1996 : "L'́p.pimagdalénien ", in Galcchter (x. (DIR.), Fouilles de Pincromt II. Le site et ses occupations récentes. (L'environnement, l'Epimagdalénien et les niveaux postglaciaires), Paris, éd. de la Société préhistorique française (Mémoires de la Société préhistorique francaise, 23), p. 69-94

Bodu P., Valentin B.

1997 : "Groupes à Federmesser ou aziliens dans le sud et l'ouest du Bassin parisien. Propositions pour un nouveau modele d'évolution ", Bulletin de la Societé préhisterique francaise, 94, 3, p. 341-347.

\section{Cattin M.-I.}

2000 : "Le niveau azilien d'Hauterive(Champréveyres (Suisse). Données préliminaires sur le matériel en silex ", in CROTTI P. (EDD.), Épipaléolithique et Mésolithique, Actes de la table ronde de Lausanne, 21-23 nov. 1997, Lausanne, (Cahiers d'archéologie romande, 18), p. 197-202.

\section{Célérier G. (DIR.)}

1994 : "L'abri sous-roche de Pont-d Ambon à Bourdeilles (Dordogne) ", Ciallia Préhistoire, 36, p. 65-144.

\section{Coudret P., Fagnart J.-P.}

1997 : "Les industries à Federmesser dans le bassin de la Somme: chronologie et identité des groupes culturels ", Bulletin de la Société préhistorique francaise, 94, 3. p. 349-360.

De BiE M., Caspar J.-P.

2000) : Rekem. A Federmesser Camp on the Meuse River Bank, Asse-Zellik, Instituut vor her Archeologisch Patrimonium - Lcuren, University Press (Archeologic in Vlaanderen, Monografie 3 el Acta Archaeologica Lovaniensia, Monographiac 10), 2 vol., 596 p.
Debout G.

2000 : Apports de l'ólude typo-technologique des locus 25, 41 et 45 a la comprihension du niveau recent de loocupation a Federmesser du Closeau à Rueil-Malmaison, mém. de maîtrise d’archéologie. unis. Paris-I.

FAGNART J.-P.

1988 : Les Industries lithiques du Paléolithique supérieur dans te Nord de la France, $10^{\circ}$ spécial de la Revue archeologique de Picardie, 153 p.

1993 : Le Paléolithique supérieur récent el final du Nord de la France dans son cadre paléorlimatique, thèse de doctorat, univ: des sciences et technologies de Lille, 2 vol., 567 p.

1997: La Fin des temps glaciaires dans le Nord de la France. Approche archéologique et environnementale des occupations humaines du Tardiglaciaure, Paris, éd. de la Société préhistorique française (Mémoires de la Socićté préhistorique francaise, 24), $270 \mathrm{p}$.

Fagnart J.-P., Coudret P.

2000 : "Le Tardiglaciaire dans le Nord de la France ", in Vantentax B., B(o) P.

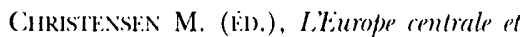
septentrionale au Tardiglaciaire. Comfromlation des modèles régionaux de peruplement, p. 111-128 [réference complète infra].

Fagnart J.-P., Plisson H.

1997 : "Fonction des pièces mâchurées du Paléolithique final du bassin de la Somme: caractères tracéologiques et données contextuclles ", in FAGiNARI J-P., THENENIN A. (BD.), l.e Tardiglaciaire en Europe du Nord-Ouest, Actes du 119 congrès des sociétés historiques et scientijüques, Amiens, oct. 1994, Parris, éd. du Comité des mavaux historiques et scientifiques, p. 95-106.

Floss $\mathbf{H}$.

1992: "Sur l'approvisionnement des matières premières atu Magdalénien "l au Paléolithique final en Rhénanie (bassin de Neuwied) ", in MontritW'ntre A. (DIR.), Les Bassins du Rhin et du Damube au Paleolithique supérieur: environnement, habitat et systèmes déchange, Actes du colloque de la commission VIIII du XI' congres de l'UISPP, Mayence, 1986, Liège, Études et recherches archéologiques de l'université de Liège, 43, p. 104-113.

2000 : "I a fin du Palćolithique en Rhénanic (Magdalénien, groupes à Federmesser, Ahrensbourgien). L'évolution du choix 
des matic̀res premic̀res lithiques, reflet d'un profond changement du climat et du comportement humain ", in

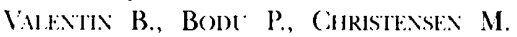
(F.D.). LTurope centrale et septentrionale au Tardiglaciaire. Confrontation des modèles régionaux de peuplement, p. $87-96$ [référence complète infra].

Fosse G.

1993 : "Le gisement du Paléolithique supérieur final de Blaru (Yvelines) ", Paléo, 5, p. 249-262.

1997 : « L.c Paléolithique récent et final du bassin de la Basse-Scine (Yvelines - Eure Seine-Maritime) ", in FagidirT J.-P., THExis: A. (E.I).), le Tardiglaciaire en Europe du Nort-Ouest, Actes du 119 congres national des sociétés historiques el scientifiques, Amiens, oct. 1994, Paris, éd. du Comité des tralaux historiques et scientifiques, p. $233-244$.

Fosse G., Valentin B., Billard C.

1997 : " Line occupation des groupes à Federmesser en Haute-Normandic: le gisement du Cornet à Ambenay (Eure)",

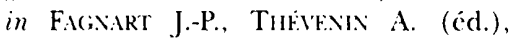
Le Tardiglariaire en Europe du NordOuest, Actes du 119 congrès national des sociétés historiques et scientifiques, Amiens, oct. 1994, Paris, éd. du Comité des travaux historiques et scientifiques, p. $245-256$.

InIZAN M.-L., RedURon M., Roche H., TIXIER J.

1995: Technologie de la pierre taillée, Meudon/Valbonne, Cercle de recherches et d'études préhistoriques, 4, $127 \mathrm{p}$.

KILDEA F.

1996: Étude du matériel lithique du niveau récent de loccupation à Federmesser du site du Closeau à Rueil-Malmaison (Hauts-de-Seine). Approche technologique, typologique et spatiale de six unités d'occupation, mém. de maitrise d'archéologic, unis: Paris-l, $101 \mathrm{p}$.

LEESCH D.

1993: " Cadre chronologique et faciès industriels ", dans Hönfistx M., Itresch D.,
Ll: Trissorr: J.-M. "Le Paléolithique supérieur récent ", in La Suisse du Palélithique à laube du Moyen Âge, vol. I. Bâle, Société suisse de préhistoire et d'archéologic, p. 153-164.

\section{MADSEN B.}

1983 : "New evidence of Late Palaeolithic settlement in East Jutland ", Journal of Danish Archaeology, 2, p. 12-31.

1992 : " Hamburgkulturens Flintteknologie I Jels ", in Holms J., Rif(:K F. (FD).), Istidsjaegere ved Jelssøerne. Hamburgkulturen i Denmark. Haderslev, Skrifter fra Museumrådet for SønderJyllands Amt, 5, p. $58-130$

\section{Pelegrin J.}

2000 : "Les techniques de débitage laminaire au Tardiglaciaire : critères de diagnose et quelques réflexions ", in VALENTIN B., Bonl' P., Christrasex M. (F.D.), LEurope centrale et septentrionale au Tardiglaciaire. Confrontation des modèles régionaux de peuplement, p. 73-86 [référence complète infra].

PIGeot N. (DIR.)

Sous presse: Les derniers Magdaléniens d'itiolles: perspectives culturelles et paléohistoriques (l'unite d'habitation Q31), Paris, (XRS Éditions (Suppl. à Gallia Préhistoire, XXXVII)

PION G. (DIR.)

1990 : "Labri de la Fru à Saint-Christophe (Saroie) ", Gallia Préhistoire. 32, p. 65-123.

\section{Street M., Baales $M$}

1997 : "L Les groupes à Federmesser de l'Allerød en Rhénanie centrale (Allemagne) ", Bulletin de la Société préhistorique fransaise, 94, 3, p. 373-386.

1998 : "Pleistocene/Holocene changes in the Rhineland fauna in a Northwest European context ", in BF..NF(Kt: N. (FI).), The Holocene History of the European Vertebrate Fauna. Modern Aspects of Research, Actes de la table ronde de Berlin, 6-9 arm: 1998, Rahden, éd. Maric Leidorf, p. 9-38.

Street M., Baales M., Cziesla E., Harz S., Heinen M., Jöris O., Koch I., Pasda C.,
Terberger T., Volbrecht J.

2001 : "Final Palacolithic and Mesolithic research in Reunified Germany ", Joumal of World Prehistory, 15, 4, p. 365-453.

\section{VALENTIN B.}

1995 : Les groupes humains et leurs traditions an Tardiglaciaire dans le Bassin parisien. Apports de la technologie lithique comparee, thèse de doctorat, univ. Paris-I, 3 vol., 834 p.

1999 : "Techniques et cultures : les chasseurscueilleurs de la fin du Tardiglaciaire au sud du Bassin Parisien ", in BiNT\% P., ThÉskix A. (ÉD.), l.turope des derniers chasseurs. Épipaléolithique et Mésolithique, Actes du colloque de la commission XII de I'UISPP, Crenoble, 18-23 sept. 1995, Paris, éd. du Comité des travaux historiques et scientifiques, p. 201-212.

2000 : "Lisage des percuteurs en pierre tendre pour le débitage des lames. Circonstances de quelques innovations au cours du Tardiglaciaire dans le Bassin parisien ", in PION (;. (E.).), Le Paleolithique supérieur récent : nouvelles données sur le peuplement et l'environnement, Actes de la table ronde de Chambéry, 12-13 mars 1999, Paris, éd. de la Société préhistorique française (Mémoires de la Société préhistorique française, 28), p. 253-260.

Val.entin B., Bodu P., Christensen M. (ĖD.)

2000 : LEurope centrale et septentrionale au Tardiglaciaire. Confrontation des modèles regionaux de peuplement, Actes de la table ronde internationale de Nemours, 14-16 mai 1997, Nemours, éd. de l'APRAIF (Mémoires du musée de Préhistoire d'Îlede-France, 7), $361 \mathrm{p}$.

Valentin B., Pigeot N.

2000: "Éléments pour une chronologie des occupations magdaléniennes dans le Bassin parisien ", in Vat.extro B., BoDt P.,

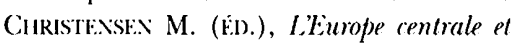
septentrionale au Tardiglaciaire. Confrontation des modèles régionaux de peuplement, p. 129-138 [référence complète supra]. 